\title{
THE ALPERIN WEIGHT CONJECTURE AND DADE'S CONJECTURE FOR THE SIMPLE GROUP Fi ${ }_{24}^{\prime}$
}

\author{
JIANBEI AN, JOHN J. CANNON, E. A. O'BRIEN AND W. R. UNGER
}

\begin{abstract}
We classify the radical $p$-subgroups and chains of the Fischer simple group $\mathrm{Fi}_{24}^{\prime}$ and then verify the Alperin weight conjecture and the Uno reductive conjecture for $\mathrm{Fi}_{24}^{\prime}$.
\end{abstract}

\section{Introduction}

Let $G$ be a finite group, $p$ a prime and $B$ a $p$-block of $G$. Alperin [1] conjectured that the number of $B$-weights equals the number of irreducible Brauer characters of $B$. Dade [11] generalized the Knörr-Robinson version of the Alperin weight conjecture and presented his ordinary conjecture exhibiting the number of ordinary irreducible characters of a fixed defect in $B$ in terms of an alternating sum of related values for $p$-blocks of some $p$-local subgroups of $G$. Dade [12] announced that his final conjecture needs only to be verified for finite non-abelian simple groups; in addition, if a finite group has a cyclic outer automorphism group, then the projective invariant conjecture is equivalent to the reductive conjecture.

Dade's reductive conjecture [12] has now been verified for all of the sporadic simple groups except the Fischer simple group $\mathrm{Fi}_{24}^{\prime}$, the Baby Monster $\mathbb{B}$ for $p=2$, and the Monster IM. Recently, Isaacs and Navarro [15] proposed a new conjecture which is a refinement of the Alperin-McKay conjecture, and Uno [21] raised an alternating sum version of the conjecture which is a refinement of the Dade conjecture [12]. In this paper, we use the local strategy of [4] and [5] to verify Alperin's conjecture and Uno's reductive conjectures for $\mathrm{Fi}_{24}^{\prime}$.

The paper is organized as follows. In Section 2, we fix notation and state the conjectures and two lemmas. In Section 3, we recall our modified local strategy and explain how we applied it to determine the radical subgroups of $\mathrm{Fi}_{24}^{\prime}$. In Section 4 , we classify the radical subgroups of $\mathrm{Fi}_{24}^{\prime}$ up to conjugacy and verify the Alperin weight conjecture. In Section 5, we do some cancellations in the alternating sum of Dade's conjecture when $p=2$ or 3 , and then determine radical chains (up to conjugacy) and their local structures. In Section 6, we verify Uno's invariant conjecture for $\mathrm{Fi}_{24}^{\prime}$ and finally we verify Uno's projective conjecture for $3 . \mathrm{Fi}_{24}^{\prime}$. Two Appendices record degrees of irreducible characters of chain normalizers.

The work of An and O'Brien was supported by the Marsden Fund of New Zealand via grant UOA 0412. The work of Cannon and Unger was supported by Australian Research Council Grant DP0452427. We thank Thomas Breuer for his assistance in constructing some of the character tables used in this work. We thank the referee for careful reading and helpful comments.

Received 11 January 2007, revised 6 August 2007; published 20 May 2008.

2000 Mathematics Subject Classification Primary 20C20, 20C34, 20D08

(c) 2008, Jianbei An, John J. Cannon, E. A. O'Brien and W. R. Unger 
The Alperin weight conjecture and Dade's conjecture for the simple group $\mathrm{Fi}_{24}^{\prime}$

\section{The conjectures and lemmas}

Let $R$ be a $p$-subgroup of a finite group $G$ and let $O_{p}(N(R))$ be the largest normal $p$-subgroup of the normalizer $N(R)=N_{G}(R)$. Then $R$ is radical if $O_{p}(N(R))=R$. Denote by $\operatorname{Irr}(G)$ the set of all irreducible ordinary characters of $G$ and by $\operatorname{Blk}(G)$ the set of $p$-blocks. Let $B \in \operatorname{Blk}(G)$ and $\varphi \in \operatorname{Irr}(N(R) / R)$. The pair $(R, \varphi)$ is called a $B$-weight if $\mathrm{d}(\varphi)=0$ and $B(\varphi)^{G}=B$ (in the sense of Brauer), where $\mathrm{d}(\varphi)=\log _{p}\left(|G|_{p}\right)-\log _{p}\left(\varphi(1)_{p}\right)$ is the $p$-defect of $\varphi$ and $B(\varphi)$ is the block of $N(R)$ containing $\varphi$. A weight is always identified with its $G$-conjugates. Let $\mathcal{W}(B)$ be the number of $B$-weights, and $\ell(B)$ the number of irreducible Brauer characters of $B$. Alperin conjectured that $\mathcal{W}(B)=\ell(B)$ for each $B \in \operatorname{Blk}(G)$.

Given a $p$-subgroup chain

$$
C: P_{0}<P_{1}<\cdots<P_{n}
$$

of $G$, define $|C|=n$, the $k$-th subchain $C_{k}: P_{0}<P_{1}<\cdots<P_{k}$, and

$$
N(C)=N_{G}(C)=N\left(P_{0}\right) \cap N\left(P_{1}\right) \cap \cdots \cap N\left(P_{n}\right) .
$$

The chain $C$ is radical if it satisfies the following two conditions:

(a) $P_{0}=O_{p}(G)$ and (b) $P_{k}=O_{p}\left(N\left(C_{k}\right)\right)$ for $1 \leqslant k \leqslant n$.

Denote by $\mathcal{R}=\mathcal{R}(G)$ the set of all radical $p$-chains of $G$. Let $H \leqslant G, B \in \operatorname{Blk}(G)$, $\operatorname{Blk}(H, B)=\left\{b \in \operatorname{Blk}(H): b^{G}=B\right\}$, and let $D(B)$ be a defect group of $B$. We define the $p$-local rank of $B$ as follows:

$$
\operatorname{plr}(B)=\max \left\{|C|: C \in \mathcal{R}, C: P_{0}<\cdots<P_{n} \leqslant D(B), \operatorname{Blk}(N(C), B) \neq \emptyset\right\} .
$$

Note that if there is a block $b$ of $N_{G}(C)$ such that $b^{G}=B$, then the final subgroup $P_{n}$ of $C$ is $G$-conjugate to a subgroup of $D(B)$, so we may suppose $P_{n} \leqslant D(B)$. Thus our definition is equivalent to that given in [2, p. 370].

Let $Z$ be a cyclic group and $\hat{G}=Z . G$ a central extension of $Z$ by $G$, and $C \in \mathcal{R}(G)$. Denote by $N_{\hat{G}}(C)$ the preimage $\eta^{-1}(N(C))$ of $N(C)$ in $\hat{G}$, where $\eta$ is the natural group homomorphism from $\hat{G}$ onto $G$ with kernel $Z$. Let $\rho$ be a faithful linear character of $Z$ and $\hat{B}$ a block of $\hat{G}$ covering the block $B(\rho)$ of $Z$ containing $\rho$. Denote by $\operatorname{Irr}\left(N_{\hat{G}}(C), \hat{B}, d, \rho\right)$ the set of irreducible characters $\psi$ of $N_{\hat{G}}(C)$ such that $\psi$ lies over $\rho, \mathrm{d}(\psi)=d$ and $B(\psi)^{\hat{G}}=\hat{B}$ and set $\mathrm{k}\left(N_{\hat{G}}(C), \hat{B}, d, \rho\right)=\left|\operatorname{Irr}\left(N_{\hat{G}}(C), \hat{B}, d, \rho\right)\right|$.

Dade's Projective Conjecture [12]. If $O_{p}(G)=1$ and $\hat{B}$ is a $p$-block of $\hat{G}$ covering $B(\rho)$ with defect group $D(\hat{B}) \neq O_{p}(Z)$, then

$$
\sum_{C \in \mathcal{R} / G}(-1)^{|C|} \mathrm{k}\left(N_{\hat{G}}(C), \hat{B}, d, \rho\right)=0,
$$

where $\mathcal{R} / G$ is a set of representatives for the $G$-orbits of $\mathcal{R}$.

Let $\hat{H}$ be a subgroup of a finite group $\hat{G}, \varphi \in \operatorname{Irr}(\hat{H})$ and let $r(\varphi)=r_{p}(\varphi)$ be the integer $0<r(\varphi) \leqslant(p-1)$ such that the $p^{\prime}$-part $(|\hat{H}| / \varphi(1))_{p^{\prime}}$ of $|\hat{H}| / \varphi(1)$ satisfies

$$
\left(\frac{|\hat{H}|}{\varphi(1)}\right)_{p^{\prime}} \equiv r(\varphi) \bmod p .
$$


The Alperin weight conjecture and Dade's conjecture for the simple group $\mathrm{Fi}_{24}^{\prime}$

Given an integer $1 \leqslant r \leqslant(p-1)$, let $\operatorname{Irr}(\hat{H},[r])$ be the subset of $\operatorname{Irr}(\hat{H})$ consisting of characters $\varphi$ such that $r(\varphi) \equiv \pm r \bmod p$, and let $\operatorname{Irr}(\hat{H}, \hat{B}, d, \rho,[r])=$ $\operatorname{Irr}(\hat{H}, \hat{B}, d, \rho) \cap \operatorname{Irr}(\hat{H},[r])$ and $\mathrm{k}(\hat{H}, \hat{B}, d, \rho,[r])=|\operatorname{Irr}(\hat{H}, \hat{B}, d, \rho,[r])|$.

Suppose $Z=1$ and let $\hat{B}=B \in \operatorname{Blk}(G)$ with a defect group $D=D(B)$ and the Brauer correspondent $b \in \operatorname{Blk}\left(N_{G}(D)\right)$. Then $\mathrm{k}(N(D), B, d(B),[r])$ is the number of characters $\varphi \in \operatorname{Irr}(b)$ such that $\varphi$ has height 0 and $r(\varphi) \equiv \pm r \bmod p$, where $\mathrm{d}(B)$ is the defect of $B$.

IsaAcs-Navarro Conjecture [15, Conjecture B]. In the notation above,

$$
\mathrm{k}(G, B, \mathrm{~d}(B),[r])=\mathrm{k}(N(D), B, \mathrm{~d}(B),[r]) .
$$

The following refinement of Dade's conjecture is due to Uno.

Uno's Projective Conjecture [21, Conjecture 3.2]. If $O_{p}(G)=1$ and if $D(\hat{B}) \neq O_{p}(Z)$, then for all integers $d \geqslant 0$, faithful $\rho \in \operatorname{Irr}(Z)$ and $1 \leqslant r \leqslant(p-1)$,

$$
\sum_{C \in \mathcal{R} / G}(-1)^{|C|} \mathrm{k}\left(N_{\hat{G}}(C), \hat{B}, d, \rho,[r]\right)=0 .
$$

If $Z=1$, then the projective conjecture is called the ordinary conjecture.

Note that if $p=2$ or 3 , then Uno's conjecture is equivalent to Dade's conjecture.

If $\hat{E}$ is an extension of $\hat{G}$ centralizing $Z$ and $N_{\hat{E}}(C, \psi)$ is the stabilizer of $\left(N_{\hat{G}}(C), \psi\right)$ in $\hat{E}$, then $N_{\hat{E} / \hat{G}}(C, \psi)=N_{\hat{E}}(C, \psi) / N_{\hat{G}}(C)$ is a subgroup of $\hat{E} / \hat{G}$. For $\hat{U} \leqslant \hat{E} / \hat{G}$, denote by $\mathrm{k}\left(N_{\hat{G}}(C), \hat{B}, d, \hat{U}, \rho,[r]\right)$ the number of characters $\psi$ in $\operatorname{Irr}\left(N_{\hat{G}}(C), \hat{B}, d, \rho,[r]\right)$ such that $N_{\hat{E} / \hat{G}}(C, \psi)=\hat{U}$. In the notation above, Uno's projective invariant conjecture is stated as follows.

Uno's Projective Invariant Conjecture. If $O_{p}(G)=1$ and $\hat{B}$ is a $p$-block of $\hat{G}$ covering $B(\rho)$ with $D(\hat{B}) \neq O_{p}(Z)$, then

$$
\sum_{C \in \mathcal{R} / G}(-1)^{|C|} \mathrm{k}\left(N_{\hat{G}}(C), \hat{B}, d, \hat{U}, \rho,[r]\right)=0 .
$$

In addition, if $\hat{E} / \hat{G}$ is cyclic and $u=|\hat{U}|$, then we set

$$
\mathrm{k}\left(N_{\hat{G}}(C), \hat{B}, d, u, \rho,[r]\right)=\mathrm{k}\left(N_{\hat{G}}(C), \hat{B}, d, \hat{U}, \rho,[r]\right) .
$$

In particular, if $Z=1$ and $\rho$ is the trivial character of $Z$, then $\hat{G}=G$ and $\hat{B}$ is a block $B$ of $G$; we set $U=\hat{U}$ and

$$
\mathrm{k}(N(C), B, d, U,[r])=\mathrm{k}\left(N_{\hat{G}}(C), \hat{B}, d, \hat{U}, \rho,[r]\right) .
$$

Then the Projective Invariant Conjecture is equivalent to the Invariant Conjecture. Uno's Invariant ConjeCture. If $O_{p}(G)=1$ and $B$ is a $p$-block of $G$ with defect $\mathrm{d}(B)>0$, then

$$
\sum_{C \in \mathcal{R} / G}(-1)^{|C|} \mathrm{k}(N(C), B, d, U,[r])=0 .
$$

The following lemma follows by [6, Lemma 7.1]. 
The Alperin weight conjecture and Dade's conjecture for the simple group $\mathrm{Fi}_{24}^{\prime}$

LEMma 2.1. Let $G$ be a finite group, $B \in \operatorname{Blk}(G)$ with $\operatorname{plr}(B)=2$ and abelian defect group $D=D(B)$. Let $O_{p}(G) \neq R<D$ be radical, $b \in B l k\left(N_{G}(R)\right)$ with $b^{G}=B$. Then

$$
\mathrm{k}\left(N_{G}(R) \cap N_{G}(D), b, d, \rho,[r]\right)=\mathrm{k}\left(N_{G}(R), b, d, \rho,[r]\right) .
$$

In Section 5, we will use the following lemma, whose proof is straight-forward. Note that it is more important to pair orbits of chains, rather than actual chains.

Lemma 2.2. Let $\sigma: O_{p}(G)<P_{1}<\ldots<P_{m-1}<Q=P_{m}<P_{m+1}<\ldots<P_{\ell}$ be a fixed radical $p$-chain of a finite group $G$, where $1 \leqslant m<\ell$. Suppose

$$
\sigma^{\prime}: O_{p}(G)<P_{1}<\ldots<P_{m-1}<P_{m+1}<\ldots<P_{\ell}
$$

is also a radical $p$-chain such that $N_{G}(\sigma)=N_{G}\left(\sigma^{\prime}\right)$ and $N_{E}(\sigma)=N_{E}\left(\sigma^{\prime}\right)$, where $E$ is an extension of $G$. Let $\mathcal{R}^{-}(\sigma, Q)$ be the subfamily of $\mathcal{R}(G)$ consisting of chains $C$ whose $(\ell-1)$-th subchain $C_{\ell-1}$ is conjugate to $\sigma^{\prime}$ in $G$, and $\mathcal{R}^{0}(\sigma, Q)$ the subfamily of $\mathcal{R}(G)$ consisting of chains $C$ whose $\ell$-th subchain $C_{\ell}$ is conjugate to $\sigma$ in $G$. Then the map $g$ sending any $O_{p}(G)<P_{1}<\ldots<P_{m-1}<P_{m+1}<\ldots<P_{\ell}<\ldots$ in $\mathcal{R}^{-}(\sigma, Q)$ to $O_{p}(G)<P_{1}<\ldots<P_{m-1}<Q<P_{m+1}<\ldots<P_{\ell}<\ldots$ induces $a$ bijection, denoted again by $g$, from $\mathcal{R}^{-}(\sigma, Q)$ onto $\mathcal{R}^{0}(\sigma, Q)$. Moreover, for any $C$ in $\mathcal{R}^{-}(\sigma, Q)$, we have $|C|=|g(C)|-1, N_{G}(C)=N_{G}(g(C))$ and $N_{E}(C)=N_{E}(g(C))$.

\section{The modified local strategy}

The maximal subgroups of $\mathrm{Fi}_{24}^{\prime}$ were classified by Wilson [22]. Using this classification, we know that each radical 2- or 3-subgroup $R$ of $\mathrm{Fi}_{24}^{\prime}$ is radical in one of the 14 maximal subgroups $M$ of $\mathrm{Fi}_{24}^{\prime}$ and further that $N_{\mathrm{Fi}_{24}^{\prime}}(R)=N_{M}(R)$.

In [4] and [5], a modified local subgroup strategy was developed to classify the radical subgroups $R$. We review this method here. Suppose $M$ is a subgroup of $G$ such that $N_{M}(R)=N_{G}(R)$.

Step (1). We first consider the case where $M$ is a $p$-local subgroup. Let $Q=$ $O_{p}(M)$, so that $Q \leqslant R$. Choose a subgroup $X$ of $M$. We explicitly compute the coset action of $M$ on the cosets of $X$ in $M$; we obtain a group $W$ representing this action, a group homomorphism $f$ from $M$ to $W$, and the kernel $K$ of $f$. For a suitable $X$, we have $K=Q$ and the degree of the action of $W$ on the cosets is usually much smaller than that of $M$. We can now directly classify the radical $p$-subgroup classes of $W$, and the preimages in $M$ of the radical subgroup classes of $W$ are the radical subgroup classes of $M$.

Step (2). Now consider the case where $M$ is not $p$-local. We may be able to find its radical $p$-subgroup classes directly. Alternatively, we find a (maximal) subgroup $L$ of $M$ such that $N_{L}(R)=N_{M}(R)$ for each radical subgroup $R$ of $M$. If $L$ is $p$-local, then we apply Step (1) to $L$. If $L$ is not $p$-local, we can replace $M$ by $L$ and repeat Step (2).

Steps (1) and (2) constitute the modified local strategy. After applying the strategy, possible fusions among the resulting list of radical subgroups can be decided readily by testing whether the subgroups in the list are pairwise $\mathrm{Fi}_{24}^{\prime}$-conjugate.

In investigating the conjectures for $\mathrm{Fi}_{24}^{\prime}$, we used its minimal degree representation as a permutation group on 306936 points. Its maximal subgroups were constructed using the details supplied in [9] and the black-box algorithms of Wilson 
[23]. We also made extensive use of the algorithm described in [10] to construct random elements, and the procedures described in [4] and [5] for deciding the conjectures.

In investigating the projective conjecture for $3 . \mathrm{Fi}_{24}^{\prime}$, we used its minimal degree representation as a permutation group on 920808 points. Both representations are available from the ATLAS of Finite Group Representations [24].

The computations reported in this paper were carried out using various versions of MAgma [7]. The construction of the character tables of various chain normalisers posed significant practical problems. Many could not be computed directly using the Magma implementation of the algorithm of Schneider [18]. Instead, we used a new and more powerful algorithm developed by Unger [19].

\section{Radical subgroups and weights of $\mathrm{Fi}_{24}^{\prime}$}

Let $\mathcal{R}_{0}(G, p)$ be a set of representatives for conjugacy classes of radical $p$ subgroups of $G$. For $H, K \leqslant G$, we write $H \leqslant G \quad K$ if $x^{-1} H x \leqslant K$; and write $H \in \in_{G} \mathcal{R}_{0}(G, p)$ if $x^{-1} H x \in \mathcal{R}_{0}(G, p)$ for some $x \in G$. We shall follow the notation of [9]. In particular, if $p$ is odd, then $p^{1+2 \gamma}$ or $p_{+}^{1+2 \gamma}$ is an extra-special group of order $p^{1+2 \gamma}$ with exponent $p$; if $\delta$ is + or - , then $2_{\delta}^{1+2 \gamma}$ is an extra-special group of order $2^{1+2 \gamma}$ with type $\delta$. If $X$ and $Y$ are groups, we use $X . Y$ and $X: Y$ to denote an extension and a split extension of $X$ by $Y$, respectively. Given a positive integer $n$, we use $E_{p^{n}}$ or simply $p^{n}$ to denote the elementary abelian group of order $p^{n}, \mathbb{Z}_{n}$ or simply $n$ to denote the cyclic group of order $n$, and $D_{2 n}$ to denote the dihedral group of order $2 n$.

Let $G$ be the simple Fischer group $\mathrm{Fi}_{24}^{\prime}$. Then

$$
|G|=2^{21} \cdot 3^{16} \cdot 5^{2} \cdot 7^{3} \cdot 11 \cdot 13 \cdot 17 \cdot 23 \cdot 29,
$$

and we may suppose $p \in\{2,3,5,7\}$, since both conjectures hold for a block with a cyclic defect group by [11, Theorem 9.1] and [3, Theorem 5.2].

We denote by $\operatorname{Irr}^{0}(H)$ the set of ordinary irreducible characters of $p$-defect 0 of a finite group $H$ and by $\mathrm{d}(H)$ the number $\log _{p}(|H|)$. Given $R \in \mathcal{R}_{0}(G$, $p)$, let $C(R)=C_{G}(R)$ and $N=N_{G}(R)$. If $B_{0}=B_{0}(G)$ is the principal $p$-block of $G$, then (c.f. $(4.1)$ of $[4])$

$$
\mathcal{W}\left(B_{0}\right)=\sum_{R}\left|\operatorname{Irr}^{0}(N / C(R) R)\right|,
$$

where $R$ runs over the set $\mathcal{R}_{0}(G, p)$ such that $\mathrm{d}(C(R) R / R)=0$. The character table of $N / C(R) R$ can be calculated by MAGMA, and so we find $\left|\operatorname{Irr}^{0}(N / C(R) R)\right|$.

Proposition 4.1. Let $G=\mathrm{Fi}_{24}^{\prime}$ and $E=\operatorname{Aut}(G)=G .2=\mathrm{Fi}_{24}$. Then the nontrivial radical p-subgroups $R$ of $G$ (up to conjugacy) and their local structures are given in Tables 1 and 2 according as $p \geqslant 3$ or $p=2$, where $S \in \operatorname{Syl}_{2}(G)$ is a Sylow 2subgroup, $H^{*}$ denotes a subgroup of $G$ such that $H^{*} \simeq H$ and $H^{*} \neq_{G} H$. Moreover, $N_{E}(R)=N .2$ for all radical $p$-subgroups $R$ except when $p=7$ and $R=7^{2}$, in which case $R^{\tau}=\left(7^{2}\right)^{*}$ for some $\tau \in E \backslash G$.

Proof. Case (1). Suppose $p=7$, so that by [9, p. 207], $7_{+}^{1+2}$ is a Sylow subgroup of $G$ and $7_{+}^{1+2}$ has 19 subgroup classes. Thus the radical 7 -subgroups can be determined easily. 
The Alperin weight conjecture and Dade's conjecture for the simple group $\mathrm{Fi}_{24}^{\prime}$

\begin{tabular}{|c|c|c|c|}
\hline$R$ & $C(R)$ & $N_{G}(R)$ & $\left|\operatorname{Irr}^{0}(N / C(R) R)\right|$ \\
\hline $\begin{array}{r}7 \\
7^{2} \\
\left(7^{2}\right)^{*} \\
7_{+}^{1+2} \\
\end{array}$ & $\begin{array}{r}\times A_{7} \\
7^{2} \\
7^{2} \\
7 \\
\end{array}$ & $\begin{array}{c}7: 6 \times A_{7} \\
7^{2}: 2 L_{2}(7) .2 \\
7^{2}: 2 L_{2}(7) .2 \\
7_{+}^{1+2}:\left(S_{3} \times 6\right) \\
\end{array}$ & $\begin{array}{l}2 \\
2 \\
18 \\
\end{array}$ \\
\hline $\begin{array}{r}5 \\
5^{2} \\
\end{array}$ & $\begin{array}{r}5 \times A_{9} \\
5^{2} \times A_{4} \\
\end{array}$ & $\begin{array}{c}\left(5: 2 \times A_{9}\right) .2 \\
\left(5^{2}: 4 A_{4} \times A_{4}\right) .2 \\
\end{array}$ & 16 \\
\hline $\begin{array}{r}3 \\
3^{2} \\
3^{7} \\
3_{+}^{1+10} \\
3_{+}^{1+10} .3 \\
3^{3} .3^{4} .3^{3} .3^{3} \\
3^{2} .3^{4} .3^{8} \\
3_{+}^{1+10} .3^{4} \\
3_{+}^{1+10} \cdot\left(3 \times 3_{+}^{1+2}\right) \\
3^{2} .3^{4} .3^{8} .3 \\
3^{2} .3^{4} \cdot 3^{8} \cdot 3^{2}\end{array}$ & $\begin{array}{r}3 \times O_{8}^{+}(3): 3 \\
3^{2} \times G_{2}(3) \\
3^{7} \\
3 \\
3 \\
3^{3} \\
3^{2} \\
3 \\
3 \\
3^{2} \\
3\end{array}$ & $\begin{array}{r}\left(3 \times O_{8}^{+}(3): 3\right): 2 \\
\left(3^{2}: 2 \times G_{2}(3)\right): 2 \\
3^{7} \cdot O_{7}(3) \\
3_{+}^{1+10} \cdot U_{5}(2): 2 \\
3_{+}^{1+10} \cdot 3 \cdot U_{4}(2): 2 \\
3^{3} .3^{4} \cdot 3^{3} \cdot 3^{3} \cdot\left(L_{3}(3) \times 2\right) \\
3^{2} \cdot 3^{4} \cdot 3^{8} \cdot\left(A_{5} \times 2 A_{4}\right): 2 \\
3_{+}^{1+10} \cdot 3^{4} \cdot\left(S_{5} \times 2\right) \\
3_{+}^{1+10} \cdot\left(3 \times 3_{+}^{1+2}\right) \cdot\left(2 \times 2 S_{4}\right) \\
3^{2} .3^{4} \cdot 3^{8} \cdot 3 \cdot\left(2 \times 2 A_{4}\right) \cdot 2 \\
3^{2} \cdot 3^{4} \cdot 3^{8} \cdot 3^{2} \cdot 2^{3}\end{array}$ & $\begin{array}{l}1 \\
1 \\
2 \\
2 \\
1 \\
2 \\
4 \\
4 \\
8\end{array}$ \\
\hline
\end{tabular}

Table 1: Non-trivial radical $p$-subgroups of $\mathrm{Fi}_{24}^{\prime}$ with $p \geqslant 3$

Case (2). Suppose $p=5$, so that $G$ has a unique class of elements $x$ of order $5, C(x)=5 \times A_{9} \leqslant\left(A_{5} \times A_{9}\right) .2$ and $N(\langle x\rangle)=\left(5: 2 \times A_{9}\right) .2$. Thus $5^{2} \in \operatorname{Syl}_{5}(G)$, $C\left(5^{2}\right)=C_{A_{5} \times A_{9}}\left(5^{2}\right)=5^{2} \times A_{4}$ and $N\left(5^{2}\right)=\left(5^{2}: 4 A_{4} \times A_{4}\right) \cdot 2$.

Case (3). Suppose $p=3, i \in\{1, \ldots, 6\}$, and $M_{i}$ is a maximal 3-local subgroup of $G$ where $M_{1}=N(3 A) \simeq\left(3 \times O_{8}^{+}(3): 3\right): 2$, and $M_{2}=N\left(3^{7}\right) \simeq 3^{7} \cdot O_{7}(3)$, and $M_{3}=N(3 B) \simeq 3_{+}^{1+10}: U_{5}(2): 2$, and $M_{4}=N\left(3 B^{2}\right) \simeq 3^{2} \cdot 3^{4} \cdot 3^{8}:\left(A_{5} \times 2 A_{4}\right): 2$, and $M_{5} \simeq\left(3^{2}: 2 \times G_{2}(3)\right) \cdot 2$ and $M_{6}=N\left(3 B^{3}\right)=3^{3} \cdot 3^{4} \cdot 3^{3} \cdot 3^{3}:\left(L_{3}(3) \times 2\right)$. By [22, Theorem B], we may suppose a 3-local subgroup $R$ of $G$ is a subgroup of some $M_{i}$ with $N_{G}(R)=N_{M_{i}}(R)$. We apply the modified local strategy to each $M_{i}$.

Case (3.1) We may take

$$
\mathcal{R}_{0}\left(M_{3}, 3\right)=\left\{3_{+}^{1+10}, 3_{+}^{1+10} \cdot 3,3_{+}^{1+10} \cdot 3^{4}, 3_{+}^{1+10} \cdot\left(3 \times 3_{+}^{1+2}\right), 3^{2} \cdot 3^{4} \cdot 3^{8} \cdot 3^{2}\right\}
$$

and moreover, $N(R)=N_{M_{3}}(R)$ and $N_{E}(R)=N(R) .2$ for each $R \in \mathcal{R}_{0}\left(M_{3}, 3\right)$. We may suppose $\mathcal{R}_{0}\left(M_{3}, 3\right) \subseteq \mathcal{R}_{0}(G, 3)$.

Case (3.2) We may take

$$
\mathcal{R}_{0}\left(M_{4}, 3\right)=\left\{3^{2} \cdot 3^{4} \cdot 3^{8}, 3_{+}^{1+10} \cdot 3^{4}, 3^{2} \cdot 3^{4} \cdot 3^{8} \cdot 3,3^{2} \cdot 3^{4} \cdot 3^{8} \cdot 3^{2}\right\},
$$

and moreover, $N(R)=N_{M_{4}}(R)$ and $N_{E}(R)=N(R) .2$ for $R \in \mathcal{R}_{0}\left(M_{4}, 3\right)$. We may suppose $\mathcal{R}_{0}\left(M_{4}, 3\right) \subseteq \mathcal{R}_{0}(G, 3)$.

Case (3.3) We may take

$$
\mathcal{R}_{0}\left(M_{5}, 3\right)=\left\{3^{2}, 3^{4} \times 3_{+}^{1+2}, 3^{2} \times\left(3^{2} \times 3_{+}^{1+2}\right) .3\right\}
$$

and moreover, $N(R) \neq N_{M_{5}}(R)$ and $N_{E}(R)=N(R) .2$ for $R \in \mathcal{R}_{0}\left(M_{5}, 3\right) \backslash\left\{3^{2}\right\}$. 
The Alperin weight conjecture and Dade's conjecture for the simple group $\mathrm{Fi}_{24}^{\prime}$

In addition, $C\left(3^{4} \times 3_{+}^{1+2}\right)=3^{5}, C\left(3^{2} \times\left(3^{2} \times 3_{+}^{1+2}\right) .3\right)=3^{4}$, and

$$
N_{M_{5}}(R)= \begin{cases}3^{2}: 2 \times\left(3^{2} \times 3_{+}^{1+2}\right): 2 S_{4} & \text { if } R=3^{4} \times 3_{+}^{1+2}, \\ \left(3^{2}: 2 \times\left(3^{2} \times 3_{+}^{1+2}\right): 3.2^{2}\right) .2 & \text { if } R=3^{2} \times\left(3^{2} \times 3_{+}^{1+2}\right) .3 .\end{cases}
$$

Case (3.4) We may take

$$
\mathcal{R}_{0}\left(M_{6}, 3\right)=\left\{3^{3} \cdot 3^{4} \cdot 3^{3} \cdot 3^{3}, 3^{2} \cdot 3^{4} \cdot 3^{8} \cdot 3,3_{+}^{1+10}\left(3 \times 3_{+}^{1+2}\right), 3^{2} \cdot 3^{4} \cdot 3^{8} \cdot 3^{2}\right\}
$$

and moreover, $N(R)=N_{M_{6}}(R)$ and $N_{E}(R)=N(R) .2$ for $R \in \mathcal{R}_{0}\left(M_{6}, 3\right)$. We may suppose $\mathcal{R}_{0}\left(M_{6}, 3\right) \subseteq \mathcal{R}_{0}(G, 3)$.

Case (3.5) We may take

$$
\begin{aligned}
& \mathcal{R}_{0}\left(M_{2}, 3\right)= \\
& \quad\left\{3^{7}, 3_{+}^{1+10} \cdot 3,3^{7} \cdot 3^{3+3}, 3^{7} \cdot 3_{+}^{1+6}, 3^{7} \cdot 3_{+}^{1+6} \cdot 3,3^{7} \cdot 3^{5} \cdot 3^{3}, 3^{7} \cdot 3^{5} \cdot 3_{+}^{1+2}, 3^{2} \cdot 3^{4} \cdot 3^{8} \cdot 3^{2}\right\}
\end{aligned}
$$

and moreover, $N(R) \neq N_{M_{2}}(R)$ and $N_{E}(R)=N(R) .2$ for $R \in \mathcal{R}_{0}\left(M_{2}, 3\right) \backslash$ $\left\{3^{7}, 3_{+}^{1+10} .3\right\}, C\left(3^{7} .3^{5} .3^{3}\right)=C\left(3^{7} .3^{5} .3_{+}^{1+2}\right)=3, C\left(3^{7} .3_{+}^{1+6}\right)=C\left(3^{7} .3_{+}^{1+6} .3\right)=3^{2}$, $C\left(3^{7} \cdot 3^{3+3}\right)=3^{3}$ and

$$
N_{M_{2}}(R)= \begin{cases}3^{7} \cdot 3^{3+3} \cdot L_{3}(3) & \text { if } R=3^{7} \cdot 3^{3+3}, \\ 3^{7} \cdot 3_{+}^{1+6} \cdot\left(2 A_{4} \times A_{4}\right) \cdot 2 & \text { if } R=3^{7} \cdot 3_{+}^{1+6} \\ 3^{7} \cdot 3_{+}^{1+6} 3 \cdot 2 S_{4} & \text { if } R=3^{7} \cdot 3_{+}^{1+6} \cdot 3 \\ 3^{7} \cdot 3^{5} \cdot 3^{3} \cdot\left(S_{4} \times 2\right) & \text { if } R=3^{7} \cdot 3^{5} \cdot 3^{3}, \\ 3^{7} \cdot 3^{5} \cdot 3_{+}^{1+2} \cdot 2 S_{4} & \text { if } R=3^{7} \cdot 3^{5} \cdot 3_{+}^{1+2} \\ 3^{2} \cdot 3^{4} \cdot 3^{8} \cdot 3^{2} \cdot 2^{2} & \text { if } R=3^{2} \cdot 3^{4} \cdot 3^{8} \cdot 3^{2} .\end{cases}
$$

Case (3.6) Let $R$ be a radical subgroup of $M_{1}=\left(3 \times O_{8}^{+}(3): 3\right): 2$ and $Q=R \cap H$, where $H=3 \times O_{8}^{+}(3)$ is a normal subgroup of $M_{1}$. Then $Q$ is a radical subgroup of $H$ and $Q$ is normal in $N_{M_{1}}(R)$. In particular, $N_{M_{1}}(R) \leqslant N_{M_{1}}(Q)$ and $R$ is radical in $N_{M_{1}}(Q)$.

Let $L_{1} \simeq\left(3 \times 3^{6}: L_{4}(2)\right): 2, L_{2} \simeq\left(3 \times 3_{+}^{1+8}: 2\left(A_{4} \times A_{4} \times A_{4}\right) 2: 3\right): 2$ and $L_{3}=$ $3^{2}: 2 \times G_{2}(3)$ be $p$-local subgroups of $M_{1}$, so that we may suppose $Q \in \mathcal{R}_{0}\left(L_{i} \cap H, 3\right)$ (cf. [9, p. 140]). In addition, if $Q \leqslant \mathcal{R}_{0}\left(L_{i} \cap H, 3\right)$ for $i=2,3$, then $N_{M_{1}}(R) \leqslant L_{i}$ and so $R \in \mathcal{R}_{0}\left(L_{i}, 3\right)$ with $N(R)=N_{L_{i}}(R)=N_{M_{1}}(R)$.

We may take

$$
\mathcal{R}_{0}\left(L_{1}, 3\right)=\left\{3^{7}, 3^{7}: 3^{3}, 3^{7}: 3^{4}, 3^{7}: 3^{3} \cdot 3^{2}, 3^{7}: 3^{4} \cdot 3,3^{7}: 3^{4} \cdot 3^{2}\right\}
$$

and moreover, $N(R) \neq N_{M_{1}}(R) \neq N_{L_{1}}(R)$ for $R \in \mathcal{R}_{0}\left(L_{1}, 3\right) \backslash\left\{3^{7}, 3^{7}: 3^{4}\right\}, N(R) \neq$ $N_{M_{1}}(R)=N_{L_{1}}(R)$ for $R=3^{7}$ or $3^{7}: 3^{4} .3^{2}$. In addition, $N_{M_{1} .2}(R)=N_{N_{M_{1} .2}\left(L_{1}\right)}(R)$ for $R \in \mathcal{R}_{0}\left(L_{1}, 3\right), C\left(3^{7}\right)=3^{7}, C\left(3^{7}: 3^{3}\right)=3^{4}, C\left(3^{7}: 3^{4}\right)=C\left(3^{7}: 3^{3} \cdot 3^{2}\right)=$ $C\left(3^{7}: 3^{4} .3^{2}\right)=3^{2}, C\left(3^{7}: 3^{4} \cdot 3\right)=3^{3}$, and

$$
N_{L_{1}}(R)= \begin{cases}3^{7} \cdot 3^{3} \cdot L_{3}(3) & \text { if } R=3^{7} \cdot 3^{3} \\ 3^{7} \cdot 3^{4} \cdot 2\left(A_{4} \times A_{4}\right) \cdot 2 \cdot 2 & \text { if } R=3^{7} \cdot 3^{4} \\ 3^{7} \cdot 3^{3} \cdot 3^{2} \cdot 2 S_{4} & \text { if } R=3^{7} \cdot 3^{3} \cdot 3^{2} \\ 3^{7} \cdot 3^{4} \cdot 3 \cdot 2 S_{4} \cdot 2 & \text { if } R=3^{7} \cdot 3^{4} \cdot 3 \\ 3^{7} \cdot 3^{4} \cdot 3^{2} \cdot 2^{3} & \text { if } R=3^{7} \cdot 3^{4} \cdot 3^{2}\end{cases}
$$


The Alperin weight conjecture and Dade's conjecture for the simple group $\mathrm{Fi}_{24}^{\prime}$

\begin{tabular}{|c|c|c|c|}
\hline$R$ & $C(R)$ & $N$ & $\left|\operatorname{Irr}^{0}(N / C(R) R)\right|$ \\
\hline 2 & $2 . \mathrm{Fi}_{22} .2$ & 2. $\mathrm{Fi}_{22} .2$ & \\
\hline $2^{2}$ & $2^{2} \cdot U_{6}(2)$ & $2^{2} \cdot U_{6}(2) \cdot S_{3}$ & \\
\hline$\left(2^{2}\right)^{*}$ & $2^{2} \times O_{8}^{+}(2): 3$ & $\left(A_{4} \times O_{8}^{+}(2): 3\right): 2$ & \\
\hline$D_{8}$ & $2 \times S_{6}(2)$ & $D_{8} \times S_{6}(2)$ & \\
\hline $2^{8}$ & $2^{8}$ & $2^{8} \cdot O_{8}^{-}(2)$ & 1 \\
\hline $2^{11}$ & $2^{11}$ & $2^{11} \cdot M_{24}$ & 0 \\
\hline $2_{+}^{1+12}$ & 2 & $2_{+}^{1+12} \cdot 3 U_{4}(3): 2$ & 2 \\
\hline $2_{+}^{1+12} .2$ & 2 & $2_{+}^{1+12} \cdot 2 U_{4}(2)$ & 1 \\
\hline $2^{6+8}$ & $2^{6}$ & $2^{6+8} \cdot\left(A_{8} \times S_{3}\right)$ & 1 \\
\hline $2^{11} .2^{4}$ & $2^{6}$ & $2^{11} \cdot 2^{4} \cdot A_{8}$ & 1 \\
\hline $2^{3+12}$ & $2^{3}$ & $2^{3+12} \cdot\left(A_{6} \times L_{3}(2)\right)$ & 2 \\
\hline $2^{11} \cdot 2^{6}$ & 2 & $2^{11} \cdot 2^{6} \cdot 3 S_{6}$ & 1 \\
\hline $2^{3} \cdot 2^{6} \cdot 2^{8}$ & $2^{3}$ & $2^{3} \cdot 2^{6} \cdot 2^{8} \cdot\left(S_{3} \times L_{3}(2)\right)$ & 1 \\
\hline $2_{+}^{1+12} \cdot 2^{4}$ & 2 & $2_{+}^{1+12} \cdot 2^{4} \cdot\left(A_{6} \times S_{3}\right)$ & 2 \\
\hline $2^{3+12} \cdot 2^{2}$ & $2^{2}$ & $2^{3+12} \cdot 2^{2}\left(A_{6} \times S_{3}\right)$ & 2 \\
\hline $2^{3} \cdot 2^{3} \cdot 2^{6} \cdot 2^{5}$ & $2^{3}$ & $2^{3} \cdot 2^{3} \cdot 2^{6} \cdot 2^{5} \cdot\left(S_{3} \times L_{3}(2)\right)$ & 1 \\
\hline $2^{6+8} \cdot 2^{3}$ & $2^{3}$ & $2^{6+8} .2^{3}\left(L_{3}(2) \times S_{3}\right)$ & 1 \\
\hline $2^{11} \cdot 2^{3} \cdot 2^{4}$ & $2^{3}$ & $2^{11} \cdot 2^{3} \cdot 2^{4} \cdot L_{3}(2)$ & 1 \\
\hline $2^{11} \cdot 2^{1+6}$ & $2^{3}$ & $2^{11} \cdot 2^{1+6} \cdot L_{3}(2)$ & 1 \\
\hline $2_{+}^{1+12} \cdot 2.2^{4}$ & 2 & $2_{+}^{1+12} \cdot 2.2^{4} \cdot\left(S_{3} \times S_{3} \times S_{3}\right)$ & 1 \\
\hline $2_{+}^{1+12} \cdot 2^{4} \cdot 2$ & 2 & $2_{+}^{1+12} \cdot 2^{4} \cdot 2 \cdot A_{6}$ & 2 \\
\hline $2^{11} \cdot 2^{2} \cdot 2^{6}$ & $2^{2}$ & $2^{11} \cdot 2^{2} \cdot 2^{6} \cdot\left(S_{3} \times S_{3}\right)$ & 1 \\
\hline $2^{11} \cdot 2^{4} \cdot 2^{4}$ & 2 & $2^{11} \cdot 2^{4} \cdot 2^{4} \cdot\left(S_{3} \times S_{3}\right)$ & 1 \\
\hline $2^{1+12} \cdot 2.2^{4} \cdot 2$ & 2 & $2^{1+12} \cdot 2 \cdot 2^{4} \cdot 2 \cdot\left(S_{3} \times S_{3}\right)$ & 1 \\
\hline $2^{1+12} \cdot 2^{2} \cdot 2^{4}$ & 2 & $2^{1+12} \cdot 2^{2} \cdot 2^{4} \cdot\left(S_{3} \times S_{3}\right)$ & 1 \\
\hline $2^{6+8} \cdot 2^{4} \cdot 2$ & 2 & $2^{6+8} \cdot 2^{4} \cdot 2 \cdot\left(S_{3} \times S_{3}\right)$ & 1 \\
\hline $2^{6+8} \cdot 2^{3} \cdot 2^{2}$ & $2^{2}$ & $2^{6+8} \cdot 2^{3} \cdot 2^{2}\left(S_{3} \times S_{3}\right)$ & 1 \\
\hline $2^{6+8} \cdot 2^{4} \cdot 2^{2}$ & 2 & $2^{6+8} \cdot 2^{4} \cdot 2^{2} \cdot S_{3}$ & 1 \\
\hline $2^{6+8} \cdot 2^{3} \cdot 2^{3}$ & $2^{2}$ & $2^{6+8} \cdot 2^{3} \cdot 2^{3} \cdot S_{3}$ & 1 \\
\hline $2^{11} \cdot 2^{2} \cdot 2^{3} \cdot 2^{4}$ & 2 & $2^{11} \cdot 2^{2} 2^{3} \cdot 2^{4} \cdot S_{3}$ & 1 \\
\hline $2^{1+12} \cdot 2^{4} \cdot 2^{2} \cdot 2$ & 2 & $2^{1+12} \cdot 2^{4} \cdot 2^{2} \cdot 2 \cdot S_{3}$ & 1 \\
\hline $2^{3+12} \cdot\left(D_{8} \times 2^{2}\right)$ & 2 & $2^{3+12} \cdot\left(D_{8} \times 2^{2}\right) \cdot S_{3}$ & 1 \\
\hline$S$ & 2 & $S$ & 1 \\
\hline
\end{tabular}

Table 2: Non-trivial radical 2-subgroups of $\mathrm{Fi}_{24}^{\prime}$

Suppose $R \in \mathcal{R}_{0}\left(M_{1}, 3\right)$ such that $Q=R \cap H \in \mathcal{R}_{0}\left(L_{1}, 3\right)$. Then

$$
N_{M_{1}}(R)= \begin{cases}3^{7} \cdot 3^{3} \cdot\left(L_{3}(3) \times 2\right) & \text { if } Q=3^{7} \cdot 3^{3}, \\ 3^{7} \cdot 3^{4} \cdot 2\left(A_{4} \times A_{4}\right) \cdot 2 \cdot 2 & \text { if } Q=3^{7} \cdot 3^{4}, \\ 3^{7} \cdot 3^{3} \cdot 3^{2} \cdot 2 S_{4} \cdot 2 & \text { if } Q=3^{7} \cdot 3^{3} \cdot 3^{2}, \\ 3^{5} \cdot 3^{4} \cdot 3^{4} \cdot 2 S_{4} \cdot 2 & \text { if } Q=3^{7} \cdot 3^{4} \cdot 3, \\ \left(3 \times 3_{+}^{1+8}\right) \cdot 3^{3} \cdot 3 \cdot 2^{3} & \text { if } Q=3^{7} \cdot 3^{4} \cdot 3^{2} .\end{cases}
$$

We may take

$$
\mathcal{R}_{0}\left(L_{2}, 3\right)=\left\{3 \times 3_{+}^{1+8}, 3^{7} \cdot 3^{4},\left(3 \times 3_{+}^{1+8}\right) \cdot 3,\left(3 \times 3_{+}^{1+8}\right) \cdot 3^{2},\left(3 \times 3_{+}^{1+8}\right) \cdot 3^{3} \cdot 3\right\}
$$


The Alperin weight conjecture and Dade's conjecture for the simple group $\mathrm{Fi}_{24}^{\prime}$

and then $N(R) \neq N_{M_{1}}(R)=N_{L_{2}}(R), N_{M_{1} .2}(R)=N_{N_{M_{1} .2}\left(L_{2}\right)}(R)$ for all $R \in$ $\mathcal{R}_{0}\left(L_{2}, 3\right)$. In addition, $C(R)=3^{2}$ for $R \in \mathcal{R}_{0}\left(L_{2}, 3\right)$ and

$$
N_{L_{2}}(R)= \begin{cases}\left(3 \times 3_{+}^{1+8}\right) \cdot 3 \cdot 2 S_{4} \cdot 2 & \text { if } R=\left(3 \times 3_{+}^{1+8}\right) \cdot 3 \\ \left(3 \times 3_{+}^{1+8}\right) \cdot 3^{2} \cdot 2 S_{4} \cdot 2 & \text { if } R=\left(3 \times 3_{+}^{1+8}\right) \cdot 3^{2} \\ \left(3 \times 3_{+}^{1+8}\right) \cdot 3^{3} \cdot 3 \cdot 2^{3} & \text { if } R=\left(3 \times 3_{+}^{1+8}\right) \cdot 3^{3} \cdot 3 .\end{cases}
$$

We may take

$$
\mathcal{R}_{0}\left(L_{3}, 3\right)=\left\{3^{2}, 3^{4} \times 3_{+}^{1+2},\left(3^{4} \times 3_{+}^{1+2}\right)^{*}, 3^{2} \times\left(3^{2} \times 3_{+}^{1+2}\right) .3\right\},
$$

and $N(R) \neq N_{M_{1}}(R) \neq N_{L_{3}}(R), N_{M_{1} .2}(R)=N_{N_{M_{1} .2}\left(L_{3}\right)}(R)$ for $R \in \mathcal{R}_{0}\left(L_{3}, 3\right) \backslash\left\{3^{2}\right\}$.

It follows that $\mathcal{R}_{0}\left(M_{1}, 3\right)=$ $\left\{3,3^{2}, 3^{7}, 3 \times 3_{+}^{1+8}, 3^{7} \cdot 3^{3}, 3^{7}: 3^{4},\left(3 \times 3_{+}^{1+8}\right) \cdot 3,\left(3 \times 3_{+}^{1+8}\right) \cdot 3^{2}, 3^{5} \cdot 3^{4} \cdot 3^{4},\left(3 \times 3_{+}^{1+8}\right) \cdot 3^{3} \cdot 3\right\}$, and $N(R) \neq N_{M_{1}}(R)$ for $R \in \mathcal{R}_{0}\left(M_{3}, 3\right) \backslash\{3\}$.

Case (4) For $1 \leqslant i \leqslant 8$, let $M_{i}$ be the maximal 2-local subgroups of $\mathrm{Fi}_{24}^{\prime}$ such that $M_{1}=N(2 A) \simeq 2 . \mathrm{Fi}_{22}: 2, M_{2}=N\left(2^{11}\right) \simeq 2^{11} \cdot M_{24}, M_{3}=N\left(2 A^{2}\right) \simeq 2^{2} \cdot U_{6}(2): S_{3}$, $M_{4}=N(2 B) \simeq 2_{+}^{1+12} .3 \cdot U_{4}(3): 2, M_{5}=N\left(2 A^{2}\right) \simeq\left(A_{4} \times O_{8}^{+}(2): 3\right): 2, M_{6}=N\left(2 B^{3}\right)$ $\simeq 2^{3+12} \cdot\left(A_{6} \times L_{3}(2)\right), M_{7}=N\left(2^{6}\right)=2^{6+8} \cdot\left(A_{8} \times S_{3}\right)$ and $M_{8}=N\left(2^{8}\right) \simeq 2^{8}: O_{8}^{-}(2)$.

If $R$ is a non-trivial radical 2-subgroup of $G=\mathrm{Fi}_{24}^{\prime}$, then we may suppose $R \in \mathcal{R}_{0}\left(M_{i}, 2\right)$ such that $N(R)=N_{M_{i}}(R)$ for some $i=1, \ldots, 8$.

Case (4.1) We may take

$$
\begin{aligned}
\mathcal{R}_{0}\left(M_{2}, 2\right)= & \left\{2^{11}, 2^{11} \cdot 2^{4}, 2^{11} \cdot 2^{6}, 2^{3} \cdot 2^{6} \cdot 2^{8}, 2^{11} \cdot 2^{3} \cdot 2^{4}, 2^{11} \cdot 2_{+}^{1+6}, 2^{11} \cdot 2^{2} \cdot 2^{6}, 2^{11} \cdot 2^{4} \cdot 2^{4},\right. \\
& \left.2_{+}^{1+12} \cdot 2 \cdot 2^{4} \cdot 2,2^{6+8} \cdot 2^{4} \cdot 2^{2}, 2^{6+8} \cdot 2^{3} \cdot 2^{3}, 2^{11} \cdot 2^{2} \cdot 2^{3} \cdot 2^{4}, 2_{+}^{1+12} \cdot 2^{4} \cdot 2^{2} \cdot 2, S\right\}
\end{aligned}
$$

and moreover, $N(R)=N_{M_{2}}(R)$ for each $R \in \mathcal{R}_{0}\left(M_{2}, 2\right)$, so that we may suppose $\mathcal{R}_{0}\left(M_{2}, 2\right) \subseteq \mathcal{R}_{0}(G, 2)$.

Case (4.2) Let $K_{1} \simeq\left(2^{2} \times 2_{+}^{1+8}\right) \cdot U_{4}(2): S_{3}, K_{2} \simeq 2^{11} \cdot L_{3}(4): S_{3}, K_{3} \simeq 2^{6+8} \cdot\left(S_{3} \times\right.$ $\left.S_{5}\right) .3$ and $K_{4} \simeq D_{8} \times S_{6}(2)$ be the maximal $p$-local subgroups of $M_{3}$ (cf. [9, p. 115]). Then we may suppose each radical subgroup $R$ of $M_{3}$ is a subgroup of $\mathcal{R}_{0}\left(K_{i}, 3\right)$ for some $i$ with $N(R)=N_{K_{i}}(R)=N_{M_{3}}(R)$.

The radical subgroups $R \in \mathcal{R}_{0}\left(K_{1}, 2\right)$ and their local structures are given in Table 3 and moreover, $N(R) \neq N_{M_{3}}(R)=N_{K_{1}}(R), N_{M_{3} .2}(R)=N_{N_{M_{3} .2}\left(K_{1}\right)}(R)$ for each $R \in \mathcal{R}_{0}\left(K_{1}, 2\right)$.

We may take

$$
\begin{gathered}
\mathcal{R}_{0}\left(K_{2}, 2\right)=\left\{2^{11}, 2^{11} \cdot 2,\left(2^{2} \times 2_{+}^{1+8}\right) \cdot 2^{4}, 2^{11} \cdot 2^{4}, 2^{6+8} \cdot 2^{2},\left(2^{2} \times 2_{+}^{1+8}\right) \cdot 2^{4} \cdot 2,\right. \\
\left.\left(2^{2} \times 2_{+}^{1+8}\right) \cdot 2^{4} \cdot 2^{2},\left(2^{2} \times 2_{+}^{1+8}\right) \cdot 2^{4} \cdot 2^{2} \cdot 2\right\}
\end{gathered}
$$

and moreover, $N(R) \neq N_{M_{3}}(R)=N_{K_{2}}(R), N_{M_{3} .2}(R)=N_{N_{M_{3} .2}\left(K_{2}\right)}(R)$ for each $R \in \mathcal{R}_{0}\left(K_{2}, 2\right)$. In addition, $C\left(2^{11}\right)=2^{11}, C\left(2^{11} .2\right)=2^{7}, C\left(2^{11} .2^{4}\right)=2^{6}$, $C\left(2^{6+8} \cdot 2^{2}\right)=2^{4}$ and

$$
N_{K_{2}}(R)= \begin{cases}2^{11} \cdot 2 \cdot L_{2}(7) & \text { if } R=2^{11} \cdot 2 \\ 2^{11} \cdot 2^{4} \cdot A_{5} \cdot S_{3} & \text { if } R=2^{11} \cdot 2^{4} \\ 2^{6+8} \cdot 2^{2} \cdot S_{3} & \text { if } R=2^{6+8} \cdot 2^{2}\end{cases}
$$


The Alperin weight conjecture and Dade's conjecture for the simple group $\mathrm{Fi}_{24}^{\prime}$

\begin{tabular}{|r|c|l|}
\hline$R$ & $C(R)$ & $N_{K_{1}}(R)$ \\
\hline \hline $2^{2} \times 2_{+}^{1+8}$ & $2^{3}$ & $\left(2^{2} \times 2_{+}^{1+8}\right) \cdot U_{4}(2): S_{3}$ \\
$\left(2^{2} \times 2_{+}^{1+8}\right) \cdot 2$ & $2^{2}$ & $\left(2^{2} \times 2_{+}^{1+8}\right) \cdot 2 S_{6}$ \\
$\left(2^{2} \times 2_{+}^{1+8}\right) \cdot 2^{4}$ & $2^{3}$ & $\left(2^{2} \times 2_{+}^{1+8}\right) \cdot 2^{4}: A_{5}: S_{3}$ \\
$\left(2^{2} \times 2_{+}^{1+8}\right) \cdot 2 \cdot 2^{4}$ & $2^{3}$ & $\left(2^{2} \times 2_{+}^{1+8}\right) \cdot 2 \cdot 2^{4} \cdot 3^{2} \cdot 2 \cdot S_{3}$ \\
$\left(2^{2} \times 2_{+}^{1+8}\right) \cdot 2^{4} \cdot 2$ & $2^{2}$ & $\left(2^{2} \times 2_{+}^{1+8}\right) \cdot 2^{4} \cdot 2 \cdot S_{3}$ \\
$\left(2^{2} \times 2_{+}^{1+8}\right) \cdot 2^{4} \cdot 2^{2}$ & $2^{3}$ & $\left(2^{2} \times 2_{+}^{1+8}\right) \cdot 2^{4} \cdot 2^{2} \cdot\left(3 \times S_{3}\right)$ \\
$\left(2^{2} \times 2_{+}^{1+8}\right) \cdot 2 \cdot 2^{4} \cdot 2$ & $2^{2}$ & $\left(2^{2} \times 2_{+}^{1+8}\right) \cdot 2 \cdot 2^{4} \cdot 2 \cdot S_{3}$ \\
$\left(2^{2} \times 2_{+}^{1+8}\right) \cdot 2^{4} \cdot 2^{2} \cdot 2$ & $2^{2}$ & $\left(2^{2} \times 2_{+}^{1+8}\right) \cdot 2^{4} \cdot 2^{2} \cdot 2$ \\
\hline
\end{tabular}

Table 3: Radical 2-subgroups of $\left(2^{2} \times 2_{+}^{1+8}\right) \cdot U_{4}(2): S_{3}$

We may take

$$
\begin{gathered}
\mathcal{R}_{0}\left(K_{3}, 2\right)=\left\{2^{6+8}, 2^{11} \cdot 2^{4}, 2^{6+8} \cdot 2,\left(2^{2} \times 2_{+}^{1+8}\right) \cdot 2 \cdot 2^{4}, 2^{6+8} \cdot 2^{2},\left(2^{2} \times 2_{+}^{1+8}\right) \cdot 2^{4} \cdot 2^{2},\right. \\
\left.\left(2^{2} \times 2_{+}^{1+8}\right) \cdot 2 \cdot 2^{4} \cdot 2,\left(2^{2} \times 2_{+}^{1+8}\right) \cdot 2^{4} \cdot 2^{2} \cdot 2\right\}
\end{gathered}
$$

and moreover, $N(R) \neq N_{M_{3}}(R)=N_{K_{3}}(R), N_{M_{3} .2}(R)=N_{N_{M_{3} .2}\left(K_{3}\right)}(R)$ for each $R \in \mathcal{R}_{0}\left(K_{3}, 2\right)$. In addition, $C\left(2^{6+8}\right)=2^{6}, C\left(2^{6+8} .2\right)=2^{4}$, and $N_{K_{3}}\left(2^{6+8} .2\right)=$ $2^{6+8} .2 .\left(S_{3} \times S_{3}\right)$.

The radical subgroups $R \in \mathcal{R}_{0}\left(K_{4}, 2\right)$ and their local structures are given in Table 4 and moreover, $N(R) \neq N_{M_{3}}(R) \neq N_{K_{4}}(R), N_{M_{3} .2}(R)=N_{N_{M_{3} .2}\left(K_{4}\right)}(R)$ for each $R \in \mathcal{R}_{0}\left(K_{4}, 2\right) \backslash\left\{D_{8}\right\}$.

\begin{tabular}{|r|r|l|}
\hline$R$ & $C(R)$ & $N_{K_{4}}(R)$ \\
\hline \hline$D_{8}$ & $2 \times S_{6}(2)$ & $D_{8} \times S_{6}(2)$ \\
$D_{8} \times 2^{5}$ & $2^{6}$ & $D_{8} \times 2^{5}: S_{6}$ \\
$D_{8} \times 2^{6}$ & $2^{7}$ & $D_{8} \times 2^{6}: L_{3}(2)$ \\
$D_{8} \times 2^{3} .2^{4}$ & $2^{4}$ & $D_{8} \times 2^{3} .2^{4} \cdot\left(S_{3} \times S_{3}\right)$ \\
$D_{8} \times 2^{3} .2^{2} .2^{3}$ & $2^{4}$ & $D_{8} \times 2^{3} .2^{2} .2^{3} . S_{3}$ \\
$D_{8} \times 2^{3} .2^{5}$ & $2^{4}$ & $D_{8} \times 2^{3} .2^{5} . S_{3}$ \\
$D_{8} \times 2^{2} .2^{3} .2^{3} . S_{3}$ & $2^{3}$ & $D_{8} \times 2^{2} .2^{3} .2^{3} \cdot S_{3}$ \\
$D_{8} \times 2^{3} .2^{5} .2$ & $2^{2}$ & $D_{8} \times 2^{3} .2^{5} .2$ \\
\hline
\end{tabular}

Table 4: Radical 2-subgroups of $D_{8} \times S_{6}(2)$

It follows that we may take

$$
\begin{aligned}
\mathcal{R}_{0}\left(M_{3}, 2\right)= & \left\{2^{2}, D_{8}, 2^{11}, 2^{2} \times 2_{+}^{1+8}, 2^{11} \cdot 2,\left(2^{2} \times 2_{+}^{1+8}\right) \cdot 2,2^{6+8}, 2^{11} \cdot 2^{4},\right. \\
& \left(2^{2} \times 2_{+}^{1+8}\right) \cdot 2^{4}, 2^{6+8} \cdot 2,\left(2^{2} \times 2_{+}^{1+8}\right) \cdot 2 \cdot 2^{4}, 2^{6+8} \cdot 2^{2}, \\
& \left(2^{2} \times 2_{+}^{1+8}\right) \cdot 2^{4} \cdot 2,\left(2^{2} \times 2_{+}^{1+8}\right) \cdot 2 \cdot 2^{4} \cdot 2, \\
& \left.\left(2^{2} \times 2_{+}^{1+8}\right) \cdot 2^{4} \cdot 2^{2},\left(2^{2} \times 2_{+}^{1+8}\right) \cdot 2^{4} \cdot 2^{2} \cdot 2\right\}
\end{aligned}
$$

and moreover, $N(R) \neq N_{M_{3}}(R)$ for each $R \in \mathcal{R}_{0}\left(M_{3}, 2\right) \backslash\left\{2^{2}, D_{8}\right\}$.

Case (4.3) We may take

$$
\mathcal{R}_{0}\left(M_{4}, 2\right)=\left\{2^{1+12}, 2^{1+12} \cdot 2,2^{1+12} \cdot 2^{4}, 2^{11} \cdot 2^{6}, 2_{+}^{1+12} \cdot 2 \cdot 2^{4}, 2_{+}^{1+12} \cdot 2^{4} \cdot 2,\right.
$$


The Alperin weight conjecture and Dade's conjecture for the simple group $\mathrm{Fi}_{24}^{\prime}$

$$
\begin{gathered}
2_{+}^{1+12} \cdot 2 \cdot 2^{4} \cdot 2,2_{+}^{1+12} \cdot 2^{2} \cdot 2^{4}, 2^{11} \cdot 2^{4} \cdot 2^{4}, 2^{6+8} \cdot 2^{4} \cdot 2,2^{6+8} \cdot 2^{4} \cdot 2^{2}, \\
\left.2^{3+12} \cdot\left(D_{8} \times 2^{2}\right), 2^{11} \cdot 2^{2} \cdot 2^{3} \cdot 2^{4}, 2_{+}^{1+12} \cdot 2^{4} \cdot 2^{2} \cdot 2, S\right\}
\end{gathered}
$$

and moreover, $N(R)=N_{M_{4}}(R)$ for each $R \in \mathcal{R}_{0}\left(M_{4}, 2\right)$, so that we may suppose $\mathcal{R}_{0}\left(M_{4}, 2\right) \subseteq \mathcal{R}_{0}(G, 2)$.

Case (4.4) The radical subgroups $R \in \mathcal{R}_{0}\left(M_{5}, 2\right)$ and their local structures are given in Table 5 and moreover, $N(R) \neq N_{M_{5}}(R), N_{M_{5} .2}(R)=N_{M_{5}}(R) .2$ for each $R \in \mathcal{R}_{0}\left(M_{5}, 2\right) \backslash\left\{\left(2^{2}\right)^{*}, D_{8}\right\}$ and $N(R)=N_{M_{5}}(R)$ for $R \in\left\{\left(2^{2}\right)^{*}, D_{8}\right\}$.

\begin{tabular}{|r|r|l|}
\hline$R$ & $C(R)$ & $N_{M_{5}}(R)$ \\
\hline \hline$\left(2^{2}\right)^{*}$ & $2^{2} \times O_{8}^{+}(2): 3$ & $\left(A_{4} \times O_{8}^{+}(2): 3\right): 2$ \\
$D_{8}$ & $2 \times S_{6}(2)$ & $D_{8} \times S_{6}(2)$ \\
$2^{8}$ & $2^{8}$ & $\left(A_{4} \times 2^{6}: A_{8}\right): 2$ \\
$2^{8} \cdot 2$ & $2^{6}$ & $2^{8} \cdot 2 \cdot S_{6}$ \\
$2^{8} \cdot 2^{3}$ & $2^{5}$ & $2^{8} \cdot 2^{3} \cdot 3\left(L_{3}(2) \times S_{3}\right)$ \\
$2^{3} \cdot 2^{8}$ & $2^{3}$ & $2^{3} \cdot 2^{8} \cdot 3 \cdot\left(S_{3} \times S_{3} \times S_{3}\right) \cdot S_{3}$ \\
$2^{8} \cdot 2^{4}$ & $2^{3}$ & $2^{8} \cdot 2^{4} \cdot\left(S_{3} \times S_{3}\right) \cdot S_{3}$ \\
$2^{3} \cdot 2^{8} \cdot 2$ & $2^{2}$ & $2^{3} \cdot 2^{8} \cdot 2 \cdot\left(S_{3} \times S_{3}\right)$ \\
$2^{4} \cdot 2^{4} \cdot 2^{4}$ & $2^{4}$ & $2^{4} \cdot 2^{4} \cdot 2^{4} \cdot L_{3}(2)$ \\
$2^{4} \cdot 2^{3} \cdot 2^{6}$ & $2^{4}$ & $2^{4} \cdot 2^{3} \cdot 2^{6} \cdot\left(S_{3} \times S_{3}\right) \cdot 3$ \\
$2^{8} \cdot 2^{2} \cdot 2^{3}$ & $2^{2}$ & $2^{8} \cdot 2^{2} \cdot 2^{3} \cdot S_{3}$ \\
$2^{3} \cdot 2^{8} \cdot 2^{2}$ & $2^{3}$ & $2^{3} \cdot 2^{8} \cdot 2^{2} \cdot\left(S_{3} \times S_{3}\right)$ \\
$2^{8} \cdot 2^{3} \cdot 2^{2} \cdot 2$ & $2^{3}$ & $2^{8} \cdot 2^{3} \cdot 2^{2} \cdot 2 \cdot S_{3}$ \\
$2^{3} \cdot 2^{8} \cdot 2^{3}$ & $2^{3}$ & $2^{3} \cdot 2^{8} \cdot 2^{3} \cdot S_{3}$ \\
$2^{3} \cdot 2^{8} \cdot 2^{2} \cdot 2$ & $2^{2}$ & $2^{3} \cdot 2^{8} \cdot 2^{2} \cdot 2 \cdot S_{3}$ \\
$2^{8} \cdot 2^{4} \cdot 2^{3}$ & $2^{2}$ & $2^{8} \cdot 2^{4} \cdot 2^{3}$ \\
\hline
\end{tabular}

Table 5: Radical 2-subgroups of $\left(A_{4} \times O_{8}^{+}(2): 3\right): 2$

Case (4.5) We may take

$$
\begin{aligned}
& \mathcal{R}_{0}\left(M_{6}, 2\right)=\left\{2^{3+12}, 2^{3} \cdot 2^{6} \cdot 2^{8}, 2^{3+12} \cdot 2^{2}, 2^{3} \cdot 2^{3} \cdot 2^{6} \cdot 2^{5}, 2^{1+12} \cdot 2^{4}, 2^{11} \cdot 2^{3} \cdot 2^{4},\right. \\
& 2^{1+12} \cdot 2^{4} \cdot 2,2^{6+8} \cdot 2^{3} \cdot 2^{2}, 2^{6+8} \cdot 2^{4} \cdot 2,2^{11} \cdot 2^{4} \cdot 2^{4}, 2^{11} \cdot 2^{2} \cdot 2^{6}, 2^{11} \cdot 2^{2} \cdot 2^{3} \cdot 2^{4}, \\
& \left.2_{+}^{1+12} \cdot 2^{4} \cdot 2^{2} \cdot 2,2^{6+8} \cdot 2^{3} \cdot 2^{3}, 2^{3+12} \cdot\left(D_{8} \times 2\right), S\right\}
\end{aligned}
$$

and moreover, $N(R)=N_{M_{6}}(R)$ for each $R \in \mathcal{R}_{0}\left(M_{6}, 2\right)$.

Case (4.6) We may take

$$
\begin{aligned}
\mathcal{R}_{0}\left(M_{7}, 2\right)= & \left\{2^{6+8}, 2^{11} \cdot 2^{4}, 2^{6+8} \cdot 2^{3}, 2^{3} \cdot 2^{3} \cdot 2^{6} \cdot 2^{5}, 2^{11} \cdot 2^{1+6}, 2^{11} \cdot 2^{3} \cdot 2^{4},\right. \\
& 2^{1+12} \cdot 2 \cdot 2^{4}, 2^{6+8} \cdot 2^{4} \cdot 2,2^{1+12} \cdot 2 \cdot 2^{4} \cdot 2,2^{1+12} \cdot 2^{2} \cdot 2^{4}, 2^{6+8} \cdot 2^{3} \cdot 2^{2}, \\
& \left.2^{6+8} \cdot 2^{4} \cdot 2^{2}, 2^{1+12} \cdot\left(D_{8} \times 2^{2}\right), 2^{6+8} \cdot 2^{3} \cdot 2^{3}, 2^{11} \cdot 2^{2} \cdot 2^{3} \cdot 2^{4}, S\right\}
\end{aligned}
$$

and moreover, $N(R)=N_{M_{7}}(R)$ for each $R \in \mathcal{R}_{0}\left(M_{7}, 2\right)$.

Case (4.7) We may take $\mathcal{R}_{0}\left(M_{8}, 2\right)=$

$$
\left\{2^{8}, 2^{1+12} \cdot 2,2^{8} \cdot 2^{3+6}, 2^{8} \cdot 2^{1+8}, 2^{8} \cdot 2^{6} \cdot 2^{4}, 2^{8} \cdot 2^{6} \cdot 2 \cdot 2^{4}, 2^{8} \cdot 2^{3+6} \cdot 2^{2}, 2^{8} \cdot 2^{3+6} \cdot D_{8}\right\}
$$

and moreover, $N(R) \neq N_{M_{8}}(R)$ for each $R \in \mathcal{R}_{0}\left(M_{8}, 2\right) \backslash\left\{2^{8}, 2^{1+12} .2\right\}, N\left(2^{1+12} .2\right)=$ $N_{M_{8}}\left(2^{1+12} \cdot 2\right), C\left(2^{8}: 2^{3+6}\right)=2^{3}, C\left(2^{8} \cdot 2^{6} \cdot 2^{4}\right)=C\left(2^{8} \cdot 2^{6} \cdot 2 \cdot 2^{4}\right)=C\left(2^{8} \cdot 2^{3+6} \cdot D_{8}\right)=2$, 
The Alperin weight conjecture and Dade's conjecture for the simple group $\mathrm{Fi}_{24}^{\prime}$ $C\left(2^{8} \cdot 2^{1+8}\right)=2^{2}=C\left(2^{8}: 2^{3+6} \cdot 2^{2}\right)$ and

$$
N_{M_{8}}(R)= \begin{cases}2^{8} \cdot 2^{3+6} \cdot\left(L_{3}(2) \times 3\right) & \text { if } R=2^{8} \cdot 2^{3+6}, \\ 2^{8} \cdot 2^{1+8} \cdot\left(S_{3} \times A_{5}\right) & \text { if } R=2^{8} \cdot 2^{1+8}, \\ 2^{8} \cdot 2^{6} \cdot 2^{4} \cdot A_{5} & \text { if } R=2^{8} \cdot 2^{6} \cdot 2^{4}, \\ 2^{8} \cdot 2^{6} \cdot 2 \cdot 2^{4} \cdot 3^{2} \cdot 2 & \text { if } R=2^{8} \cdot 2^{6} \cdot 2 \cdot 2^{4}, \\ 2^{8} \cdot 2^{3+6} \cdot 2^{2} \cdot\left(S_{3} \times 3\right) & \text { if } R=2^{8} \cdot 2^{3+6} \cdot 2^{2}, \\ 2^{8} \cdot 2^{3+6} \cdot D_{8} \cdot 3 & \text { if } R=2^{8} \cdot 2^{3+6} \cdot D_{8} .\end{cases}
$$

Case (4.8) Let

$$
\begin{array}{ll}
T_{1} \simeq 2^{2} \cdot U_{6}(2): 2, & T_{2} \simeq 2^{11} \cdot M_{22}: 2, \\
T_{3} \simeq 2^{8} \cdot S_{6}(2), & T_{4} \simeq 2^{2} \cdot 2^{10} \cdot U_{4}(2) \cdot 2, \\
T_{5} \simeq 2^{6+8} \cdot\left(S_{3} \times S_{6}\right), & T_{6} \simeq\left(2^{2} \times O_{8}^{+}(2): 3\right): 2
\end{array}
$$

be the maximal 2-local subgroups of $M_{1}=2 \cdot \mathrm{Fi}_{22}: 2$. Then we may suppose each radical subgroup of $M_{1}$ is a subgroup of $\mathcal{R}_{0}\left(T_{i}, 3\right)$ for some $i$ with $N(R)=N_{T_{i}}(R)=$

\begin{tabular}{|c|c|c|}
\hline$R$ & $C(R)$ & $N_{T_{1}}(R)$ \\
\hline $2^{2}$ & $\overline{2^{2} . U_{6}(2)}$ & $\overline{2^{2} \cdot U_{6}(2): 2}$ \\
\hline$D_{8}$ & $2 \times S_{6}(2)$ & $D_{8} \times S_{6}(2)$ \\
\hline $2^{11}$ & $2^{11}$ & $2^{11} \cdot L_{3}(4): 2$ \\
\hline $2^{2} \times 2_{+}^{1+8}$ & $2^{3}$ & $\left(2^{2} \times 2_{+}^{1+8}\right) \cdot U_{4}(2) \cdot 2$ \\
\hline $2^{11} \cdot 2$ & $2^{7}$ & $2^{11} \cdot 2 \cdot L_{2}(7)$ \\
\hline$\left(2^{2} \times 2_{+}^{1+8}\right) .2$ & $2^{2}$ & $\left(2^{2} \times 2_{+}^{1+8}\right) \cdot 2 S_{6}$ \\
\hline $2^{6+8}$ & $2^{6}$ & $2^{6+8} \cdot\left(S_{3} \times S_{5}\right)$ \\
\hline $2^{11} \cdot 2^{4}$ & $2^{6}$ & $2^{11} \cdot 2^{4} \cdot S_{5}$ \\
\hline$\left(2^{2} \times 2_{+}^{1+8}\right) \cdot 2^{4}$ & $2^{3}$ & $\left(2^{2} \times 2_{+}^{1+8}\right) \cdot 2^{4} \cdot S_{5}$ \\
\hline $2^{6+8} \cdot 2$ & $2^{4}$ & $2^{6+8} \cdot 2 .\left(S_{3} \times S_{3}\right)$ \\
\hline$\left(2^{2} \times 2_{+}^{1+8}\right) \cdot 2 \cdot 2^{4}$ & $2^{3}$ & $\left(2^{2} \times 2_{+}^{1+8}\right) \cdot 2 \cdot 2^{4} \cdot\left(S_{3} \times S_{3}\right)$ \\
\hline$\left(2^{2} \times 2_{+}^{1+8}\right) \cdot 2^{4} \cdot 2$ & $2^{2}$ & $\left(2^{2} \times 2_{+}^{1+8}\right) \cdot 2^{4} \cdot 2^{2} \cdot S_{3}$ \\
\hline $2^{6+8} \cdot 2^{2}$ & $2^{4}$ & $2^{6+8} \cdot 2^{2} \cdot S_{3}$ \\
\hline$\left(2^{2} \times 2_{+}^{1+8}\right) \cdot 2 \cdot 2^{4} \cdot 2$ & $2^{2}$ & $\left(2^{2} \times 2_{+}^{1+8}\right) \cdot 2 \cdot 2^{4} \cdot 2 \cdot S_{3}$ \\
\hline$\left(2^{2} \times 2_{+}^{1+8}\right) \cdot 2^{4} \cdot 2^{2}$ & $2^{3}$ & $\left(2^{2} \times 2_{+}^{1+8}\right) \cdot 2^{4} \cdot 2^{2} \cdot S_{3}$ \\
\hline$\left(2^{2} \times 2_{+}^{1+8}\right) \cdot 2^{4} \cdot D_{8}$ & $2^{2}$ & $\left(2^{2} \times 2_{+}^{1+8}\right) \cdot 2^{4} \cdot D_{8}$ \\
\hline
\end{tabular}
$N_{M_{1}}(R)$.

The radical subgroups $R \in \mathcal{R}_{0}\left(T_{1}, 2\right)$ and their local structures are given in Table 6 and moreover, $N(R) \neq N_{M_{1}}(R) \neq N_{T_{1}}(R)$ for each $R \in \mathcal{R}_{0}\left(T_{1}, 2\right) \backslash\left\{2^{2}, D_{8}\right\}$.

Table 6: Radical 2-subgroups of $2^{2} \cdot U_{6}(2): 2$

We may take $\mathcal{R}_{0}\left(T_{2}, 2\right)=$

$$
\left\{2^{11}, 2^{11} \cdot 2^{4}, 2^{11} \cdot 2^{3} \cdot 2,2^{11} \cdot 2^{4} \cdot 2,2^{11} \cdot 2^{2} \cdot 2^{3} \cdot 2,2^{6+8} \cdot 2^{3} \cdot 2,2^{11} \cdot 2^{2} \cdot 2^{4} \cdot 2,2^{6+8} \cdot 2^{3} \cdot 2^{2}\right\}
$$

and moreover, $N(R) \neq N_{M_{1}}(R)=N_{T_{2}}(R)$ for each $R \in \mathcal{R}_{0}\left(T_{2}, 2\right)$.

We may take

$$
\mathcal{R}_{0}\left(T_{3}, 2\right)=\left\{2^{8}, 2^{8} \cdot 2^{5}, 2^{8} \cdot 2^{6}, 2^{8} \cdot 2^{3} \cdot 2^{4}, 2^{8} \cdot 2^{5} \cdot 2^{3}, 2^{8} \cdot 2^{3} \cdot 2^{4} \cdot 2,2^{2} \cdot 2^{3} \cdot 2^{5} \cdot 2^{6}, 2^{8} \cdot 2^{5} \cdot 2^{3} \cdot 2\right\}
$$


and moreover, $N(R) \neq N_{M_{1}}(R) \neq N_{T_{3}}(R)$ for each $R \in \mathcal{R}_{0}\left(T_{3}, 2\right) \backslash\left\{2^{8}, 2^{8} .2^{5}\right\}$ and $N(R) \neq N_{M_{1}}(R)=N_{T_{3}}(R)$ for $R \in\left\{2^{8}, 2^{8} \cdot 2^{5}\right\}$. In addition, $C\left(2^{8} .2^{6}\right)=2^{4}$, $C\left(2^{8} \cdot 2^{3} \cdot 2^{4}\right)=C\left(2^{8} \cdot 2^{3} \cdot 2^{4} \cdot 2\right)=2^{3}, C\left(2^{8} \cdot 2^{5} \cdot 2^{3}\right)=C\left(2^{2} \cdot 2^{3} \cdot 2^{5} \cdot 2^{6}\right)=C\left(2^{8} \cdot 2^{5} \cdot 2^{3} \cdot 2\right)=2^{2}$, and

$$
N_{T_{3}}(R)= \begin{cases}2^{8} \cdot 2^{6} \cdot L_{3}(2) & \text { if } R=2^{8} \cdot 2^{6}, \\ 2^{8} \cdot 2^{3} \cdot 2^{4} \cdot\left(S_{3} \times S_{3}\right) & \text { if } R=2^{8} \cdot 2^{3} \cdot 2^{4}, \\ 2^{8} \cdot 2^{5} \cdot 2^{3} \cdot S_{3} & \text { if } R=2^{8} \cdot 2^{5} \cdot 2^{3}, \\ 2^{8} \cdot 2^{3} \cdot 2^{4} \cdot 2 \cdot S_{3} & \text { if } R=2^{8} \cdot 2^{3} \cdot 2^{4} \cdot 2, \\ 2^{2} \cdot 2^{3} \cdot 2^{5} \cdot 2^{6} \cdot S_{3} & \text { if } R=2^{2} \cdot 2^{3} \cdot 2^{5} \cdot 2^{6}, \\ 2^{8} \cdot 2^{5} \cdot 2^{3} \cdot 2 & \text { if } R=2^{8} \cdot 2^{5} \cdot 2^{3} \cdot 2 .\end{cases}
$$

We may take $\mathcal{R}_{0}\left(T_{4}, 2\right)=$

$\left\{2^{2} \cdot 2^{10}, 2^{8} \cdot 2^{5}, 2^{11} \cdot 2^{4} \cdot 2,2^{2} \cdot 2^{10} \cdot 2 \cdot 2^{4}, 2^{11} \cdot 2^{2} \cdot 2^{3} \cdot 2,2^{11} \cdot 2^{2} \cdot 2^{4} \cdot 2,2^{6+8} \cdot D_{8} \cdot 2,2^{6+8} \cdot 2^{3} \cdot 2^{2}\right\}$

and moreover, $N(R) \neq N_{M_{1}}(R)=N_{T_{4}}(R)$ for each $R \in \mathcal{R}_{0}\left(T_{4}, 2\right)$.

The radical subgroups $R \in \mathcal{R}_{0}\left(T_{6}, 2\right)$ and their local structures are given in Table 7. Moreover, $N(R) \neq N_{M_{1}}(R) \neq N_{T_{6}}(R)$ for each $R \in \mathcal{R}_{0}\left(T_{6}, 2\right) \backslash\left\{2^{2}, D_{8}\right\}$.

\begin{tabular}{|c|c|c|}
\hline$R$ & $C(R)$ & $N_{T_{6}}(R)$ \\
\hline$\left(2^{2}\right)^{*}$ & $2^{2} \times O_{8}^{+}(2): 3$ & $\left(2^{2} \times O_{8}^{+}(2): 3\right): 2$ \\
\hline$D_{8}$ & $2 \times S_{6}(2)$ & $D_{8} \times S_{6}(2)$ \\
\hline $2^{8}$ & $2^{8}$ & $2^{8} \cdot A_{8}: 2$ \\
\hline $2^{8} .2$ & $2^{6}$ & $2^{8} .2 . S_{6}$ \\
\hline $2^{3} \cdot 2^{8}$ & $2^{3}$ & $2^{3} \cdot 2^{8} \cdot 3\left(S_{3} \times S_{3} \times S_{3}\right) \cdot 2$ \\
\hline $2^{8} \cdot 2^{4}$ & $2^{3}$ & $2^{8} .2^{4} \cdot\left(S_{3} \times S_{3}\right) .2$ \\
\hline $2^{4} \cdot 2^{4} \cdot 2^{4}$ & $2^{4}$ & $2^{4} \cdot 2^{4} \cdot 2^{4} \cdot L_{3}(2)$ \\
\hline $2^{3} .2^{8} .2$ & $2^{2}$ & $2^{3} .2^{8} \cdot 2 .\left(S_{3} \times S_{3}\right)$ \\
\hline $2^{4} \cdot 2^{3} \cdot 2^{6}$ & $2^{4}$ & $2^{4} \cdot 2^{3} \cdot 2^{6} \cdot\left(S_{3} \times S_{3}\right)$ \\
\hline $2^{8} \cdot 2^{2} \cdot 2^{3}$ & $2^{2}$ & $2^{8} \cdot 2^{2} \cdot 2^{3} \cdot S_{3}$ \\
\hline $2^{3} \cdot 2^{8} \cdot 2^{3}$ & $2^{3}$ & $2^{3} \cdot 2^{8} \cdot 2^{3} \cdot S_{3}$ \\
\hline $2^{8} \cdot 2^{3} \cdot 2^{2} \cdot 2$ & $2^{3}$ & $2^{8} \cdot 2^{3} \cdot 2^{2} \cdot 2 \cdot S_{3}$ \\
\hline $2^{3} \cdot 2^{8} \cdot 2^{2} \cdot 2$ & $2^{2}$ & $2^{3} \cdot 2^{8} \cdot 2^{2} \cdot 2 \cdot S_{3}$ \\
\hline $2^{8} \cdot 2^{4} \cdot 2^{3}$ & $2^{2}$ & $2^{8} \cdot 2^{4} \cdot 2^{3}$ \\
\hline
\end{tabular}

Table 7: Radical 2-subgroups of $\left(2^{2} \times O_{8}^{+}(2): 3\right): 2$

We may take $\mathcal{R}_{0}\left(T_{5}, 2\right)=$

$$
\left\{2^{6+8}, 2^{11} \cdot 2^{4}, 2^{6+8} \cdot 2^{3}, 2^{2} \cdot 2^{10} \cdot 2 \cdot 2^{4}, 2^{11} \cdot 2^{2} \cdot 2^{4} \cdot 2,2^{6+8} \cdot D_{8} \cdot 2,2^{6+8} \cdot 2^{3} \cdot 2,2^{6+8} \cdot 2^{3} \cdot 2^{2}\right\}
$$

and moreover, $N(R) \neq N_{M_{1}}(R)=N_{T_{5}}(R)$ for each $R \in \mathcal{R}_{0}\left(T_{5}, 2\right)$.

It follows that the radical subgroups of $M_{1}$ and their local structures are given in Table 8. Moreover, $N(R) \neq N_{M_{1}}(R)$ for each $R \in \mathcal{R}_{0}\left(M_{1}, 2\right) \backslash\left\{2, D_{8}\right\}$.

This completes the classification of radical 2 -subgroups of $G$. The centralizers and normalizers of $R \in \mathcal{R}_{0}(G, 2)$ are given by MAGMA.

LEMMA 4.2. Let $G=\mathrm{Fi}_{24}^{\prime}$, and let $\mathrm{Blk}^{0}(G, p)$ be the set of $p$-blocks with a nontrivial defect group and $\operatorname{Irr}^{+}(G)$ the characters of $\operatorname{Irr}(G)$ with positive p-defect. If a defect group $D(B)$ of $B$ is cyclic and $p \neq 2$, then $\operatorname{Irr}(B)$ is given by $[\mathbf{1 4}$, p. 352]. 
The Alperin weight conjecture and Dade's conjecture for the simple group $\mathrm{Fi}_{24}^{\prime}$

\begin{tabular}{|r|r|l|}
\hline$R$ & $C(R)$ & $N_{M_{1}}(R)$ \\
\hline \hline 2 & $2 \cdot \mathrm{Fi}_{22} \cdot 2$ & $2 \cdot \mathrm{Fi}_{22} \cdot 2$ \\
$2^{2}$ & $2^{2} \cdot U_{6}(2)$ & $2^{2} \cdot U_{6}(2) \cdot 2$ \\
$\left(2^{2}\right)^{*}$ & $2^{2} \times O_{8}^{+}(2): 3$ & $\left(2^{2} \times O_{8}^{+}(2): 3\right): 2$ \\
$D_{8}$ & $2 \times S_{6}(2)$ & $D_{8} \times S_{6}(2)$ \\
$2^{8}$ & $2^{8}$ & $2^{8} \cdot S_{6}(2)$ \\
$2^{11}$ & $2^{11}$ & $2^{11} \cdot M_{22}: 2$ \\
$2^{2} \cdot 2^{10}$ & $2^{2}$ & $2^{2} \cdot 2^{10} \cdot U_{4}(2) \cdot 2$ \\
$2^{8} \cdot 2^{5}$ & $2^{2}$ & $2^{8} \cdot 2^{5} \cdot S_{6}$ \\
$2^{6+8}$ & $2^{6}$ & $2^{6+8} \cdot\left(S_{6} \times S_{3}\right)$ \\
$2^{11} \cdot 2^{4}$ & $2^{6}$ & $2^{11} \cdot 2^{4} \cdot S_{6}$ \\
$2^{11} \cdot 2^{3} \cdot 2$ & $2^{4}$ & $2^{11} 2^{3} \cdot 2 \cdot L_{3}(2)$ \\
$2^{11} \cdot 2^{4} \cdot 2$ & $2^{2}$ & $2^{11} \cdot 2^{4} \cdot 2 \cdot S_{5}$ \\
$2^{11} \cdot 2^{2} \cdot 2^{3} \cdot 2$ & $2^{2}$ & $2^{11} \cdot 2^{2} \cdot 2^{3} \cdot 2 \cdot S_{3}$ \\
$2^{2} \cdot 2^{10} \cdot 2 \cdot 2^{4}$ & $2^{2}$ & $2^{2} \cdot 2^{10} \cdot 2 \cdot 2^{4} \cdot\left(S_{3} \times S_{3}\right)$ \\
$2^{6+8} \cdot 2^{3}$ & $2^{3}$ & $2^{6+6} \cdot 2^{3} \cdot\left(S_{3} \times S_{3}\right)$ \\
$2^{6+8} \cdot 2^{3} \cdot 2$ & $2^{3}$ & $2^{6+6} \cdot 2^{3} \cdot 2 S_{3}$ \\
$2^{11} \cdot 2^{2} \cdot 2^{4} \cdot 2$ & $2^{2}$ & $2^{11} \cdot 2^{2} \cdot 2^{4} \cdot 2 \cdot S_{3}$ \\
$2^{6+8} \cdot D_{8} \cdot 2$ & $2^{2}$ & $2^{6+8} \cdot D_{8} \cdot 2 \cdot S_{3}$ \\
$2^{6+8} \cdot 2^{3} \cdot 2^{2}$ & $2^{2}$ & $2^{6+8} \cdot 2^{3} \cdot 2^{2}$ \\
\hline
\end{tabular}

Table 8: Radical 2-subgroups of $2 . \mathrm{Fi}_{22}: 2$

(a) If $p=7$, then $\operatorname{Blk}^{0}(G, p)=\left\{B_{i} \mid 0 \leqslant i \leqslant 4\right\}$ such that $D\left(B_{0}\right) \simeq 7_{+}^{1+2}$ and $D\left(B_{i}\right) \simeq 7$ for $i \geqslant 1$, where $B_{0}=B_{0}(G)$ is the principal block of $G$. In addition, $\operatorname{Irr}\left(B_{0}\right)=\operatorname{Irr}^{+}(G) \backslash\left(\cup_{i=1}^{4} \operatorname{Irr}\left(B_{i}\right)\right), \ell\left(B_{i}\right)=6$ for $1 \leqslant i \leqslant 4$ and $\ell\left(B_{0}\right)=22$.

(b) If $p=5$, then $\operatorname{Blk}^{0}(G, p)=\left\{B_{i} \mid 0 \leqslant i \leqslant 5\right\}$ such that $D\left(B_{i}\right) \simeq 5^{2}$ and $D\left(B_{j}\right) \simeq 5$ with $0 \leqslant i \leqslant 2$ and $3 \leqslant j \leqslant 5$. In the notation of [9, p. 200], $\operatorname{Irr}\left(B_{1}\right)=$ $\left\{\chi_{k}: k \in\{4,5,13,17,19,20,21,23,25,31,33,51,54,55,67,71,79,85,94,103\}\right\}$ $\operatorname{Irr}\left(B_{2}\right)=\left\{\chi_{k}: k \in\{2,3,16,38,46,47,52,64,65,77,78,82,88,91,92,104\}\right\}$, and

$\operatorname{Irr}\left(B_{0}\right)=\operatorname{Irr}^{+}(G) \backslash\left(\cup_{i=1}^{4} \operatorname{Irr}\left(B_{i}\right)\right)$. Moreover, $\ell\left(B_{i}\right)=4$ for $3 \leqslant i \leqslant 4, \ell\left(B_{5}\right)=$ $2, \ell\left(B_{2}\right)=14$, and $\ell\left(B_{1}\right)=\ell\left(B_{0}\right)=16$.

(c) If $p=3$, then $\operatorname{Blk}^{0}(G, 2)=\left\{B_{0}, B_{1}\right\}$ such that $D\left(B_{1}\right) \simeq 3^{2}$. In the notation of $[\mathbf{9}$, p. 200],

$$
\operatorname{Irr}\left(B_{1}\right)=\left\{\chi_{k}: k \in\{59,76,88,89,91,92\}\right\}
$$

and $\operatorname{Irr}\left(B_{0}\right)=\operatorname{Irr}^{+}(G) \backslash \operatorname{Irr}\left(B_{1}\right)$. Moreover, $\ell\left(B_{1}\right)=4$ and $\ell\left(B_{0}\right)=25$.

(d) If $p=2$, then $\operatorname{Blk}^{0}(G, 2)=\left\{B_{0}, B_{1}, B_{2}\right\}$ such that $D\left(B_{1}\right) \simeq\left(2^{2}\right)^{*}$ and $D\left(B_{2}\right) \simeq D_{8}$. In the notation of $[\mathbf{9}$, p. 184],

$$
\operatorname{Irr}\left(B_{1}\right)=\left\{\chi_{35}, \chi_{64}, \chi_{65}, \chi_{79}\right\}
$$

$\operatorname{Irr}\left(B_{2}\right)=\left\{\chi_{54}, \chi_{71}, \chi_{84}, \chi_{95}, \chi_{104}\right\}$ and $\operatorname{Irr}\left(B_{0}\right)=\operatorname{Irr}^{+}(G) \backslash\left(\operatorname{Irr}\left(B_{1}\right) \cup \operatorname{Irr}\left(B_{2}\right)\right)$. Moreover, $\ell\left(B_{1}\right)=\ell\left(B_{2}\right)=3$ and $\ell\left(B_{0}\right)=33$. 
The Alperin weight conjecture and Dade's conjecture for the simple group $\mathrm{Fi}_{24}^{\prime}$

In addition, let $D=D_{8}, 3_{+}^{1+2}$ or $5^{2}$ be a subgroup of the covering group $\hat{G}=$ 3. $\mathrm{Fi}_{24}^{\prime}$, and let $\operatorname{Irr}\left(Z\left(3 . \mathrm{Fi}_{24}^{\prime}\right)\right)=\left\{1, \zeta, \zeta^{\prime}\right\}$. If $B(\zeta)$ is the block of $Z\left(3 . \mathrm{Fi}_{24}^{\prime}\right)$ containing $\zeta$, then $3 . \mathrm{Fi}_{24}^{\prime}$ has a unique block $\hat{B}_{1}$ such that $\hat{B}_{1}$ covers $B(\zeta)$ and $D\left(\hat{B}_{1}\right) \simeq D$. Let $\hat{B}_{1}^{\prime}$ be the complex dual of $\hat{B}_{1}$, so that $\hat{B}_{1}^{\prime}$ covers $B\left(\zeta^{\prime}\right)$. In the notation of $[\mathbf{9}$, p. 204], if $\operatorname{Irr}\left(\hat{B}_{1}, \zeta\right)$ denotes the characters of $\operatorname{Irr}\left(\hat{B}_{1}\right)$ covering $\zeta$, then

$$
\operatorname{Irr}\left(\hat{B}_{1}, \zeta\right) \cup \operatorname{Irr}\left(\hat{B}_{1}^{\prime}, \zeta^{\prime}\right)= \begin{cases}\left\{\chi_{j}, \chi_{j+1}: j \in\{203,205,215,217,239\}\right\} & \text { if } p=2, \\ \left\{\chi_{j}, \chi_{j+1}: j \in\{167,169,237,247\}\right\} & \text { if } p=3,\end{cases}
$$

and $\operatorname{Irr}\left(\hat{B}_{1}, \zeta\right) \cup \operatorname{Irr}\left(\hat{B}_{1}^{\prime}, \zeta^{\prime}\right)=\left\{\chi_{j}, \chi_{j+1}: j \in\{113,121,123,127,129,135,151,161\right.$, $175,189,199,203,213,217,219,237,245,247,251,255\}\}$ when $p=5$.

Moreover, if $D$ is a Sylow p-subgroup of $\hat{G}$, then $\hat{G}$ has a block $\hat{B}$ covering $B(\zeta)$ with $D(\hat{B}) \simeq D$. Let $\hat{B}^{\prime}$ be the complex dual of $\hat{B}$, so that $\hat{B}^{\prime}$ covers $B\left(\zeta^{\prime}\right)$. Let

$$
\Omega=\operatorname{Irr}\left(\hat{B}_{1}, \zeta\right) \cup \operatorname{Irr}\left(\hat{B}_{1}^{\prime}, \zeta^{\prime}\right) \cup\left(\bigcup_{B^{\prime}} \operatorname{Irr}\left(B^{\prime}\right)\right),
$$

where $B^{\prime}$ runs over the blocks of $\hat{G}$ with cyclic defect group p given by $[\mathbf{1 4}$, p. 352]. Then

$$
\operatorname{Irr}(\hat{B}, \zeta) \cup \operatorname{Irr}\left(\hat{B}^{\prime}, \zeta^{\prime}\right)=\operatorname{Irr}^{+}(\hat{G}) \backslash\left(\Omega \cup \operatorname{Irr}^{+}(G)\right)
$$

Proof. If $B \in \operatorname{Blk}(G, p)$ is non-principal with $D=D(B)$, then $\operatorname{Irr}^{0}(C(D) D / D)$ has a non-trivial character $\theta$ and $N(\theta) / C(D) D$ is a $p^{\prime}$-group, where $N(\theta)$ is the stabilizer of $\theta$ in $N(D)$. If $p$ is odd, then by [14, p. 352], we may suppose $D$ is non-cyclic, so by Proposition 4.1, $D \in_{G}\left\{5^{2}, 3^{2}, 2,2^{2},\left(2^{2}\right)^{*}, D_{8}\right\}$.

If $D=5^{2}$, then $C(D)=5^{2} \times A_{4}$ and $N(D)=\left(5^{2}: 4 A_{4} \times A_{4}\right) .2$, so that $N(D)$ has 2 orbits on $\operatorname{Irr}^{0}(C(D) / D)$ and $G$ has 2 blocks with $D=5^{2}$.

If $D=3^{2}$, then $C(D)=3^{2} \times G_{2}(3)$ and $N(D)=\left(3^{2}: 2 \times G_{2}(3)\right) .2$, so that $N(D)$ has one orbit on $\operatorname{Irr}^{0}(C(D) / D)$ and $G$ has one block with $D=3^{2}$.

If $D=2$, the $C(D)=N(D)=2 . \mathrm{Fi}_{22} .2$ and $\left|\operatorname{Irr}^{0}(C(D) / D)\right|=0$.

If $D=2^{2}$, then $C(D)=2^{2} \cdot U_{6}(2)$ and $N(D)=2^{2} \cdot U_{6}(2) . S_{3}$, so that the only character of $\operatorname{Irr}^{0}(C(D) / D)$ is stabilized by a 2-element in $N(D) \backslash C(D)$. In particular, $G$ has no block with $D=2^{2}$.

If $D=\left(2^{2}\right)^{*}$, then $C(D)=2^{2} \times O_{8}^{+}(2): 3$ and $N(D)=\left(A_{4} \times O_{8}^{+}(2): 3\right): 2$. Now $\operatorname{Irr}^{0}(C(D) / D)$ consists of two characters $\theta$ with $N(\theta) / C(D)$ a $p^{\prime}$-group, and both lying in an orbit of $N(D)$. Thus $G$ has one block with $D=\left(2^{2}\right)^{*}$.

If $D=D_{8}$, then $C(D)=2 \times S_{6}(2)$ and $N(D)=D_{8} \times S_{6}(2)$, so that $N(D)$ has one orbit on $\operatorname{Irr}^{0}(C(D) / D)$ and $G$ has one block with $D=D_{8}$.

Using the method of central characters, $\operatorname{Irr}(B)$ is as above. If $D(B)$ is cyclic or isomorphic to $2^{2}$ or $D_{8}$, then $\ell(B)$ is the number of $B$-weights (see [11] and [20]).

Suppose $p=5$ and $B=B_{0}, B_{1}, B_{2}$, so that $D(B)={ }_{G} 5^{2}$ and the non-trivial elements of $D\left(B_{1}\right)$ consists of $5 A$-elements. By [16, Theorem 4.13],

$$
\mathrm{k}\left(B_{i}\right)=\ell\left(B_{i}\right)+\sum_{b_{i}} \ell\left(b_{i}\right),
$$

where $b_{i}$ runs over blocks of $C_{G}(5 A)=5 \times A_{9}$ such that $b_{i}^{G}=B_{i}$. Thus $b_{i}=B_{0}(5) \times$ $b_{i}^{\prime}$ for some $b_{i}^{\prime} \in \operatorname{Blk}\left(A_{9}\right)$ with $D\left(b_{i}^{\prime}\right)=5$ and $\ell\left(b_{i}\right)=\ell\left(b_{i}^{\prime}\right)$. Since $D\left(b_{i}^{\prime}\right)$ is cyclic, it follows that $\ell\left(b_{i}^{\prime}\right)$ is the number of $b_{i}^{\prime}$-weights. Now $N_{A_{9}}\left(D\left(b_{i}^{\prime}\right)\right) \simeq\left(5: 2 \times A_{4}\right) .2$, so for each $i$ there exists a unique such block $b_{i}^{\prime}$ of $A_{9}$, and $\ell\left(b_{0}^{\prime}\right)=4=\ell\left(b_{1}^{\prime}\right), \ell\left(b_{2}^{\prime}\right)=2$. It follows that $\ell\left(B_{0}\right)=\ell\left(B_{1}\right)=16$ and $\ell\left(B_{2}\right)=14$. 
Suppose $p=3$ and $B=B_{1}$, so that $D(B)={ }_{G} 3^{2}$. The non-trivial elements of $D(B)$ lie in $3 A$ and $3 E, C_{G}(3 A)=3 \times O_{8}^{+}(3): 3$ and $C_{G}(3 E)=3^{2} \times G_{2}(3)$. But $D(B) \cap O_{8}^{+}(3)=1$ and $C_{O_{8}^{+}(3): 3}\left(D(B) \cap O_{8}^{+}(3): 3\right)=3 \times G_{2}(3)$, so a similar argument to above shows that $\ell(B)=6-1-1=4$.

If $\ell_{p}(G)$ is the number of $p$-regular $G$-conjugacy classes, then $\ell_{7}(G)=95, \ell_{5}(G)=$ $94, \ell_{3}(G)=30$ and $\ell_{2}(G)=41$. Thus $\ell\left(B_{0}\right)$ can be calculated by the following equation due to Brauer:

$$
\ell_{p}(G)=\bigcup_{B \in \operatorname{Blk}^{0}(G, p)} \ell(B)+\left|\operatorname{Irr}^{0}(G)\right|,
$$

where $\left|\operatorname{Irr}^{0}(G)\right|=49,38,1$ or 2 when $p=7,5,3$ or 2 .

Since $C_{\hat{G}}\left(5^{2}\right)=3 \times 5^{2} \times A_{4}$, it follows that $\hat{G}$ has 7 blocks with defect group $5^{2}$ and 3 of these are blocks of $G$. Similarly, since $C_{\hat{G}}\left(D_{8}\right)=6 \times S_{6}(2)$, it follows that $\hat{G}$ has 3 blocks with defect group $D_{8}$. Using the method of central characters, $\operatorname{Irr}(\hat{B})$ is as stated for $\hat{B} \in \operatorname{Blk}(\hat{G})$.

THEOREM 4.3. Let $G=\mathrm{Fi}_{24}^{\prime}$ and let $B$ be a p-block of $G$ with a non-cyclic defect group. Then the number of $B$-weights is the number of irreducible Brauer characters of $B$.

Proof. If $B=B_{0}$, then the proof follows by Proposition 4.1, Lemma 4.2 and (4.1). Suppose $B \neq B_{0}$.

If $p=2$, then $B=B_{1}$ or $B_{2}$, and $D(B) \simeq 2^{2}$ or $D_{8}$, so that the weight conjecture for $B$ follows by Uno $[\mathbf{2 0}]$.

Suppose $p=3$ and $B=B_{1}$, so that $D=D\left(B_{1}\right)=3^{2}$. Since $C(D) \simeq 3^{2} \times G_{2}(3)$ and $N(D) \simeq\left(3^{2}: 2 \times G_{2}(3)\right): 2$, it follows that $B$ has 4 weights and so $\ell(B)=\mathcal{W}(B)$.

Suppose $p=5$ and $B=B_{1}$ or $B_{2}$, so that $D=D(B)=5^{2}$. Thus $C(D)=5^{2} \times A_{4}$ and $N(D)=\left(5^{2}: 4 A_{4} \times A_{4}\right) .2$. Since $|\operatorname{Irr}(N(D) / D)|=46, G$ has 46 weights of the form $(D, \varphi)$ for $\varphi \in \operatorname{Irr}(N(D) / D)$. If $B=B_{1}$, then the canonical character $\theta$ of the root block $b$ of $B$ has an extension to $N(D)$, so that $B$ has 16 weights, since $|\operatorname{Irr}(N(D) / C(D))|=16$. Thus $\mathcal{W}\left(B_{2}\right)=46-16-16=14=\ell\left(B_{2}\right)$.

\section{Radical chains of $\mathrm{Fi}_{24}^{\prime}$}

Let $G=\mathrm{Fi}_{24}^{\prime}, C \in \mathcal{R}(G)$ and $N(C)=N_{G}(C)$. In this section, we do some cancellations in the alternating sum of Uno's conjecture. First we list some radical $p$-chains $C(i)$ with their normalizers, then reduce the proof of the conjecture to the subfamily $\mathcal{R}^{0}(G)$ of $\mathcal{R}(G)$ consisting of the union of $G$-orbits of all $C(i)$. The subgroups of the $p$-chains in Tables $10-13$ are given either by Tables 1 and 2 or in the proofs of Lemmas 4.1 and 5.1. If $p$ is 5 or 7 , then the radical $p$-chains are given in Table 9 .

LEMmA 5.1. Let $G=\mathrm{Fi}_{24}^{\prime}, E=G .2$ and let $\mathcal{R}^{0}(G)$ be the $G$-invariant subfamily of $\mathcal{R}(G)$ such that

$$
\mathcal{R}^{0}(G) / G= \begin{cases}\{C(i): 1 \leqslant i \leqslant 36\} & \text { with } C(i) \text { given in Table } 10 \text { if } p=3, \\ \{C(i): 1 \leqslant i \leqslant 88\} & \text { with } C(i) \text { given in Tables } 11-13 \text { if } p=2,\end{cases}
$$


The Alperin weight conjecture and Dade's conjecture for the simple group $\mathrm{Fi}_{24}^{\prime}$

Then

$$
\sum_{C \in \mathcal{R}(G) / G}(-1)^{|C|} \mathrm{k}(N(C), B, d, u,[r])=\sum_{C \in \mathcal{R}^{0}(G) / G}(-1)^{|C|} \mathrm{k}(N(C), B, d, u,[r])
$$

for all integers $d, r, u \geqslant 0$. If $p=3$ or 2 , then $N_{E}(C(i))=N(C(i)) .2$ for each $i$.

\begin{tabular}{|r|r|r|l|}
\hline$C$ & & $N(C)$ & \multicolumn{1}{|c|}{$N_{E}(C)$} \\
\hline$C(1)$ & 1 & $\mathrm{Fi}_{24}^{\prime}$ & $\mathrm{Fi}_{24}$ \\
$C(2)$ & $1<5$ & $\left(5: 2 \times A_{9}\right) .2$ & $N(C) .2$ \\
$C(3)$ & $1<5<5^{2}$ & $\left(5^{2} \times A_{4}\right) \cdot 4^{2}$ & $N(C) .2$ \\
$C(4)$ & $1<5^{2}$ & $\left(5^{2}: 4 A_{4} \times A_{4}\right) .2$ & $N(C) .2$ \\
\hline \hline$C(1)$ & 1 & $\mathrm{Fi}_{24}^{\prime}$ & $\mathrm{Fi}_{24}$ \\
$C(2)$ & $1<7$ & $7: 6 \times A_{7}$ & $N(C) .2$ \\
$C(3)$ & $1<7<7^{2}$ & $7^{2} \cdot(6 \times 3)$ & $N(C) .2$ \\
$C(4)$ & $1<7^{2}$ & $7^{2}: 2 S L_{2}(7) .2$ & $N(C)$ \\
$C(5)$ & $1<7^{2}<7_{+}^{1+2}$ & $7^{1+2}:(6 \times 2)$ & $N(C)$ \\
$C(6)$ & $1<\left(7^{2}\right)^{*}$ & $7^{2}: 2 S L_{2}(7) .2$ & $N(C)$ \\
$C(7)$ & $1<\left(7^{2}\right)^{*}<7_{+}^{1+2}$ & $7^{1+2}:(6 \times 2)$ & $N(C)$ \\
$C(8)$ & $1<7^{1+2}$ & $7^{1+2}:\left(S_{3} \times 6\right)$ & $N(C) .2$ \\
\hline
\end{tabular}

Table 9: Radical $p$-chains of $\mathrm{Fi}_{24}^{\prime}$ with $p=5,7$

Proof. Throughout, $C$ and $C^{\prime}$ will denote radical chains $C: 1<P_{1}<\cdots<P_{n}$ and

$$
C^{\prime}: 1<P_{1}^{\prime}<\ldots<P_{m}^{\prime}
$$

Thus $C \in \mathcal{R}(G)$ and $P_{1}$ is a radical subgroup of $G$. We may suppose $P_{1} \in \mathcal{R}_{0}(G, p)$. Sometimes we also denote by $g\left(C^{\prime}\right)$ a radical chain of $G$ corresponding to $C^{\prime}$ such that $N\left(C^{\prime}\right)=N\left(g\left(C^{\prime}\right)\right)$ and $N_{E}\left(C^{\prime}\right)=N_{E}\left(g\left(C^{\prime}\right)\right)$.

Case (1) Suppose $p=3$, and $R \in \mathcal{R}_{0}\left(M_{3}, 3\right) \backslash\left\{3^{1+10}\right\}$ given by (4.2). Let $\sigma(R)$ : $1<Q=3^{1+10}<R$ and $\sigma(R)^{\prime}: 1<R$. Then $\sigma(R)$ and $\sigma(R)^{\prime}$ satisfy the conditions of Lemma 2.2 , so there is a bijection $g$ from $\mathcal{R}^{-}\left(\sigma(R), 3^{1+10}\right)$ onto $\mathcal{R}^{0}\left(\sigma(R)^{\prime}, 3^{1+10}\right)$ such that $N\left(C^{\prime}\right)=N\left(g\left(C^{\prime}\right)\right), N_{E}\left(C^{\prime}\right)=N_{E}\left(g\left(C^{\prime}\right)\right)$ and $\left|C^{\prime}\right|=\left|g\left(C^{\prime}\right)\right|-1$ for each $C^{\prime} \in \mathcal{R}^{-}\left(\sigma(R), 3^{1+10}\right)$. Thus

$$
\mathrm{k}\left(N\left(C^{\prime}\right), B, d, u,[r]\right)=\mathrm{k}\left(N\left(g\left(C^{\prime}\right)\right), B, d, u,[r]\right),
$$

and we may suppose

$$
C \notin \bigcup_{R \in \mathcal{R}_{0}\left(M_{3}, 3\right) \backslash\left\{3^{1+10}\right\}}\left(\mathcal{R}^{-}\left(\sigma(R), 3^{1+10}\right) \cup \mathcal{R}^{0}\left(\sigma(R), 3^{1+10}\right)\right) .
$$

Thus we may suppose $P_{1} \notin\left\{3^{1+10} .3,3^{1+10} .3^{4}, 3^{1+10} \cdot\left(3 \times 3^{1+2}\right), 3^{2} .3^{4} .3^{8} .3^{2}\right\}$, and if $P_{1}=3^{1+10}$, then $C={ }_{G} C(28)$. We may suppose

$$
P_{1} \in\left\{3,3^{2}, 3^{7}, 3^{3} \cdot 3^{4} \cdot 3^{3} \cdot 3^{3}, 3^{2} \cdot 3^{4} \cdot 3^{8}, 3^{2} \cdot 3^{4} \cdot 3^{8} \cdot 3\right\} \subseteq \mathcal{R}_{0}(G, 3) .
$$

Let $C^{\prime}: 1<3^{2} .3^{4} .3^{8}<3^{2} \cdot 3^{4} .3^{8} .3^{2}$ and $g\left(C^{\prime}\right): 1<3^{2} .3^{4} .3^{8}<3_{+}^{1+10} .3^{4}<$ $3^{2} .3^{4} \cdot 3^{8} \cdot 3^{2}$, where $3^{2} \cdot 3^{4} \cdot 3^{8} \cdot 3^{2}, 3_{+}^{1+10} .3^{4} \in \mathcal{R}_{0}\left(M_{4}, 3\right)$. Then $N\left(C^{\prime}\right)=N\left(g\left(C^{\prime}\right)\right)$ and $N_{E}\left(C^{\prime}\right)=N_{E}\left(g\left(C^{\prime}\right)\right)$ and we may suppose $C \neq_{G} C^{\prime}, g\left(C^{\prime}\right)$. 
The Alperin weight conjecture and Dade's conjecture for the simple group $\mathrm{Fi}_{24}^{\prime}$

\begin{tabular}{|c|c|c|}
\hline$C$ & & $N(C)$ \\
\hline$C(1)$ & 1 & $\mathrm{Fi}_{24}^{\prime}$ \\
\hline$C(2)$ & $1<3$ & $\left(3 \times O_{8}^{+}(3): 3\right): 2$ \\
\hline$C(3)$ & $1<3<3^{2}$ & $3^{2}: 2 \times G_{2}(3)$ \\
\hline$C(4)$ & $1<3<3^{2}<3^{4} \times 3_{+}^{1+2}$ & $3^{2}: 2 \times\left(3^{2} \times 3_{+}^{1+2}\right): 2 S_{4}$ \\
\hline$C(5)$ & $1<3<3^{7}$ & $3^{7}: L_{4}(3): 2$ \\
\hline$C(6)$ & $1<3<3^{7}<3^{7}: 3^{3}$ & $3^{7}: 3^{3} \cdot L_{3}(3)$ \\
\hline$C(7)$ & $1<3<3^{7}<3^{7}: 3^{3}<3^{7}: 3^{4} .3$ & $3^{7}: 3^{4} \cdot 3.2 S_{4}$ \\
\hline$C(8)$ & $1<3<3^{7}<3^{7}: 3^{4}$ & $3^{7}: 3^{4}: 2\left(A_{4} \times A_{4}\right) \cdot 2.2$ \\
\hline$C(9)$ & $1<3<3^{7}<3^{7}: 3^{4}<3^{7} \cdot 3^{3} \cdot 3^{2}$ & $3^{7} \cdot 3^{3} \cdot 3^{2} \cdot 2 S_{4}$ \\
\hline$C(10)$ & $1<3<3^{7}<3^{7}: 3^{4}<3^{7} \cdot 3^{3} \cdot 3^{2}<3^{7} \cdot 3^{4} \cdot 3^{2}$ & $3^{7} \cdot 3^{4} \cdot 3^{2} \cdot 2^{2}$ \\
\hline$C(11)$ & $1<3<3^{7}<3^{7}: 3^{4} \cdot 3<3^{7} \cdot 3^{4} \cdot 3^{2}$ & $3^{7} \cdot 3^{4} \cdot 3^{2} \cdot 2^{3}$ \\
\hline$C(12)$ & $1<3<3^{7}<3^{7}: 3^{4} .3$ & $3^{7}: 3^{4} \cdot 3.2 S_{4} \cdot 2$ \\
\hline$C(13)$ & $1<3<3 \times 3_{+}^{1+8}$ & $\left.\left(3 \times 3_{+}^{1+8}\right) 2\left(A_{4} \times A_{4} \times A_{4}\right) \cdot 2: 3\right): 2$ \\
\hline$C(14)$ & $1<3<3^{7} \cdot 3^{3}<3^{3} \cdot 3^{3} \cdot 3^{6}$ & $3^{3} \cdot 3^{3} \cdot 3^{6} \cdot\left(2 \times 2 S_{4}\right)$ \\
\hline$C(15)$ & $1<3<3^{7} .3^{3}$ & $3^{7} \cdot 3^{3} \cdot\left(2 \times L_{3}(3)\right)$ \\
\hline$C(16)$ & $1<3<3^{7} \cdot 3^{3}<3^{2} \cdot 3^{2} \cdot 3^{4} \cdot 3^{4}$ & $3^{2} \cdot 3^{2} \cdot 3^{4} \cdot 3^{4} \cdot\left(2 \times 2 S_{4}\right)$ \\
\hline$C(17)$ & $1<3<3^{7} \cdot 3^{3}<3^{3} \cdot 3^{3} \cdot 3^{6}<3^{7} \cdot 3^{4} \cdot 3^{2}$ & $3^{7} \cdot 3^{4} \cdot 3^{2} \cdot 2^{3}$ \\
\hline$C(18)$ & $1<3<3^{5} \cdot 3^{4} \cdot 3^{4}<\left(3 \times 3_{+}^{1+8}\right) \cdot 3^{3} \cdot 3$ & $\left(3 \times 3_{+}^{1+8}\right) \cdot 3^{3} \cdot 3 \cdot 2^{3}$ \\
\hline$C(19)$ & $1<3<3^{5} \cdot 3^{4} \cdot 3^{4}$ & $3^{5} \cdot 3^{4} \cdot 3^{4} \cdot 2 S_{4} \cdot 2$ \\
\hline$C(20)$ & $1<3^{7}$ & $3^{7} . O_{7}(3)$ \\
\hline$C(21)$ & $1<3^{7}<3_{+}^{1+10} .3$ & $3_{+}^{1+10} \cdot 3 \cdot U_{4}(2): 2$ \\
\hline$C(22)$ & $1<3^{7}<3^{7} \cdot 3^{3+3}<3^{7} \cdot 3^{5} \cdot 3_{+}^{1+2}$ & $3^{7} \cdot 3^{5} \cdot 3_{+}^{1+2} \cdot 2 S_{4}$ \\
\hline$C(23)$ & $1<3^{7}<3^{7} .3^{3+3}$ & $3^{7} \cdot 3^{3+3} \cdot L_{3}(3)$ \\
\hline$C(24)$ & $1<3^{7}<3^{7} \cdot 3_{+}^{1+6}<3^{7} \cdot 3_{+}^{1+6} .3$ & $3^{7} \cdot 3_{+}^{1+6} \cdot 3.2 S_{4}$ \\
\hline$C(25)$ & $1<3^{7}<3^{7} \cdot 3_{+}^{1+6}$ & $3^{7} \cdot 3_{+}^{1+6} \cdot\left(2 A_{4} \times A_{4}\right) \cdot 2$ \\
\hline$C(26)$ & $1<3^{7}<3^{7} \cdot 3_{+}^{1+6}<3^{7} \cdot 3^{5} \cdot 3^{3}$ & $3^{7} \cdot 3^{5} \cdot 3^{3} \cdot\left(S_{4} \times 2\right)$ \\
\hline$C(27)$ & $1<3^{7}<3^{7} \cdot 3_{+}^{1+6}<3^{7} \cdot 3_{+}^{1+6} \cdot 3<3^{2} \cdot 3^{4} \cdot 3^{8} \cdot 3^{2}$ & $3^{2} \cdot 3^{4} \cdot 3^{8} \cdot 3^{2} \cdot 2^{2}$ \\
\hline$C(28)$ & $1<3_{+}^{1+10}$ & $3_{+}^{1+10} \cdot U_{5}(2): 2$ \\
\hline$C(29)$ & $1<3^{2} .3^{4} \cdot 3^{8}<3_{+}^{1+10} .3^{4}$ & $3_{+}^{1+10} \cdot 3^{4} \cdot\left(2 \times A_{5}\right): 2$ \\
\hline$C(30)$ & $1<3^{2} \cdot 3^{4} \cdot 3^{8}$ & $3^{2} \cdot 3^{4} \cdot 3^{8} \cdot\left(2 A_{4} \times A_{5}\right): 2$ \\
\hline$C(31)$ & $1<3^{2}<3^{2} \times\left(3^{2} \times 3_{+}^{1+2}\right) .3$ & $\left(3^{2}: 2 \times\left(3^{2} \times 3_{+}^{1+2}\right) \cdot 3.2^{2}\right) \cdot 2$ \\
\hline$C(32)$ & $1<3^{2}$ & $\left(3^{2}: 2 \times G_{2}(3)\right): 2$ \\
\hline$C(33)$ & $1<3^{3} \cdot 3^{4} \cdot 3^{3} \cdot 3^{3}<3^{2} \cdot 3^{4} \cdot 3^{8} \cdot 3$ & $3^{2} \cdot 3^{4} \cdot 3^{8} \cdot 3 \cdot\left(2 S_{4} \times 2\right)$ \\
\hline$C(34)$ & $1<3^{3} \cdot 3^{4} \cdot 3^{3} \cdot 3^{3}$ & $3^{3} \cdot 3^{4} \cdot 3^{3} \cdot 3^{3}:\left(L_{3}(3) \times 2\right)$ \\
\hline$C(35)$ & $1<3^{3} \cdot 3^{4} \cdot 3^{3} \cdot 3^{3}<3_{+}^{1+10} \cdot\left(3 \times 3_{+}^{1+2}\right)$ & $3_{+}^{1+10} \cdot\left(3 \times 3_{+}^{1+2}\right) \cdot\left(2 S_{4} \times 2\right)$ \\
\hline$C(36)$ & $1<3^{3} \cdot 3^{4} \cdot 3^{3} \cdot 3^{3}<3^{2} \cdot 3^{4} \cdot 3^{8} \cdot 3<3^{2} \cdot 3^{4} \cdot 3^{8} \cdot 3^{2}$ & $3^{2} \cdot 3^{4} \cdot 3^{8} \cdot 3^{2} \cdot 2^{3}$ \\
\hline
\end{tabular}

Table 10: Some radical 3-chains of $\mathrm{Fi}_{24}^{\prime}$ 
The Alperin weight conjecture and Dade's conjecture for the simple group $\mathrm{Fi}_{24}^{\prime}$

Let $\sigma: 1<Q=3^{2} .3^{4} .3^{8}<3^{2} .3^{4} .3^{8} .3$, so that $\sigma^{\prime}: 1<3^{2} .3^{4} .3^{8} .3$. A similar proof to above shows that we may suppose

$$
C \notin\left(\mathcal{R}^{-}\left(\sigma, 3^{2} \cdot 3^{4} \cdot 3^{8}\right) \cup \mathcal{R}^{0}\left(\sigma, 3^{2} \cdot 3^{4} .3^{8}\right)\right) .
$$

In particular, we may suppose $P_{1} \neq_{G} 3^{2} .3^{4} .3^{8} .3$ and moreover, if $P_{1}=3^{2} .3^{4} .3^{8}$, then $C \in_{G}\{C(29), C(30)\}$.

Let $\sigma: 1<Q=3<3^{2}<3^{4} \times 3^{1+2}$, so that $\sigma^{\prime}: 1<3^{2}<3^{4} \times 3^{1+2}$. A similar proof to above shows that we may suppose

$$
C \notin\left(\mathcal{R}^{-}(\sigma, 3) \cup \mathcal{R}^{0}(\sigma, 3) .\right.
$$

In particular, we may suppose $P_{3} \neq_{G} 3^{4} \times 3^{1+2}$ when $P_{1}=3$ and $P_{2}=3^{2}$, and moreover, if $P_{1}=3^{2}$, then $C \in \in_{G}\{C(31), C(32)\}$.

Let $C^{\prime}: 1<3^{3} \cdot 3^{4} \cdot 3^{3} \cdot 3^{3}<3^{2} \cdot 3^{4} \cdot 3^{8} .3^{2}$ and $g\left(C^{\prime}\right): 1<3^{3} \cdot 3^{4} \cdot 3^{3} \cdot 3^{3}<3^{1+10} \cdot(3 \times$ $\left.3^{1+2}\right)<3^{2} \cdot 3^{4} \cdot 3^{8} \cdot 3^{2}$. Then $N\left(C^{\prime}\right)=N\left(g\left(C^{\prime}\right)\right)$ and $N_{E}\left(C^{\prime}\right)=N_{E}\left(g\left(C^{\prime}\right)\right)$ and we may suppose $C \neq_{G} C^{\prime}, g\left(C^{\prime}\right)$. Thus if $P_{1}=3^{3} .3^{4} .3^{3} .3^{3}$, then $C \in_{G}\{C(33), C(34)$, $C(35), C(36)\}$.

Suppose $P_{1}=3^{7} \in \mathcal{R}_{0}\left(M_{2}, 3\right)$. Applying the Borel-Tits Theorem [8] (see [17, p. 361]) to $O_{7}(3)$, it follows that $C \in_{G}\{C(j): 20 \leqslant j \leqslant 27\}$.

Finally, suppose $P_{1}=3 \in \mathcal{R}_{0}\left(M_{1}, 3\right)$. Let $R \in \mathcal{R}_{0}\left(L_{2}, 3\right) \backslash\left\{3 \times 3^{1+8}\right\} \subseteq \mathcal{R}_{0}\left(M_{1}, 3\right)$, and $\sigma(R): 1<3<Q=3 \times 3^{1+8}<R$, so that $\sigma(R)^{\prime}: 1<3<R$. A similar proof to above shows that $(5.4)$ holds with $3^{1+10}$ replaced by $3 \times 3^{1+8}$ and $\mathcal{R}_{0}\left(M_{3}, 3\right) \backslash\left\{3^{1+10}\right\}$ by $\mathcal{R}_{0}\left(L_{2}, 3\right) \backslash\left\{3 \times 3^{1+8}\right\}$.

In particular, we may suppose $P_{2} \notin \mathcal{R}_{0}\left(L_{2}, 3\right) \backslash\left\{3 \times 3^{1+8}\right\}$ and moreover, if $P_{2}=$ $3 \times 3^{1+8}$, then $C={ }_{G} C(13)$.

We may suppose $P_{2} \in\left\{3^{2}, 3^{7}, 3^{7} \cdot 3^{3}, 3^{5} .3^{4} .3^{4}\right\}$ and if $P_{2}=3^{2}$, then $P_{3} \neq_{G} 3^{4} \times$ $3^{1+2}$. Let $C^{\prime}: 1<3<3^{2}<\left(3^{4} \times 3^{1+2}\right)^{*}<\left(3^{4} \times 3^{1+2}\right) .3$ and $g\left(C^{\prime}\right): 1<3<$ $3^{2}<\left(3^{4} \times 3^{1+2}\right) .3$. Then $N\left(C^{\prime}\right)=N\left(g\left(C^{\prime}\right)\right)$ and $N_{E}\left(C^{\prime}\right)=N_{E}\left(g\left(C^{\prime}\right)\right)$ and we may suppose $C \neq_{G} C^{\prime}, g\left(C^{\prime}\right)$. Thus if $P_{1}=3$ and $P_{2}=3^{2}$, then $C \in_{G}\{C(3), C(4)\}$.

If $P_{2}=3^{5} .3^{4} .3^{4}$, then $N_{M_{1}}\left(P_{2}\right)=3^{5} .3^{4} .3^{4} .2 S_{4} .2$, so that $C \in_{G}\{C(18), C(19)\}$.

If $P_{2}=3^{7} .3^{3} \in \mathcal{R}_{0}\left(M_{1}, 3\right)$, then $L_{0}:=N_{M_{1}}\left(P_{2}\right)=3^{7} .3^{3} \cdot\left(2 \times L_{3}(3)\right)$ and we may take

$$
\mathcal{R}_{0}\left(L_{0}, 3\right)=\left\{3^{7} \cdot 3^{3}, 3^{3} \cdot 3^{3} \cdot 3^{6}, 3^{2} \cdot 3^{2} \cdot 3^{4} \cdot 3^{4}, 3^{7} \cdot 3^{4} \cdot 3^{2}\right\}
$$

and $N_{L_{0}}\left(3^{3} \cdot 3^{3} \cdot 3^{6}\right)=3^{3} \cdot 3^{3} \cdot 3^{6} \cdot\left(2 S_{4} \times 2\right), N_{L_{0}}\left(3^{2} \cdot 3^{2} \cdot 3^{4} \cdot 3^{4}\right)=3^{2} \cdot 3^{2} \cdot 3^{4} \cdot 3^{4} \cdot\left(2 S_{4} \times 2\right)$ and

$N_{L_{0}}\left(3^{7} \cdot 3^{4} \cdot 3^{2}\right)=3^{7} \cdot 3^{4} \cdot 3^{2} \cdot 2^{3}$.

Let $C^{\prime}: 1<3<3^{7} .3^{3}<3^{2} \cdot 3^{2} \cdot 3^{4} \cdot 3^{4}<3^{7} .3^{4} .3^{2}$ and $g\left(C^{\prime}\right): 1<3<3^{7}<3^{7} .3^{3}<$ $3^{7} \cdot 3^{4} \cdot 3^{2}$. Then $N\left(C^{\prime}\right)=N\left(g\left(C^{\prime}\right)\right)$ and $N_{E}\left(C^{\prime}\right)=N_{E}\left(g\left(C^{\prime}\right)\right)$ and we may suppose $C \neq_{G} C^{\prime}, g\left(C^{\prime}\right)$. It follows that if $P_{1}=3$ and $P_{2}=3^{7} \cdot 3^{3}$, then $C \in_{G}\{C(i): 14 \leqslant$ $i \leqslant 17\}$.

Suppose $P_{2}=3^{7}$, so that $L_{1}=N_{M_{1}}\left(3^{7}\right)$. If $3^{7} .3^{3} \in \mathcal{R}_{0}\left(L_{1}, 3\right)$, then $L_{4}:=$ $N_{L_{1}}\left(3^{7} .3^{3}\right)$

$=3^{7} \cdot 3^{3} \cdot L_{3}(3)$ and we may take

$$
\mathcal{R}_{0}\left(L_{4}, 3\right)=\left\{3^{7} \cdot 3^{3}, 3^{7} \cdot 3^{4} \cdot 3,3^{7} \cdot 3^{3} \cdot 3^{2}, 3^{7} \cdot 3^{4} \cdot 3^{2}\right\}
$$

and $N_{L_{4}}\left(3^{7} .3^{3} \cdot 3^{2}\right)=N_{L_{1}}\left(3^{7} .3^{3} .3^{2}\right), N_{L_{4}}\left(3^{7} \cdot 3^{4} \cdot 3\right)=3^{7} .3^{4} \cdot 3 \cdot 2 S_{4} \neq N_{L_{1}}\left(3^{7} .3^{4} \cdot 3\right)$ and

$N_{L_{4}}\left(3^{7} \cdot 3^{4} \cdot 3^{2}\right)=3^{7} \cdot 3^{4} \cdot 3^{2} \cdot 2^{2}$. 
Let $\sigma: 1<3<3^{7}<Q=3^{7} .3^{3}<3^{7} .3^{3} .3^{2}$, so that $\sigma^{\prime}: 1<3<3^{7}<3^{7} .3^{3} .3^{2}$. A similar proof to above shows that we may suppose $(5.5)$ holds with $3^{2} \cdot 3^{4} .3^{8}$ replaced by $3^{7} .3^{3}$. Let $C^{\prime}: 1<3<3^{7}<3^{7} .3^{3}<3^{7} .3^{4} .3<3^{7} .3^{4} .3^{2}$ and $g\left(C^{\prime}\right): 1<3<3^{7}<$ $3^{7} .3^{3}<3^{7} \cdot 3^{4} .3^{2}$. Then $N\left(C^{\prime}\right)=N\left(g\left(C^{\prime}\right)\right)$ and $N_{E}\left(C^{\prime}\right)=N_{E}\left(g\left(C^{\prime}\right)\right)$ and we may suppose $C \neq_{G} C^{\prime}, g\left(C^{\prime}\right)$. Thus we may suppose $P_{3} \neq_{G} 3^{7} .3^{3} .3^{2}$ and if $P_{3}=3^{7} .3^{4}$, then $P_{4} \neq \neq_{G} 3^{7} .3^{3} \cdot 3^{2}$.

If $3^{7} .3^{4} \in \mathcal{R}_{0}\left(L_{1}, 3\right)$, then $L_{5}:=N_{L_{1}}\left(3^{7} .3^{4}\right)=3^{7} .3^{4} .2 .\left(A_{4} \times A_{4}\right) .2 .2$ and we may take

$$
\mathcal{R}_{0}\left(L_{5}, 3\right)=\left\{3^{7} \cdot 3^{4}, 3^{7} \cdot 3^{3} \cdot 3^{2}, 3^{7} \cdot 3^{4} \cdot 3^{2}\right\}
$$

and $N_{L_{5}}(R)=N_{L_{1}}(R)$ and $N_{L_{1} .2}(R)=N_{N_{L_{1} .2}\left(L_{5}\right)}(R)$ for each $R \in \mathcal{R}_{0}\left(L_{5}, 3\right)$.

Let $C^{\prime}: 1<3<3^{7}<3^{7} .3^{4} .3^{2}$ and $g\left(C^{\prime}\right): 1<3<3^{7}<3^{7} .3^{4}<3^{7} .3^{4} .3^{2}$. Then $N\left(C^{\prime}\right)=N\left(g\left(C^{\prime}\right)\right)$ and $N_{E}\left(C^{\prime}\right)=N_{E}\left(g\left(C^{\prime}\right)\right)$ and we may suppose $C \neq_{G} C^{\prime}, g\left(C^{\prime}\right)$. It follows that if $P_{1}=3$ and $P_{2}=3^{7}$, then $C \in_{G}\{C(i): 5 \leqslant i \leqslant 12\}$.

Case (2) Let $R \in \mathcal{R}_{0}\left(M_{2}, 2\right) \backslash\left\{2^{11}\right\}$, and $\sigma(R): 1<Q=2^{11}<R$, so that $\sigma(R): 1<R$. A similar proof to that of Case (1) shows that we may suppose (5.4) holds with $3^{1+10}$ replaced by $2^{11}$ and $\mathcal{R}_{0}\left(M_{3}, 3\right) \backslash\left\{3^{1+10}\right\}$ by $\mathcal{R}_{0}\left(M_{2}, 2\right) \backslash\left\{2^{11}\right\}$. Thus if $P_{1}=2^{11}$, then $C={ }_{G} C(42)$ and we may assume that $P_{1} \notin \mathcal{R}_{0}\left(M_{2}, 2\right)$.

Case (2.1) Let $\sigma: 1<Q=2<2^{2}<D_{8}$, so that $\sigma^{\prime}: 1<2^{2}<D_{8}$. A similar proof to above shows that we may suppose (5.5) holds with $3^{2} .3^{4} .3^{8}$ replaced by 2 . Thus if $P_{1}=2^{2}$, then $P_{2} \neq_{G} D_{8}$, and if $P_{1}=2$ and $P_{2}=2^{2}$, then $P_{3} \neq_{G} D_{8}$.

Let $R \in \mathcal{R}_{0}\left(K_{2}, 2\right) \backslash\left\{2^{11}\right\}$, and $\sigma(R): 1<2^{2}<Q=2^{11}<R$, so that $\sigma(R)^{\prime}: 1<$ $2^{2}<R$. A similar proof to that of Case (1) shows that we may suppose (5.4) holds with $\mathcal{R}_{0}\left(M_{3}, 2\right) \backslash\left\{3^{1+10}\right\}$ replaced by $\mathcal{R}_{0}\left(K_{2}, 2\right) \backslash\left\{2^{11}\right\}$.

Let $\mathcal{V}=\left\{\left(2 \times 2_{+}^{1+8}\right) .2,\left(2 \times 2_{+}^{1+8}\right) .2 .2^{4},\left(2 \times 2_{+}^{1+8}\right) .2 .2^{4} .2\right\} \subseteq \mathcal{R}_{0}\left(K_{1}, 2\right), R \in \mathcal{V}$ and let $\sigma(R): 1<2^{2}<Q=2 \times 2_{+}^{1+8}<R$, so that $\sigma(R)^{\prime}: 1<2^{2}<R$. A similar proof to Case (1) shows that we may suppose (5.4) holds with $3^{1+10}$ replaced by $2 \times 2_{+}^{1+8}$ and $\mathcal{R}_{0}\left(M_{3}, 3\right) \backslash\left\{3^{1+10}\right\}$ by $\mathcal{V}$. Thus if $P_{1}=2^{2}$, then $P_{2} \notin_{G} \mathcal{V}$ and in addition, if $P_{2}=2 \times 2_{+}^{1+8}$, then $P_{3} \notin_{G} \mathcal{V}$.

If $V_{1}=\left(2 \times 2_{+}^{1+8}\right): 2^{4} \cdot A_{5}: S_{3} \leqslant K_{1}$, then we may take $\mathcal{R}_{0}\left(V_{1}, 2\right)=$

$$
\left\{\left(2 \times 2_{+}^{1+8}\right): 2^{4},\left(2 \times 2_{+}^{1+8}\right): 2^{4} .2,\left(2 \times 2_{+}^{1+8}\right): 2^{4} .2^{2},\left(2 \times 2_{+}^{1+8}\right): 2^{4} .2^{2} .2\right\} \subseteq \mathcal{R}_{0}\left(K_{1}, 2\right),
$$

so that $\mathcal{R}_{0}\left(K_{1}, 2\right)=\mathcal{V} \cup \mathcal{R}_{0}\left(V_{1}, 2\right)$. In addition, $N_{K_{1}}(R)=N_{V_{1}}(R), N_{K_{1} .2}(R)=$ $N_{N_{K_{1} .2}\left(V_{1}\right)}(R)$ for each $R \in \mathcal{R}_{0}\left(V_{1}, 2\right)$.

Let $R \in \mathcal{R}_{0}\left(V_{1}, 2\right) \backslash\left\{\left(2 \times 2_{+}^{1+8}\right): 2^{4}\right\}$ and $\sigma(R): 1<2^{2}<2 \times 2_{+}^{1+8}<Q=$ $\left(2 \times 2_{+}^{1+8}\right): 2^{4}<R$, so that $\sigma(R)^{\prime}: 1<2^{2}<2 \times 2_{+}^{1+8}<R$. We may suppose (5.4) holds with $3^{1+10}$ replaced by $\left(2 \times 2_{+}^{1+8}\right): 2^{4}$ and $\mathcal{R}_{0}\left(M_{3}, 3\right) \backslash\left\{3^{1+10}\right\}$ by $\mathcal{R}_{0}\left(V_{1}, 2\right) \backslash$ $\left\{\left(2 \times 2_{+}^{1+8}\right): 2^{4}\right\}$.

Let $\sigma: 1<2^{2}<Q=2^{6+8}<2^{6+8} .2$, so that $\sigma^{\prime}: 1<2^{2}<2^{6+8}$.2. A similar proof to above shows that we may suppose (5.5) holds with $3^{2} .3^{4} .3^{8}$ replaced by $2^{6+8}$. Thus if $P_{1}=2^{2}$, then $P_{2} \neq \neq_{G} 2^{6+8} .2$.

If $V_{2}=\left(2 \times 2_{+}^{1+8}\right) \cdot 2.2^{4} \cdot\left(S_{3} \times S_{3}\right) .3 \leqslant K_{3}$, then we may take $\mathcal{R}_{0}\left(V_{2}, 2\right)=$ $\left\{\left(2 \times 2_{+}^{1+8}\right) \cdot 2.2^{4},\left(2 \times 2_{+}^{1+8}\right) 2^{4} \cdot 2^{2},\left(2 \times 2_{+}^{1+8}\right) 2.2^{4} \cdot 2,\left(2 \times 2_{+}^{1+8}\right): 2^{4} \cdot 2^{2} .2\right\} \subseteq \mathcal{R}_{0}\left(K_{3}, 2\right)$.

In addition, $N_{K_{3}}(R)=N_{V_{2}}(R), N_{K_{3} .2}(R)=N_{N_{K_{3} .2}\left(V_{2}\right)}(R)$ for each $R \in \mathcal{R}_{0}\left(V_{2}, 2\right)$. 
The Alperin weight conjecture and Dade's conjecture for the simple group $\mathrm{Fi}_{24}^{\prime}$

\begin{tabular}{|c|c|c|}
\hline$C$ & & $N(C)$ \\
\hline$C(1)$ & 1 & $\mathrm{Fi}_{24}^{\prime}$ \\
\hline$C(2)$ & $1<2$ & 2. $\mathrm{Fi}_{22} \cdot 2$ \\
\hline$C(3)$ & $1<2<2^{2}$ & $2^{2} \cdot U_{6}(2): 2$ \\
\hline$C(4)$ & $1<2<2^{2}<2^{11}$ & $2^{11} \cdot L_{3}(4): 2$ \\
\hline$C(5)$ & $1<2<2^{2}<2^{2} \times 2_{+}^{1+8}<\left(2^{2} \times 2_{+}^{1+8}\right): 2^{4}$ & $\left(2^{2} \times 2_{+}^{1+8}\right): 2^{4} \cdot S_{5}$ \\
\hline$C(6)$ & $1<2<2^{2}<2^{2} \times 2_{+}^{1+8}$ & $\left(2^{2} \times 2_{+}^{1+8}\right) \cdot U_{4}(2): 2$ \\
\hline$C(7)$ & $1<2<2^{2}<2^{6+8}<2^{11} \cdot 2^{4}$ & $2^{11} \cdot 2^{4} \cdot S_{5}$ \\
\hline$C(8)$ & $1<2<2^{2}<2^{6+8}$ & $2^{6+8} \cdot\left(S_{3} \times S_{5}\right)$ \\
\hline$C(9)$ & $1<2<2^{2}<2^{6+8}<\left(2 \times 2_{+}^{1+8}\right) .2 .2^{4}$ & $\left(2 \times 2_{+}^{1+8}\right) \cdot 2.2^{4}\left(S_{3} \times S_{3}\right)$ \\
\hline$C(10)$ & $1<2<2^{2}<2^{6+8}<\left(2 \times 2_{+}^{1+8}\right) \cdot 2 \cdot 2^{4}<\left(2 \times 2_{+}^{1+8}\right) \cdot 2^{4} \cdot 2^{2}$ & $\left(2 \times 2_{+}^{1+8}\right) \cdot 2^{4} \cdot 2^{2} \cdot S_{3}$ \\
\hline$C(11)$ & $1<2<\left(2^{2}\right)^{*}$ & $\left(2^{2} \times O_{8}^{+}(2): 3\right): 2$ \\
\hline$C(12)$ & $1<2<\left(2^{2}\right)^{*}<2^{8}$ & $2^{8}: S_{8}$ \\
\hline$C(13)$ & $1<2<\left(2^{2}\right)^{*}<2^{8}<2^{8} \cdot 2^{3}$ & $2^{8} \cdot 2^{3} \cdot L_{3}(2)$ \\
\hline$C(14)$ & $1<2<\left(2^{2}\right)^{*}<2^{8}<2^{8} \cdot 2^{3}<2^{8} \cdot 2^{3} \cdot 2^{2}$ & $2^{8} \cdot 2^{3} \cdot 2^{2} \cdot S_{3}$ \\
\hline$C(15)$ & $1<2<\left(2^{2}\right)^{*}<2^{3} \cdot 2^{8}<2^{8} \cdot 2^{4}$ & $2^{8} .2^{4} \cdot\left(S_{3} \times S_{3}\right) \cdot 2$ \\
\hline$C(16)$ & $1<2<\left(2^{2}\right)^{*}<2^{3} \cdot 2^{8}<2^{8} \cdot 2^{4}<2^{3} \cdot 2^{2} \cdot 2^{4} \cdot 2^{4}$ & $2^{3} \cdot 2^{2} \cdot 2^{4} \cdot 2^{4} \cdot S_{3}$ \\
\hline$C(17)$ & $1<2<\left(2^{2}\right)^{*}<2^{3} \cdot 2^{8}<2^{8} \cdot 2^{4}<2^{3} \cdot 2^{2} \cdot 2^{4} \cdot 2^{4}<2^{8} \cdot 2^{4} \cdot 2^{2}$ & $2^{8} \cdot 2^{4} \cdot 2^{2}$ \\
\hline$C(18)$ & $1<2<\left(2^{2}\right)^{*}<2^{3} \cdot 2^{8}$ & $2^{3} \cdot 2^{8} \cdot 3 \cdot\left(S_{3} \times S_{3} \times S_{3}\right) \cdot 2$ \\
\hline$C(19)$ & $1<2<\left(2^{2}\right)^{*}<2^{4} \cdot 2^{4} \cdot 2^{4}<2^{4} \cdot 2^{4} \cdot 2^{4} \cdot 2^{2}$ & $2^{4} \cdot 2^{4} \cdot 2^{4} \cdot 2^{2} \cdot S_{3}$ \\
\hline$C(20)$ & $1<2<\left(2^{2}\right)^{*}<2^{4} \cdot 2^{4} \cdot 2^{4}$ & $2^{4} \cdot 2^{4} \cdot 2^{4} \cdot L_{3}(2)$ \\
\hline$C(21)$ & $1<2<\left(2^{2}\right)^{*}<2^{4} \cdot 2^{4} \cdot 2^{4}<2^{3} \cdot 2^{8} \cdot D_{8}$ & $2^{3} \cdot 2^{8} \cdot D_{8} \cdot S_{3}$ \\
\hline$C(22)$ & $1<2<\left(2^{2}\right)^{*}<2^{4} \cdot 2^{4} \cdot 2^{4}<2^{4} \cdot 2^{4} \cdot 2^{4} \cdot 2^{2}<2^{3} \cdot 2^{8} \cdot D_{8} \cdot 2$ & $2^{3} \cdot 2^{8} \cdot D_{8} \cdot 2$ \\
\hline$C(23)$ & $1<2<\left(2^{2}\right)^{*}<2^{4} \cdot 2^{3} \cdot 2^{6}<2^{4} \cdot 2^{3} \cdot 2^{6} \cdot 2$ & $2^{4} \cdot 2^{3} \cdot 2^{6} \cdot 2 \cdot S_{3}$ \\
\hline$C(24)$ & $1<2<\left(2^{2}\right)^{*}<2^{4} \cdot 2^{3} \cdot 2^{6}$ & $2^{4} \cdot 2^{3} \cdot 2^{6} \cdot\left(S_{3} \times S_{3}\right)$ \\
\hline$C(25)$ & $1<2<\left(2^{2}\right)^{*}<2^{4} \cdot 2^{3} \cdot 2^{6}<2^{4} \cdot 2^{4} \cdot 2^{4} \cdot 2^{2}$ & $2^{4} \cdot 2^{4} \cdot 2^{4} \cdot 2^{2} \cdot S_{3}$ \\
\hline$C(26)$ & $1<2<\left(2^{2}\right)^{*}<2^{4} \cdot 2^{3} \cdot 2^{6}<2^{4} \cdot 2^{4} \cdot 2^{4} \cdot 2^{2}<2^{3} \cdot 2^{8} \cdot D_{8} \cdot 2$ & $2^{3} \cdot 2^{8} \cdot D_{8} \cdot 2$ \\
\hline$C(27)$ & $1<2<2^{8}$ & $2^{8} \cdot S_{6}(2)$ \\
\hline$C(28)$ & $1<2<2^{8}<2^{8} .2^{5}$ & $2^{8} \cdot 2^{5} \cdot S_{6}$ \\
\hline$C(29)$ & $1<2<2^{8}<2^{8} \cdot 2^{6}<2^{2} \cdot 2^{3} \cdot 2^{5} \cdot 2^{6}$ & $2^{2} \cdot 2^{3} \cdot 2^{5} \cdot 2^{6} \cdot S_{3}$ \\
\hline$C(30)$ & $1<2<2^{8}<2^{8} .2^{6}$ & $2^{8} \cdot 2^{6} \cdot L_{3}(2)$ \\
\hline
\end{tabular}

Table 11: Some radical 2-chains of $\mathrm{Fi}_{24}^{\prime}$ 
The Alperin weight conjecture and Dade's conjecture for the simple group $\mathrm{Fi}_{24}^{\prime}$

\begin{tabular}{|c|c|c|}
\hline$C$ & & $N(C)$ \\
\hline$C(31)$ & $1<2<2^{8}<2^{8} \cdot 2^{3} \cdot 2^{4}<2^{8} .2^{5} \cdot 2^{3}$ & $2^{8} \cdot 2^{5} \cdot 2^{3} \cdot S_{3}$ \\
\hline$C(32)$ & $1<2<2^{8}<2^{8} \cdot 2^{3} \cdot 2^{4}$ & $2^{8} \cdot 2^{3} \cdot 2^{4} \cdot\left(S_{3} \times S_{3}\right)$ \\
\hline$C(33)$ & $1<2<2^{8}<2^{8} .2^{3} \cdot 2^{4}<2^{8} .2^{3} \cdot 2^{4} .2$ & $2^{8} \cdot 2^{3} \cdot 2^{4} \cdot 2 \cdot S_{3}$ \\
\hline$C(34)$ & $1<2<2^{8}<2^{8} .2^{3} \cdot 2^{4}<2^{8} .2^{5} .2^{3}<2^{8} .2^{5} .2^{3} .2$ & $2^{8} \cdot 2^{5} \cdot 2^{3} \cdot 2$ \\
\hline$C(35)$ & $1<2<2^{11}$ & $2^{11} \cdot M_{22}: 2$ \\
\hline$C(36)$ & $1<2<2^{2} .2^{10}<2^{11} \cdot 2^{4} .2$ & $2^{11} \cdot 2^{4} \cdot 2 \cdot S_{5}$ \\
\hline$C(37)$ & $1<2<2^{2} .2^{10}$ & $2^{2} \cdot 2^{10} \cdot U_{4}(2) \cdot 2$ \\
\hline$C(38)$ & $1<2<2^{6+8}<2^{11} \cdot 2^{4}$ & $2^{11} \cdot 2^{4} \cdot S_{6}$ \\
\hline$C(39)$ & $1<2<2^{6+8}$ & $2^{6+8} \cdot\left(S_{3} \times S_{6}\right)$ \\
\hline$C(40)$ & $1<2<2^{6+8}<2^{2} .2^{10} \cdot 2.2^{4}$ & $2^{2} .2^{10} \cdot 2.2^{4} \cdot\left(S_{3} \times S_{3}\right)$ \\
\hline$C(41)$ & $1<2<2^{6+8}<2^{2} \cdot 2^{10} \cdot 2.2^{4}<2^{11} \cdot 2^{2} \cdot 2^{4} \cdot 2$ & $2^{11} \cdot 2^{2} \cdot 2^{4} \cdot 2 . S_{3}$ \\
\hline$C(42)$ & $1<2^{11}$ & $2^{11} \cdot M_{24}$ \\
\hline$C(43)$ & $1<2^{2}<2^{11}$ & $2^{11} \cdot L_{3}(4) \cdot S_{3}$ \\
\hline$C(44)$ & $1<2^{2}$ & $2^{2} \cdot U_{6}(2) \cdot S_{3}$ \\
\hline$C(45)$ & $1<2^{2}<2^{2} \times 2_{+}^{1+8}$ & $\left(2^{2} \times 2_{+}^{1+8}\right) \cdot U_{4}(2): S_{3}$ \\
\hline$C(46)$ & $1<2^{2}<2^{2} \times 2_{+}^{1+8}<\left(2^{2} \times 2_{+}^{1+8}\right): 2^{4}$ & $\left(2^{2} \times 2_{+}^{1+8}\right): 2^{4}: A_{5}: S_{3}$ \\
\hline$C(47)$ & $1<2^{2}<2^{6+8}$ & $2^{6+8} \cdot\left(S_{3} \times S_{5}\right) \cdot 3$ \\
\hline$C(48)$ & $1<2^{2}<2^{6+8}<\left(2^{2} \times 2_{+}^{1+8}\right) \cdot 2.2^{4}$ & $\left(2^{2} \times 2_{+}^{1+8}\right) \cdot 2 \cdot 2^{4} \cdot\left(S_{3} \times S_{3}\right) \cdot 3$ \\
\hline$C(49)$ & $1<2^{2}<2^{6+8}<2^{11} \cdot 2^{4}<\left(2^{2} \times 2_{+}^{1+8}\right) \cdot 2^{4} \cdot 2^{2}$ & $\left(2^{2} \times 2_{+}^{1+8}\right) \cdot 2^{4} \cdot 2^{2} \cdot S_{3} \cdot 3$ \\
\hline$C(50)$ & $1<2^{2}<2^{6+8}<2^{11} \cdot 2^{4}$ & $2^{11} \cdot 2^{4} \cdot A_{5} \cdot S_{3}$ \\
\hline$C(51)$ & $1<2_{+}^{1+12}<2^{11} \cdot 2^{6}$ & $2^{11} \cdot 2^{6} \cdot\left(3 \times A_{6}\right) \cdot 2$ \\
\hline$C(52)$ & $1<2_{+}^{1+12}$ & $2_{+}^{1+12} \cdot 3 \cdot U_{4}(3): 2$ \\
\hline$C(53)$ & $1<\left(2^{2}\right)^{*}<2^{3} \cdot 2^{8}$ & $2^{3} \cdot 2^{8} .3 .\left(S_{3} \times S_{3} \times S_{3}\right): S_{3}$ \\
\hline$C(54)$ & $1<\left(2^{2}\right)^{*}$ & $\left(A_{4} \times O_{8}^{+}(2): 3\right): 2$ \\
\hline$C(55)$ & $1<\left(2^{2}\right)^{*}<2^{8} \cdot 2^{3}$ & $2^{8} \cdot 2^{3} \cdot\left(L_{3}(2) \times S_{3}\right)$ \\
\hline$C(56)$ & $1<\left(2^{2}\right)^{*}<2^{8} \cdot 2^{3}<2^{3} \cdot 2^{8} \cdot 2^{2}$ & $2^{3} \cdot 2^{8} \cdot 2^{2} \cdot\left(S_{3} \times S_{3}\right)$ \\
\hline$C(57)$ & $1<\left(2^{2}\right)^{*}<2^{8} \cdot 2^{3}<2^{3} \cdot 2^{8} \cdot 2^{2}<2^{3} \cdot 2^{8} \cdot 2^{3}$ & $2^{3} \cdot 2^{8} \cdot 2^{3} \cdot S_{3}$ \\
\hline$C(58)$ & $1<\left(2^{2}\right)^{*}<2^{8} \cdot 2^{3}<2^{4} \cdot 2^{3} \cdot 2^{6}$ & $2^{4} \cdot 2^{3} \cdot 2^{6} \cdot\left(S_{3} \times S_{3}\right)$ \\
\hline$C(59)$ & $1<\left(2^{2}\right)^{*}<2^{4} \cdot 2^{3} \cdot 2^{6}$ & $2^{4} \cdot 2^{3} \cdot 2^{6} \cdot\left(S_{3} \times S_{3}\right) \cdot 3$ \\
\hline$C(60)$ & $1<\left(2^{2}\right)^{*}<2^{4} \cdot 2^{3} \cdot 2^{6}<2^{3} \cdot 2^{8} \cdot 2^{3}$ & $2^{3} \cdot 2^{8} \cdot 2^{3} \cdot 3^{2} \cdot 2$ \\
\hline
\end{tabular}

Table 12: Some radical 2-chains of $\mathrm{Fi}_{24}^{\prime}$ 
The Alperin weight conjecture and Dade's conjecture for the simple group $\mathrm{Fi}_{24}^{\prime}$

\begin{tabular}{|c|c|c|}
\hline$C$ & & $N(C)$ \\
\hline$C(61)$ & $1<\left(2^{2}\right)^{*}<2^{8}$ & $\left(A_{4} \times 2^{6}: A_{8}\right) \cdot 2$ \\
\hline$C(62)$ & $1<\left(2^{2}\right)^{*}<2^{8}<2^{8} \cdot 2^{3}$ & $2^{8} \cdot 2^{3}\left(L_{3}(2) \times 3\right)$ \\
\hline$C(63)$ & $1<\left(2^{2}\right)^{*}<2^{8}<2^{8} \cdot 2^{3}<2^{4} \cdot 2^{3} \cdot 2^{6}$ & $2^{4} \cdot 2^{3} \cdot 2^{6} \cdot\left(S_{3} \times 3\right)$ \\
\hline$C(64)$ & $1<\left(2^{2}\right)^{*}<2^{8}<2^{4} \cdot 2^{3} \cdot 2^{6}$ & $2^{4} \cdot 2^{3} \cdot 2^{6} \cdot\left(S_{3} \times S_{3}\right)$ \\
\hline$C(65)$ & $1<\left(2^{2}\right)^{*}<2^{8}<2^{4} \cdot 2^{3} \cdot 2^{6}<2^{3} \cdot 2^{8} \cdot 2^{3}$ & $2^{3} \cdot 2^{8} \cdot 2^{3} \cdot S_{3}$ \\
\hline$C(66)$ & $1<\left(2^{2}\right)^{*}<2^{8}<2^{8} \cdot 2^{4}$ & $2^{8} \cdot 2^{4} \cdot\left(S_{3} \times S_{3}\right) \cdot S_{3}$ \\
\hline$C(67)$ & $1<\left(2^{2}\right)^{*}<2^{8}<2^{8} \cdot 2^{4}<2^{3} \cdot 2^{8} \cdot 2^{2}$ & $2^{3} \cdot 2^{8} \cdot 2^{2} \cdot\left(S_{3} \times 3\right)$ \\
\hline$C(68)$ & $1<\left(2^{2}\right)^{*}<2^{8}<2^{8} \cdot 2^{4}<2^{3} \cdot 2^{8} \cdot 2^{2}<2^{3} \cdot 2^{8} \cdot 2^{2} \cdot 2$ & $2^{3} \cdot 2^{8} \cdot 2^{2} \cdot 6$ \\
\hline$C(69)$ & $1<2^{3+12}<2^{3} \cdot 2^{6} \cdot 2^{8}$ & $2^{3} \cdot 2^{6} \cdot 2^{8} \cdot\left(S_{3} \times L_{3}(2)\right)$ \\
\hline$C(70)$ & $1<2^{3+12}$ & $2^{3+12} \cdot\left(A_{6} \times L_{3}(2)\right)$ \\
\hline$C(71)$ & $1<2^{3+12}<2_{+}^{1+12} \cdot 2^{4}$ & $2_{+}^{1+12} \cdot 2^{4} \cdot\left(A_{6} \times S_{3}\right)$ \\
\hline$C(72)$ & $1<2^{3+12}<2_{+}^{1+12} \cdot 2^{4}<2^{11} \cdot 2^{4} \cdot 2^{4}$ & $2^{11} \cdot 2^{4} \cdot 2^{4} \cdot\left(S_{3} \times S_{3}\right)$ \\
\hline$C(73)$ & $1<2^{8}<2_{+}^{1+12} .2$ & $2_{+}^{1+12} \cdot 2 \cdot U_{4}(2)$ \\
\hline$C(74)$ & $1<2^{8}$ & $2^{8}: O_{8}^{-}(2)$ \\
\hline$C(75)$ & $1<2^{8}<2^{8}: 2^{3+6}$ & $2^{8}: 2^{3+6} \cdot\left(L_{3}(2) \times 3\right)$ \\
\hline$C(76)$ & $1<2^{8}<2^{8}: 2_{+}^{1+8}<2^{8}: 2^{6} \cdot 2^{4}$ & $2^{8}: 2^{6} \cdot 2^{4} \cdot A_{5}$ \\
\hline$C(77)$ & $1<2^{8}<2^{8}: 2_{+}^{1+8}$ & $2^{8}: 2_{+}^{1+8} \cdot\left(S_{3} \times A_{5}\right)$ \\
\hline$C(78)$ & $1<2^{8}<2^{8}: 2_{+}^{1+8}<2^{8}: 2^{3+6} .2^{2}$ & $2^{8}: 2^{3+6} \cdot 2^{2} \cdot\left(3 \times S_{3}\right)$ \\
\hline$C(79)$ & $1<2^{8}<2^{8}: 2^{3+6}<2^{8} .2^{6} \cdot 2.2^{4}<2^{8} \cdot 2^{3+6} . D_{8}$ & $2^{8} \cdot 2^{3+6} \cdot D_{8} \cdot 3$ \\
\hline$C(80)$ & $1<2^{8}<2^{8}: 2^{3+6}<2^{8} \cdot 2^{6} \cdot 2.2^{4}$ & $2^{8} .2^{6} \cdot 2.2^{4} \cdot\left(3 \times S_{3}\right)$ \\
\hline$C(81)$ & $1<2^{6+8}<2^{11} .2^{4}$ & $2^{11} \cdot 2^{4} \cdot A_{8}$ \\
\hline$C(82)$ & $1<2^{6+8}$ & $2^{6+8} \cdot\left(S_{3} \times A_{8}\right)$ \\
\hline$C(83)$ & $1<2^{6+8}<2^{3} \cdot 2^{3} \cdot 2^{6} \cdot 2^{5}$ & $2^{3} \cdot 2^{3} \cdot 2^{6} \cdot 2^{5} \cdot\left(L_{3}(2) \times S_{3}\right)$ \\
\hline$C(84)$ & $1<2^{6+8}<2^{3} \cdot 2^{3} \cdot 2^{6} \cdot 2^{5}<2^{11} \cdot 2^{3} \cdot 2^{4}$ & $2^{11} \cdot 2^{3} \cdot 2^{4} \cdot L_{3}(2)$ \\
\hline$C(85)$ & $1<2^{6+8}<2_{+}^{1+12} .2 .2^{4}$ & $2_{+}^{1+12} \cdot 2.2^{4} \cdot\left(S_{3} \times S_{3} \times S_{3}\right)$ \\
\hline$C(86)$ & $1<2^{6+8}<2_{+}^{1+12} .2 .2^{4}<2^{1+12} .2 .2^{4} .2$ & $2^{1+12} \cdot 2 \cdot 2^{4} \cdot 2 \cdot\left(S_{3} \times S_{3}\right)$ \\
\hline$C(87)$ & $1<2^{6+8}<2_{+}^{1+12} \cdot 2.2^{4}<2^{6+8} \cdot 2^{4} \cdot 2<2^{11} \cdot 2^{2} \cdot 2^{3} \cdot 2^{4}$ & $2^{11} \cdot 2^{2} \cdot 2^{3} \cdot 2^{4} \cdot S_{3}$ \\
\hline$C(88)$ & $1<2^{6+8}<2_{+}^{1+12} \cdot 2.2^{4}<2^{6+8} .2^{4} .2$ & $2^{6+8} \cdot 2^{4} .2 .\left(S_{3} \times S_{3}\right)$ \\
\hline
\end{tabular}

Table 13: Some radical 2-chains of $\mathrm{Fi}_{24}^{\prime}$ 
The Alperin weight conjecture and Dade's conjecture for the simple group $\mathrm{Fi}_{24}^{\prime}$

Let $R \in \mathcal{R}_{0}\left(V_{2}, 2\right) \backslash\left\{\left(2 \times 2_{+}^{1+8}\right) .2 .2^{4}\right\}$ and $\sigma(R): 1<2^{2}<2^{6+8}<Q=(2 \times$ $\left.2_{+}^{1+8}\right) \cdot 2.2^{4}<R$, so that $\sigma(R)^{\prime}: 1<2^{2}<2^{6+8}<R$. We may suppose (5.4) holds with $3^{1+10}$ replaced by $\left(2 \times 2_{+}^{1+8}\right) \cdot 2 \cdot 2^{4}$ and $\mathcal{R}_{0}\left(M_{3}, 3\right) \backslash\left\{3^{1+10}\right\}$ by $\mathcal{R}_{0}\left(V_{2}, 2\right) \backslash\{(2 \times$ $\left.\left.2_{+}^{1+8}\right): 2^{4}\right\}$.

If $V_{3}=2^{11} \cdot 2^{4} \cdot A_{5} \cdot S_{3} \leqslant K_{3}$, then we may take

$$
\mathcal{R}_{0}\left(V_{3}, 2\right)=\left\{2^{11} .2^{4}, 2^{6+8} \cdot 2^{2},\left(2 \times 2_{+}^{1+8}\right) 2^{4} .2^{2},\left(2 \times 2_{+}^{1+8}\right): 2^{4} .2^{2} .2\right\} \subseteq \mathcal{R}_{0}\left(K_{3}, 2\right) .
$$

In addition, $N_{K_{3}}(R)=N_{V_{3}}(R), N_{K_{3} .2}(R)=N_{N_{K_{3} .2}\left(V_{3}\right)}(R)$ for each $R \in \mathcal{R}_{0}\left(V_{3}, 2\right)$.

Let $\sigma: 1<2^{2}<2^{6+8}<Q=2^{11} .2^{4}<2^{6+8} .2^{2}$, so that $\sigma^{\prime}: 1<2^{2}<2^{6+8}<$ $2^{6+8} \cdot 2^{2}$. A similar proof to above shows that we may suppose (5.5) holds with $3^{2} \cdot 3^{4} \cdot 3^{8}$ replaced by $2^{11} \cdot 2^{4}$.

Let $C^{\prime}: 1<2^{2}<2^{6+8}<2^{11} .2^{4}<\left(2 \times 2_{+}^{1+8}\right): 2^{4} .2^{2}<\left(2 \times 2_{+}^{1+8}\right): 2^{4} .2^{2} .2$ and $g\left(C^{\prime}\right): 1<2^{2}<2^{6+8}<2^{11} .2^{4}<\left(2 \times 2_{+}^{1+8}\right): 2^{4} .2^{2} .2$. Then $N\left(C^{\prime}\right)=N\left(g\left(C^{\prime}\right)\right)$ and $N_{E}\left(C^{\prime}\right)=N_{E}\left(g\left(C^{\prime}\right)\right)$ and we may suppose $C \neq_{G} C^{\prime}, g\left(C^{\prime}\right)$.

It follows that if $P_{1}=2^{2}$, then $C \in\{C(i): 43 \leqslant i \leqslant 50\}$.

Case (2.2) Let

$\Omega=\left\{2_{+}^{1+12} \cdot 2,2_{+}^{1+12} \cdot 2^{4}, 2_{+}^{1+12} \cdot 2 \cdot 2^{4}, 2_{+}^{1+12} \cdot 2^{4} \cdot 2,2_{+}^{1+12} \cdot 2^{2} \cdot 2^{4}, 2^{6+8} \cdot 2^{4} \cdot 2,2^{3+12} \cdot\left(D_{8} \times 2^{2}\right)\right\}$

be a subset of $\mathcal{R}_{0}\left(M_{4}, 2\right), R \in \Omega$ and let $\sigma(R): 1<Q=2_{+}^{1+12}<R$, so that $\sigma(R)^{\prime}: 1<R$. A similar proof to Case (1) shows that we may suppose (5.4) holds with $3^{1+10}$ replaced by $2_{+}^{1+12}$ and $\mathcal{R}_{0}\left(M_{3}, 3\right) \backslash\left\{3^{1+10}\right\}$ by $\Omega$. Thus $P_{1} \neq_{G} R$ and if $P_{1}=2_{+}^{1+12}$, then $P_{2} \neq_{G} R$.

If $W=2^{11} .2^{6} .3 S_{6} \leqslant M_{4}$, then we may take $\mathcal{R}_{0}(W, 2)=$

$$
\begin{aligned}
& \left\{2^{11} \cdot 2^{6}, 2_{+}^{1+12} \cdot 2 \cdot 2^{4} \cdot 2,2^{11} \cdot 2^{4} \cdot 2^{4}, 2^{6+8} \cdot 2^{4} \cdot 2^{2}, 2^{11} \cdot 2^{2} \cdot 2^{3} \cdot 2^{4}, 2_{+}^{1+12} \cdot 2^{4} \cdot 2^{2} \cdot 2, S\right\} \\
& \subseteq \mathcal{R}_{0}\left(M_{4}, 2\right),
\end{aligned}
$$

so that $\mathcal{R}_{0}\left(M_{4}, 2\right)=\Omega \cup \mathcal{R}_{0}(W, 2)$. In addition, $N_{W}(R)=N_{M_{4}}(R)$ and $N_{N_{M_{4} .2}(W)}(R)=N_{M_{4} .2}(R)$ for each $R \in \mathcal{R}_{0}(W, 2)$. Let $R \in \mathcal{R}_{0}(W, 2) \backslash\left\{2^{11} .2^{6}\right\}$ and $\sigma(R): 1<2_{+}^{1+12}<Q=2^{11} \cdot 2^{6}<R$, so that $\sigma(R)^{\prime}: 1<2_{+}^{1+12}<R$. We may suppose (5.4) holds with $3^{1+10}$ replaced by $2^{11} .2^{6}$ and $\mathcal{R}_{0}\left(M_{3}, 3\right) \backslash\left\{3^{1+10}\right\}$ by $\mathcal{R}_{0}(W, 2) \backslash\left\{2^{11} \cdot 2^{6}\right\}$. Thus if $P_{1}=2_{+}^{1+12}$, then $C \in_{G}\{C(51), C(52)\}$.

Case (2.3) Let $\sigma: 1<Q=\left(2^{2}\right)^{*}<D_{8}$ with $D_{8} \in \mathcal{R}_{0}\left(M_{5}, 2\right)$, so that $\sigma: 1<D_{8}$. Since $N\left(D_{8}\right)=N_{M_{5}}\left(D_{8}\right)$ and $N_{E}\left(D_{8}\right)=N_{M_{5} .2}\left(D_{8}\right)=N\left(D_{8}\right) .2$, it follows that we may suppose $(5.5)$ holds with $3^{2} \cdot 3^{4} \cdot 3^{8}$ replaced by $\left(2^{2}\right)^{*}$. In particular, $P_{1} \neq_{G} D_{8}$ and if $P_{1}=\left(2^{2}\right)^{*}$, then $P_{2} \neq \neq_{G} D_{8}$.

If $X_{1}=2^{3} .2^{8} .3\left(S_{3} \times S_{3} \times S_{3}\right) . S_{3} \leqslant M_{5}$, we may take $\mathcal{R}_{0}\left(X_{1}, 2\right)=$

$$
\left\{2^{3} \cdot 2^{8}, 2^{8} \cdot 2^{4}, 2^{3} \cdot 2^{8} \cdot 2,2^{3} \cdot 2^{8} \cdot 2^{2}, 2^{8} \cdot 2^{2} \cdot 2^{3}, 2^{3} \cdot 2^{8} \cdot 2^{3}, 2^{3} \cdot 2^{8} \cdot 2^{2} \cdot 2,2^{8} \cdot 2^{4} \cdot 2^{3}\right\} \subseteq \mathcal{R}_{0}\left(M_{5}, 2\right)
$$

and in addition, $N_{M_{5}}(R)=N_{X_{1}}(R)$ and $N_{M_{5} .2}(R)=N_{X_{1} .2}(R)$ for all $R \in \mathcal{R}_{0}\left(X_{1}, 2\right)$.

Let $R \in \mathcal{R}_{0}\left(X_{1}, 2\right) \backslash\left\{2^{3} .2^{8}\right\}$ and $\sigma(R): 1<\left(2^{2}\right)^{*}<Q=2^{3} .2^{8}<R$, so that $\sigma(R)^{\prime}: 1<\left(2^{2}\right)^{*}<R$. We may suppose (5.4) holds with $3^{1+10}$ replaced by $2^{3} .2^{8}$ and $\mathcal{R}_{0}\left(M_{3}, 3\right) \backslash\left\{3^{1+10}\right\}$ by $\mathcal{R}_{0}\left(X_{1}, 2\right) \backslash\left\{2^{3} .2^{8}\right\}$. Thus if $P_{1}=\left(2^{2}\right)^{*}$, then $P_{2} \notin_{G} \mathcal{R}_{0}\left(X_{1}, 2\right) \backslash\left\{2^{3} .2^{8}\right\}$ and if moreover, $P_{2}=2^{3} .2^{8}$, then $C=C(53)$.

Let $X_{2}=\left(A_{4} \times 2^{6}: A_{8}\right) .2 \leqslant M_{5}$,

$$
\mathcal{X}_{1}=\left\{2^{8}, 2^{8} \cdot 2,2^{8} \cdot 2^{4}, 2^{8} \cdot 2^{2} \cdot 2^{3}, 2^{8} \cdot 2^{3} \cdot 2^{2} \cdot 2,2^{8} \cdot 2^{4} \cdot 2^{3}\right\} \subseteq \mathcal{R}_{0}\left(M_{5}, 2\right)
$$


The Alperin weight conjecture and Dade's conjecture for the simple group $\mathrm{Fi}_{24}^{\prime}$

and $\mathcal{X}_{1}^{*}=\left\{2^{8} .2^{3}, 2^{4} .2^{3} .2^{6}, 2^{3} \cdot 2^{8} \cdot 2^{2}, 2^{3} .2^{8} .2^{3}\right\}$. We may take $\mathcal{R}_{0}\left(X_{2}, 2\right)=\mathcal{X}_{1} \cup \mathcal{X}_{1}^{*}$ such that $N_{M_{5}}(R)=N_{X_{2}}(R)$ for $R \in \mathcal{X}_{1}$ and

$$
N_{X_{2}}(R)= \begin{cases}2^{8} \cdot 2^{3} \cdot\left(L_{3}(2) \times 3\right) & \text { if } R=2^{8} \cdot 2^{3}, \\ 2^{4} \cdot 2^{3} \cdot 2^{6} \cdot\left(S_{3} \times S_{3}\right) & \text { if } R=2^{4} \cdot 2^{3} \cdot 2^{6}, \\ 2^{3} \cdot 2^{8} \cdot 2^{2} \cdot\left(S_{3} \times 3\right) & \text { if } R=2^{3} \cdot 2^{8} \cdot 2^{2}, \\ 2^{3} \cdot 2^{8} \cdot 2^{3} \cdot S_{3} & \text { if } R=2^{3} \cdot 2^{8} \cdot 2^{3} .\end{cases}
$$

Let $R \in\left\{2^{8} .2,2^{8} .2^{3} .2^{2} .2\right\} \subseteq \mathcal{X}_{1}$ and $\sigma(R): 1<\left(2^{2}\right)^{*}<Q=2^{8}<R$, so that $\sigma(R)^{\prime}: 1<\left(2^{2}\right)^{*}<R$. We may suppose (5.4) holds with $3^{1+10}$ replaced by $2^{8}$ and $\mathcal{R}_{0}\left(M_{3}, 3\right) \backslash\left\{3^{1+10}\right\}$ by $\left\{2^{8} \cdot 2,2^{8} \cdot 2^{3} \cdot 2^{2} \cdot 2\right\}$.

If $X_{3}=2^{8} .2^{3} \cdot\left(L_{3}(2) \times 3\right) \leqslant X_{2}$, then we may take

$$
\mathcal{R}_{0}\left(X_{3}, 2\right)=\left\{2^{8} \cdot 2^{3}, 2^{3} \cdot 2^{8} \cdot 2^{2}, 2^{4} \cdot 2^{3} \cdot 2^{6}, 2^{4} \cdot 2^{3} \cdot 2^{6} \cdot 2\right\} \quad \text { and }
$$

$N_{X_{3}}\left(2^{3} \cdot 2^{8} \cdot 2^{2}\right)=N_{X_{2}}\left(2^{3} \cdot 2^{8} \cdot 2^{2}\right), N_{X_{3}}\left(2^{4} \cdot 2^{3} \cdot 2^{6}\right)=2^{4} .2^{3} \cdot 2^{6} \cdot\left(S_{3} \times 3\right) \neq N_{X_{2}}\left(2^{4} \cdot 2^{3} \cdot 2^{6}\right)$, $N_{X_{3}}\left(2^{4} .2^{3} .2^{6} .2\right)=2^{4} .2^{3} .2^{6} .6$ and $N_{X_{2} .2}(R)=N_{X_{3}}(R) .2$ for all $R \in \mathcal{R}_{0}\left(X_{3}, 2\right)$.

Let $\sigma: 1<\left(2^{2}\right)^{*}<2^{8}<Q=2^{8} \cdot 2^{3}<2^{3} \cdot 2^{8} \cdot 2^{2}$, so that $\sigma^{\prime}: 1<\left(2^{2}\right)^{*}<$ $2^{8}<2^{3} \cdot 2^{8} \cdot 2^{2}$. We may suppose $(5.5)$ holds with $3^{2} \cdot 3^{4} \cdot 3^{8}$ replaced by $2^{8} \cdot 2^{3}$. Let $C^{\prime}: 1<\left(2^{2}\right)^{*}<2^{8}<2^{8} .2^{3}<2^{4} .2^{3} .2^{6}<2^{4} .2^{3} .2^{6} .2$ and $g\left(C^{\prime}\right): 1<\left(2^{2}\right)^{*}<2^{8}<$ $2^{8} .2^{3}<2^{4} .2^{3} .2^{6} .2$. Then $N\left(C^{\prime}\right)=N\left(g\left(C^{\prime}\right)\right), N_{E}\left(C^{\prime}\right)=N_{E}\left(g\left(C^{\prime}\right)\right)=N\left(C^{\prime}\right) .2$ and we may suppose $C \notin_{G}\left\{C^{\prime}, g\left(C^{\prime}\right)\right\}$.

If $X_{4}=2^{8} \cdot 2^{4} \cdot\left(S_{3} \times S_{3}\right) \cdot S_{3} \leqslant X_{2}$, then we may take

$$
\mathcal{R}_{0}\left(X_{4}, 2\right)=\left\{2^{8} .2^{4}, 2^{3} \cdot 2^{8} \cdot 2^{2}, 2^{8} \cdot 2^{2} \cdot 2^{3}, 2^{3} \cdot 2^{8} \cdot 2^{3}, 2^{8} \cdot 2^{4} .2^{3}\right\} \subseteq \mathcal{R}_{0}\left(X_{2}, 2\right)
$$

and in addition, $N_{X_{2}}(R)=N_{X_{4}}(R)$ and $N_{X_{2} \cdot 2}(R)=N_{X_{4} \cdot 2}(R)$ for all $R \in \mathcal{R}_{0}\left(X_{4}, 2\right)$.

Let $R \in \mathcal{R}_{0}\left(X_{4}, 2\right) \backslash\left\{2^{8} .2^{4}, 2^{3} .2^{8} .2^{2}\right\}$ and let $\sigma(R): 1<\left(2^{2}\right)^{*}<2^{8}<Q=$ $2^{8} .2^{4}<R$, so that $\sigma(R)^{\prime}: 1<\left(2^{2}\right)^{*}<2^{8}<R$. We may suppose (5.4) holds with $3^{1+10}$ replaced by $2^{8} \cdot 2^{4}$ and $\mathcal{R}_{0}\left(M_{3}, 3\right) \backslash\left\{3^{1+10}\right\}$ by $\mathcal{R}_{0}\left(X_{4}, 2\right) \backslash\left\{2^{8} .2^{4}, 2^{3} .2^{8} .2^{2}\right\}$.

If $X_{5}=2^{4} \cdot 2^{3} \cdot 2^{6} \cdot\left(S_{3} \times S_{3}\right) \leqslant X_{2}$, then we may take

$$
\mathcal{R}_{0}\left(X_{5}, 2\right)=\left\{2^{4} \cdot 2^{3} \cdot 2^{6}, 2^{8} \cdot 2^{3} \cdot 2^{2} \cdot 2,2^{3} \cdot 2^{8} \cdot 2^{3}, 2^{8} \cdot 2^{4} \cdot 2^{3}\right\} \subseteq \mathcal{R}_{0}\left(X_{2}, 2\right)
$$

and in addition, $N_{X_{2}}(R)=N_{X_{5}}(R)$ and $N_{X_{2} .2}(R)=N_{X_{5} .2}(R)$ for all $R \in \mathcal{R}_{0}\left(X_{5}, 2\right)$.

If $X_{6}=2^{4} .2^{3} \cdot 2^{6} .\left(S_{3} \times S_{3}\right) .3 \leqslant M_{5}$, then we may take

$$
\mathcal{R}_{0}\left(X_{6}, 2\right)=\left\{2^{4} \cdot 2^{3} \cdot 2^{6}, 2^{8} \cdot 2^{3} \cdot 2^{2} \cdot 2,2^{3} \cdot 2^{8} .2^{3}, 2^{8} \cdot 2^{4} \cdot 2^{3}\right\} \subseteq \mathcal{R}_{0}\left(M_{5}, 2\right)
$$

and in addition, $N_{M_{5}}(R)=N_{X_{6}}(R)$ and $N_{M_{5} .2}(R)=N_{X_{6} .2}(R)$ for all $R \in \mathcal{R}_{0}\left(X_{6}, 2\right)$. In particular, $N_{X_{6}}(R)={ }_{G} N_{X_{5}}(R)$ for $R \in\left\{2^{8} \cdot 2^{3} \cdot 2^{2} \cdot 2,2^{8} \cdot 2^{4} \cdot 2^{3}\right\}$ and

$$
N_{X_{6}}\left(2^{3} \cdot 2^{8} \cdot 2^{3}\right)=2^{3} \cdot 2^{8} \cdot 2^{3} \cdot 3^{2} \cdot 2 \neq_{G} N_{X_{5}}\left(2^{3} \cdot 2^{8} \cdot 2^{3}\right)=2^{3} \cdot 2^{8} \cdot 2^{3} \cdot S_{3} .
$$

Let $R \in \mathcal{R}_{0}\left(X_{6}, 2\right) \backslash\left\{2^{4} .2^{3} .2^{6}, 2^{3} .2^{8} .2^{3}\right\}$ and let $\sigma(R): 1<\left(2^{2}\right)^{*}<Q=2^{8}<$ $2^{4} .2^{3} .2^{6}<R$, so that $\sigma(R)^{\prime}: 1<\left(2^{2}\right)^{*}<2^{4} .2^{3} .2^{6}<R$. We may suppose (5.4) holds with $3^{1+10}$ replaced by $2^{8}$ and $\mathcal{R}_{0}\left(M_{3}, 3\right) \backslash\left\{3^{1+10}\right\}$ by $\mathcal{R}_{0}\left(X_{6}, 2\right) \backslash\left\{2^{4} \cdot 2^{3} \cdot 2^{6}, 2^{3} \cdot 2^{8} \cdot 2^{3}\right\}$.

Let $C^{\prime}: 1<\left(2^{2}\right)^{*}<2^{8}<2^{4} \cdot 2^{3} \cdot 2^{6}<2^{3} \cdot 2^{8} \cdot 2^{3}<2^{8} \cdot 2^{4} .2^{3}$ and $g\left(C^{\prime}\right): 1<\left(2^{2}\right)^{*}<$ $2^{4} .2^{3} .2^{6}<2^{3} .2^{8} .2^{3}<2^{8} .2^{4} .2^{3}$. Then $N\left(C^{\prime}\right)=N\left(g\left(C^{\prime}\right)\right)$ and $N_{E}\left(C^{\prime}\right)=N_{E}\left(g\left(C^{\prime}\right)\right)$ and we may suppose $C \neq_{G} C^{\prime}, g\left(C^{\prime}\right)$.

If $X_{7}=2^{8} \cdot 2^{3} \cdot\left(L_{3}(2) \times S_{3}\right) \leqslant M_{5}$, then we may take $\mathcal{R}_{0}\left(X_{7}, 2\right)=$

$$
\left\{2^{8} \cdot 2^{3}, 2^{4} \cdot 2^{4} \cdot 2^{4}, 2^{3} \cdot 2^{8} \cdot 2^{2}, 2^{4} \cdot 2^{3} \cdot 2^{6}, 2^{3} \cdot 2^{8} \cdot 2^{3}, 2^{3} \cdot 2^{8} \cdot 2^{2} \cdot 2,2^{8} \cdot 2^{3} \cdot 2^{2} \cdot 2,2^{8} \cdot 2^{4} \cdot 2^{3}\right\}
$$


and $N_{X_{7}}(R)=N_{M_{5}}(R)$ for $R \in \mathcal{R}_{0}\left(X_{7}, 2\right) \backslash\left\{2^{4} .2^{3} .2^{6}, 2^{3} .2^{8} .2^{3}\right\}, N_{X_{7}}(R)={ }_{G} N_{X_{2}}(R)$ for $R \in\left\{2^{4} .2^{3} .2^{6}, 2^{3} .2^{8} .2^{3}\right\}$ and $N_{X_{7} .2}(R)=N_{X_{7}}(R) .2$ for all $R \in \mathcal{R}_{0}\left(X_{7}, 2\right)$.

Let $\sigma: 1<\left(2^{2}\right)^{*}<Q=2^{8} .2^{3}<2^{4} .2^{4} .2^{4}$, so that $\sigma^{\prime}: 1<\left(2^{2}\right)^{*}<2^{4} .2^{4} .2^{4}$. We may suppose (5.5) holds with $3^{2} \cdot 3^{4} \cdot 3^{8}$ replaced by $2^{8} \cdot 2^{3}$.

We may suppose $X_{5}=2^{4} \cdot 2^{3} \cdot 2^{6} \cdot\left(S_{3} \times S_{3}\right) \leqslant X_{7}$, so that $\mathcal{R}_{0}\left(X_{5}, 2\right) \subseteq \mathcal{R}_{0}\left(X_{7}, 2\right)$ and $N_{X_{5}}(R)=N_{X_{7}}(R)$. Let $R \in \mathcal{R}_{0}\left(X_{5}, 2\right) \backslash\left\{2^{4} .2^{3} .2^{6}\right\}$ and let $\sigma(R): 1<\left(2^{2}\right)^{*}<$ $2^{8} .2^{3}<Q=2^{4} .2^{3} .2^{6}<R$, so that $\sigma(R)^{\prime}: 1<\left(2^{2}\right)^{*}<2^{8} .2^{3}<R$. We may suppose (5.4) holds with $3^{1+10}$ replaced by $2^{4} .2^{3} .2^{6}$ and $\mathcal{R}_{0}\left(M_{3}, 3\right) \backslash\left\{3^{1+10}\right\}$ by $\mathcal{R}_{0}\left(X_{5}, 2\right) \backslash\left\{2^{4} .2^{3} .2^{6}\right\}$.

If $X_{8}=2^{3} \cdot 2^{8} \cdot 2^{2} \cdot\left(S_{3} \times S_{3}\right) \leqslant X_{7}$, then we may take

$$
\mathcal{R}_{0}\left(X_{8}, 2\right)=\left\{2^{3} \cdot 2^{8} \cdot 2^{2}, 2^{3} \cdot 2^{8} \cdot 2^{3}, 2^{3} \cdot 2^{8} \cdot 2^{2} \cdot 2,2^{8} \cdot 2^{4} \cdot 2^{3}\right\} \subseteq \mathcal{R}_{0}\left(X_{7}, 2\right)
$$

and $N_{X_{8}}(R)=N_{X_{7}}(R)$ and $N_{X_{8} .2}(R)=N_{X_{7} .2}(R)$ for all $R \in \mathcal{R}_{0}\left(X_{8}, 2\right)$.

Let $\sigma: 1<\left(2^{2}\right)^{*}<2^{8} .2^{3}<Q=2^{3} .2^{8} .2^{2}<2^{3} .2^{8} .2^{2} .2$, so that $\sigma^{\prime}: 1<\left(2^{2}\right)^{*}<$ $2^{8} .2^{3}<2^{3} .2^{8} .2^{2} .2$. We may suppose (5.5) holds with $3^{2} \cdot 3^{4} .3^{8}$ replaced by $2^{3} \cdot 2^{8} \cdot 2^{2}$.

Let $C^{\prime}: 1<\left(2^{2}\right)^{*}<2^{8} .2^{3}<2^{3} .2^{8} .2^{2}<2^{3} .2^{8} .2^{3}<2^{8} .2^{4} .2^{3}$ and $g\left(C^{\prime}\right): 1<$ $\left(2^{2}\right)^{*}<2^{8} .2^{3}<2^{3} .2^{8} \cdot 2^{2}<2^{8} \cdot 2^{4} \cdot 2^{3}$. Then $N\left(C^{\prime}\right)=N\left(g\left(C^{\prime}\right)\right)$ and $N_{E}\left(C^{\prime}\right)=$ $N_{E}\left(g\left(C^{\prime}\right)\right)$ and we may suppose $C \neq_{G} C^{\prime}, g\left(C^{\prime}\right)$.

It follows that if $P_{1}=\left(2^{2}\right)^{*}$, then $C \in_{G}\{C(j): 53 \leqslant j \leqslant 68\}$.

Case (2.4) Let $\mathcal{Y}_{1}=\left\{2^{3+12} .2^{2}, 2^{3} \cdot 2^{3} \cdot 2^{6} .2^{5}, 2^{6+8} .2^{3} .2^{2}\right\} \subseteq \mathcal{R}_{0}\left(M_{6}, 2\right), R \in \mathcal{Y}_{1}$ and $\sigma(R): 1<Q=2^{3+12}<R$, so that $\sigma(R)^{\prime}: 1<R$. We may suppose (5.4) holds with $3^{1+10}$ replaced by $2^{3+12}$ and $\mathcal{R}_{0}\left(M_{3}, 3\right) \backslash\left\{3^{1+10}\right\}$ by $\mathcal{Y}_{1}$. Thus we may suppose $P_{1} \notin_{G} \mathcal{Y}_{1}$ and if $P_{1}=2^{3+12}$, then $P_{2} \notin \mathcal{Y}_{1}$.

If $Y_{1}=2^{3} \cdot 2^{6} \cdot 2^{8}$. $\left(S_{4} \times L_{3}(2)\right) \leqslant M_{6}$, then we may take $\mathcal{R}_{0}\left(Y_{1}, 2\right)=$ $\left\{2^{3} \cdot 2^{6} \cdot 2^{8}, 2^{11} \cdot 2^{3} \cdot 2^{4}, 2^{11} \cdot 2^{4} \cdot 2^{4}, 2^{11} \cdot 2^{2} \cdot 2^{6}, 2^{11} \cdot 2^{2} \cdot 2^{3} \cdot 2^{4}, 2^{1+12} \cdot 2^{4} \cdot 2^{2} \cdot 2,2^{6+8} \cdot 2^{3} \cdot 2^{3}, S\right\}$

as a subset of $\mathcal{R}_{0}\left(M_{6}, 2\right)$, so $N_{M_{6}}(R)=N_{Y_{1}}(R)$ and $N_{M_{6} .2}(R)=N_{N_{M_{6} .2}\left(Y_{1}\right)}(R)$ for $R \in \mathcal{R}_{0}\left(Y_{1}, 2\right)$.

Let $R \in \mathcal{R}_{0}\left(Y_{1}, 2\right) \backslash\left\{2^{3} .2^{6} .2^{8}\right\}$, and $\sigma(R): 1<2^{3+12}<Q=2^{3} .2^{6} .2^{8}<R$, so that $\sigma(R)^{\prime}: 1<2^{3+12}<R$. A similar proof to that of Case (1) shows that we may suppose (5.4) holds with $3^{1+10}$ replaced by $2^{3} \cdot 2^{6} \cdot 2^{8}$ and $\mathcal{R}_{0}\left(M_{3}, 3\right) \backslash\left\{3^{1+10}\right\}$ by $\mathcal{R}_{0}\left(Y_{1}, 2\right) \backslash\left\{2^{3} \cdot 2^{6} \cdot 2^{8}\right\}$.

If $Y_{2}=2^{1+12} \cdot 2^{4} \cdot\left(S_{4} \times A_{6}\right) \leqslant M_{6}$, then we may take $\mathcal{R}_{0}\left(Y_{2}, 2\right)=$

$$
\begin{aligned}
\left\{2^{1+12} \cdot 2^{4}, 2^{1+12} \cdot 2^{4} \cdot 2,2^{6+8} \cdot 2^{4} \cdot 2,2^{11} \cdot 2^{4} \cdot 2^{4},\right. \\
\left.2^{11} \cdot 2^{2} \cdot 2^{3} \cdot 2^{4}, 2^{1+12} \cdot 2^{4} \cdot 2^{2} \cdot 2,2^{3+12} \cdot\left(D_{8} \times 2^{2}\right), S\right\}
\end{aligned}
$$

as a subset of $\mathcal{R}_{0}\left(M_{6}, 2\right)$, so $N_{M_{6}}(R)=N_{Y_{2}}(R)$ and $N_{M_{6} .2}(R)=N_{N_{M_{6} .2}\left(Y_{2}\right)}(R)$ for $R \in \mathcal{R}_{0}\left(Y_{2}, 2\right)$.

Let $\mathcal{Y}_{2}:=\left\{2^{1+12} \cdot 2^{4} .2,2^{6+8} .2^{4} .2,2^{3+12} \cdot\left(D_{8} \times 2^{2}\right)\right\} \subseteq \mathcal{R}_{0}\left(Y_{2}, 2\right), R \in \mathcal{Y}_{2}$, and $\sigma(R): 1<2^{3+12}<Q=2^{1+12} .2^{4}<R$, so that $\sigma(R)^{\prime}: 1<2^{3+12}<R$. A similar proof to that of Case (1) shows that we may suppose (5.4) holds with $3^{1+10}$ replaced by $2^{1+12} \cdot 2^{4}$ and $\mathcal{R}_{0}\left(M_{3}, 3\right) \backslash\left\{3^{1+10}\right\}$ by $\mathcal{Y}_{2}$.

If $Y_{3}=2^{11} \cdot 2^{4} \cdot 2^{4} \cdot\left(S_{3} \times S_{3}\right) \leqslant Y_{2}$, then we may take

$$
\mathcal{R}_{0}\left(Y_{3}, 2\right)=\left\{2^{11} \cdot 2^{4} \cdot 2^{4}, 2^{11} \cdot 2^{2} \cdot 2^{3} \cdot 2^{4}, 2^{1+12} \cdot 2^{4} \cdot 2^{2}, S\right\} \subseteq \mathcal{R}_{0}\left(M_{6}, 2\right),
$$

so that $N_{M_{6}}(R)=N_{Y_{2}}(R)=N_{Y_{3}}(R)$ and $N_{M_{6} .2}(R)=N_{N_{M_{6} .2}\left(Y_{3}\right)}(R)$ for $R \in$ $\mathcal{R}_{0}\left(Y_{3}, 2\right)$. 
The Alperin weight conjecture and Dade's conjecture for the simple group $\mathrm{Fi}_{24}^{\prime}$

Let $R \in \mathcal{R}_{0}\left(Y_{3}, 2\right) \backslash\left\{2^{11} \cdot 2^{4} .2^{4}\right\}$, and $\sigma(R): 1<2^{3+12}<2^{1+12} \cdot 2^{4}<Q=$ $2^{11} .2^{4} .2^{4}<R$, so that $\sigma(R)^{\prime}: 1<2^{3+12}<2^{1+12} \cdot 2^{4}<R$. A similar proof to that of Case (1) shows that we may suppose (5.4) holds with $3^{1+10}$ replaced by $2^{11} \cdot 2^{4} \cdot 2^{4}$ and $\mathcal{R}_{0}\left(M_{3}, 3\right) \backslash\left\{3^{1+10}\right\}$ by $\mathcal{R}_{0}\left(Y_{3}, 2\right) \backslash\left\{2^{11} \cdot 2^{4} \cdot 2^{4}\right\}$.

It follows that if $P_{1}=2^{3+12}$, then then $C \in_{G}\{C(i): 69 \leqslant i \leqslant 73\}$.

Case (2.5) Let $\sigma: 1<Q=2^{6+8}<2^{6+8} \cdot 2^{3}$, so that $\sigma^{\prime}: 1<2^{6+8} .2^{3}$. A similar proof to that of Case (1) shows that we may suppose (5.5) holds with $3^{2} .3^{4} .3^{8}$ replaced by $2^{6+8}$. Thus we may suppose $P_{1} \neq \neq_{G} 2^{6+8} \cdot 2^{3}$ and if $P_{1}=2^{6+8}$, then $P_{2} \neq 2^{6+8} \cdot 2^{3}$.

If $Z_{1}=2^{11} \cdot 2^{4} \cdot A_{8} \leqslant M_{7}$, then we may take $\mathcal{R}_{0}\left(Z_{1}, 2\right)=$

$$
\left\{2^{11} \cdot 2^{4}, 2^{11} \cdot 2^{1+6}, 2^{11} \cdot 2^{3} \cdot 2^{4}, 2^{1+12} \cdot 2 \cdot 2^{4} \cdot 2,2^{6+8} \cdot 2^{4} \cdot 2^{2}, 2^{6+8} \cdot 2^{3} \cdot 2^{3}, 2^{11} \cdot 2^{2} \cdot 2^{3} \cdot 2^{4}, S\right\}
$$

as a subset of $\mathcal{R}_{0}\left(M_{7}, 2\right)$, so that $N_{M_{7}}(R)=N_{Z_{1}}(R)$ and $N_{M_{7} .2}(R)=N_{N_{M_{7} .2}\left(Z_{1}\right)}(R)$.

Let $R \in \mathcal{R}_{0}\left(Z_{1}, 2\right) \backslash\left\{2^{11} .2^{4}\right\}$, and $\sigma(R): 1<2^{6+8}<Q=2^{11} .2^{4}<R$, so that $\sigma(R)^{\prime}: 1<2^{6+8}<R$. A similar proof to that of Case (1) shows that we may suppose (5.4) holds with $3^{1+10}$ replaced by $2^{11} \cdot 2^{4}$ and $\mathcal{R}_{0}\left(M_{3}, 3\right) \backslash\left\{3^{1+10}\right\}$ by $\mathcal{R}_{0}\left(Z_{1}, 2\right) \backslash\left\{2^{11} \cdot 2^{4}\right\}$

If $Z_{2}=2^{3} \cdot 2^{3} \cdot 2^{6} \cdot 2^{5} \cdot\left(L_{3}(2) \times S_{3}\right) \leqslant M_{7}$, then we may take

$$
\begin{aligned}
\mathcal{R}_{0}\left(Z_{2}, 2\right)= & \left\{2^{3} \cdot 2^{3} \cdot 2^{6} \cdot 2^{5}, 2^{11} \cdot 2^{3} \cdot 2^{4}, 2^{6+8} \cdot 2^{4} \cdot 2,2^{6+8} \cdot 2^{3} \cdot 2^{2},\right. \\
& \left.2^{11} \cdot 2^{2} \cdot 2^{3} \cdot 2^{4}, 2^{3+12}\left(D_{8} \times 2^{2}\right), 2^{6+8} \cdot 2^{3} \cdot 2^{3}, S\right\} \subseteq \mathcal{R}_{0}\left(M_{7}, 2\right)
\end{aligned}
$$

so that $N_{M_{7}}(R)=N_{Z_{2}}(R)$ and $N_{M_{7} \cdot 2}(R)=N_{N_{M_{7} \cdot 2}\left(Z_{2}\right)}(R)$.

Let $\mathcal{Z}_{1}:=\left\{2^{6+8} .2^{4} .2,2^{6+8} .2^{3} .2^{2}, 2^{3+12} .\left(D_{8} \times 2^{2}\right)\right\} \subseteq \mathcal{R}_{0}\left(Z_{2}, 2\right), R \in \mathcal{Z}_{1}$, and $\sigma(R): 1<2^{6+8}<Q=2^{3} \cdot 2^{3} \cdot 2^{6} \cdot 2^{5}<R$, so that $\sigma(R)^{\prime}: 1<2^{6+8}<R$. A similar proof to that of Case (1) shows that we may suppose (5.4) holds with $3^{1+10}$ replaced by $2^{3} \cdot 2^{3} \cdot 2^{6} \cdot 2^{5}$ and $\mathcal{R}_{0}\left(M_{3}, 3\right) \backslash\left\{3^{1+10}\right\}$ by $\mathcal{Z}_{1}$.

If $Z_{3}=2^{11} \cdot 2^{3} \cdot 2^{4} \cdot L_{3}(2) \leqslant Z_{2}$, then we may take

$$
\mathcal{R}_{0}\left(Z_{3}, 2\right)=\left\{2^{11} \cdot 2^{3} \cdot 2^{4}, 2^{11} \cdot 2^{2} \cdot 2^{3} \cdot 2^{4}, 2^{6+8} \cdot 2^{3} .2^{3}, S\right\} \subseteq \mathcal{R}_{0}\left(Z_{2}, 2\right)
$$

so that $N_{M_{7}}(R)=N_{Z_{2}}(R)=N_{Z_{3}}(R)$ and $N_{M_{7} \cdot 2}(R)=N_{N_{M_{7} \cdot 2\left(Z_{3}\right)}}(R)$.

Let $R \in \mathcal{R}_{0}\left(Z_{3}, 2\right) \backslash\left\{2^{11} .2^{3} .2^{4}\right\}$, and $\sigma(R): 1<2^{6+8}<2^{3} .2^{6} .2^{5}<Q=$ $2^{11} .2^{3} .2^{4}<R$, so that $\sigma(R)^{\prime}: 1<2^{6+8}<2^{3} .2^{6} .2^{5}<R$. A similar proof to that of Case (1) shows that we may suppose (5.4) holds with $3^{1+10}$ replaced by $2^{11} .2^{3} .2^{4}$ and $\mathcal{R}_{0}\left(M_{3}, 3\right) \backslash\left\{3^{1+10}\right\}$ by $\mathcal{R}_{0}\left(Z_{3}, 2\right) \backslash\left\{2^{11} \cdot 2^{3} .2^{4}\right\}$.

If $Z_{4}=2^{1+12} \cdot 2.2^{4} \cdot\left(S_{3} \times S_{3} \times S_{3}\right) \leqslant M_{7}$, then we may take

$$
\begin{aligned}
\mathcal{R}_{0}\left(Z_{4}, 2\right)= & \left\{2^{1+12} \cdot 2.2^{4}, 2^{6+8} \cdot 2^{4} \cdot 2,2^{1+12} \cdot 2 \cdot 2^{4} \cdot 2,2^{1+12} \cdot 2^{2} \cdot 2^{4}, 2^{6+8} \cdot 2^{4} .2^{2},\right. \\
& \left.2^{3+12}\left(D_{8} \times 2^{2}\right), 2^{11} \cdot 2^{2} \cdot 2^{3} \cdot 2^{4}, S\right\} \subseteq \mathcal{R}_{0}\left(M_{7}, 2\right)
\end{aligned}
$$

so that $N_{M_{7}}(R)=N_{Z_{4}}(R)$ and $N_{M_{7} .2}(R)=N_{N_{M_{7} .2}\left(Z_{4}\right)}(R)$.

Let $\sigma: 1<2^{6+8}<Q=2^{1+12} \cdot 2.2^{4}<2^{1+12} \cdot 2^{2} \cdot 2^{4}$, so that $\sigma^{\prime}: 1<2^{6+8}<$ $2^{1+12} \cdot 2^{2} \cdot 2^{4}$. A similar proof to that of Case (1) shows that we may suppose (5.5) holds with $3^{2} \cdot 3^{4} \cdot 3^{8}$ replaced by $2^{1+12} \cdot 2 \cdot 2^{4}$.

If $Z_{5}=2^{1+12} \cdot 2 \cdot 2^{4} \cdot 2 \cdot\left(S_{3} \times S_{3}\right) \leqslant Z_{4}$, then we may take

$$
\mathcal{R}_{0}\left(Z_{5}, 2\right)=\left\{2^{1+12} \cdot 2.2^{4} \cdot 2,2^{6+8} \cdot 2^{4} \cdot 2^{2}, 2^{11} \cdot 2^{2} \cdot 2^{3} \cdot 2^{4}, S\right\} \subseteq \mathcal{R}_{0}\left(Z_{4}, 2\right)
$$

so that $N_{M_{7}}(R)=N_{Z_{5}}(R)=N_{Z_{4}}(R)$ and $N_{M_{7} \cdot 2}(R)=N_{N_{M_{7} \cdot 2}\left(Z_{5}\right)}(R)$. 
Let $R \in \mathcal{R}_{0}\left(Z_{5}, 2\right) \backslash\left\{2^{1+12} \cdot 2.2^{4} .2\right\}$, and $\sigma(R): 1<2^{6+8}<2^{1+12} \cdot 2.2^{4}<Q=$ $2^{1+12} .2 .2^{4} .2<R$, so that $\sigma(R)^{\prime}: 1<2^{6+8}<2^{1+12} \cdot 2.2^{4}<R$. A similar proof to that of Case (1) shows that we may suppose (5.5) holds with $3^{2} .3^{4} .3^{8}$ replaced by $2^{1+12} \cdot 2.2^{4} .2$ and $\mathcal{R}_{0}\left(M_{3}, 3\right) \backslash\left\{3^{1+10}\right\}$ by $\mathcal{R}_{0}\left(Z_{5}, 2\right) \backslash\left\{2^{1+12} \cdot 2.2^{4} .2\right\}$.

If $Z_{6}=2^{6+8} \cdot 2^{4} \cdot 2 \cdot\left(S_{3} \times S_{3}\right) \leqslant Z_{4}$, then we may suppose

$$
\mathcal{R}_{0}\left(Z_{6}, 2\right)=\left\{2^{6+8} \cdot 2^{4} \cdot 2,2^{11} \cdot 2^{2} \cdot 2^{3} \cdot 2^{4}, 2^{3+12}\left(D_{8} \times 2^{2}\right), S\right\} \subseteq \mathcal{R}_{0}\left(Z_{4}, 2\right)
$$

so that $N_{M_{7}}(R)=N_{Z_{4}}(R)=N_{Z_{6}}(R)$ and $N_{M_{7} .2}(R)=N_{N_{M_{7} .2}\left(Z_{6}\right)}(R)$.

Let $\sigma: 1<2^{6+8}<2^{1+12} .2 .2^{4}<Q=2^{6+8} .2^{4} .2<2^{3+12}\left(D_{8} \times 2^{2}\right)$, so that $\sigma^{\prime}: 1<2^{6+8}<2^{1+12} \cdot 2.2^{4}<2^{3+12}\left(D_{8} \times 2^{2}\right)$. A similar proof to that of Case (1) shows that we may suppose (5.5) holds with $3^{2} \cdot 3^{4} \cdot 3^{8}$ replaced by $2^{6+8} \cdot 2^{4} \cdot 2$.

Let $C^{\prime}: 1<2^{6+8}<2^{1+12} .2 .2^{4}<2^{6+8} .2^{4} .2<2^{11} .2^{2} .2^{3} .2^{4}<S$ and $g\left(C^{\prime}\right)$ : $1<2^{6+8}<2^{1+12} .2 .2^{4}<2^{6+8} .2^{4} .2<S$. Then $N\left(C^{\prime}\right)=N\left(g\left(C^{\prime}\right)\right), N_{E}\left(C^{\prime}\right)=$ $N_{E}\left(g\left(C^{\prime}\right)\right)=N\left(C^{\prime}\right) .2$ and we may suppose $C \notin_{G}\left\{C^{\prime}, g\left(C^{\prime}\right)\right\}$.

It follows that if $P_{1}=2^{6+8}$, then

$$
C \in_{G}\{C(j): 81 \leqslant j \leqslant 88\} .
$$

Case (2.6) If $P_{1}=2^{8}$, then $N\left(P_{1}\right)=M_{8}=2^{8} \cdot O_{8}^{-}(2)$. Applying the Borel-Tits theorem to $O_{8}^{-}(2)$, it follows that $C \in_{G}\{C(j): 73 \leqslant j \leqslant 80\}$.

Case (2.7) Let $\sigma: 1<2<Q=\left(2^{2}\right)^{*}<D_{8}$, so that $\sigma^{\prime}: 1<2<D_{8}$, where $D_{8} \in \mathcal{R}_{0}\left(T_{1}, 2\right)$. A similar proof to that of Case (1) shows that we may suppose (5.5) holds with $3^{2} .3^{4} .3^{8}$ replaced by $\left(2^{2}\right)^{*}$. Similarly, if $\sigma: 1<Q=2<2^{2}<D_{8}$ with $\sigma^{\prime}: 1<2^{2}<D_{8}$, then (5.5) holds with $3^{2} .3^{4} .3^{8}$ replaced by 2 . Thus if $P_{1}=2$, then we may suppose $P_{2} \neq_{G} D_{8}$ and if moreover, $P_{2} \in\left\{2^{2},\left(2^{2}\right)^{*}\right\}$, then we may suppose $P_{3} \neq_{G} D_{8}$.

Let $R \in \mathcal{R}_{0}\left(T_{2}, 2\right) \backslash\left\{2^{11}\right\}$, and $\sigma(R): 1<2<Q=2^{11}<R$, so that $\sigma(R)^{\prime}: 1<$ $2<R$. A similar proof to that of Case (1) shows that we may suppose (5.4) holds with $3^{1+10}$ replaced by $2^{11}$ and $\mathcal{R}_{0}\left(M_{3}, 3\right) \backslash\left\{3^{1+10}\right\}$ by $\mathcal{R}_{0}\left(T_{2}, 2\right) \backslash\left\{2^{11}\right\}$.

Let $\mathcal{T}_{1}:=\left\{2^{8} .2^{5}, 2^{2} \cdot 2^{10} \cdot 2 \cdot 2^{4}, 2^{6+8} . D_{8} .2\right\} \subseteq \mathcal{R}_{0}\left(T_{4}, 2\right), R \in \mathcal{T}_{1}$, and $\sigma(R): 1<$ $2<Q=2^{2} .2^{10}<R$, so that $\sigma(R)^{\prime}: 1<2<R$. A similar proof to that of Case (1) shows that we may suppose (5.4) holds with $3^{1+10}$ replaced by $2^{2} .2^{10}$ and $\mathcal{R}_{0}\left(M_{3}, 3\right) \backslash\left\{3^{1+10}\right\}$ by $\mathcal{T}_{1}$.

If $T_{7}=2^{11} \cdot 2^{4} \cdot 2 . S_{5} \leqslant T_{4}$, then we may suppose

$$
\mathcal{R}_{0}\left(T_{7}, 2\right)=\left\{2^{11} \cdot 2^{4} \cdot 2,2^{11} \cdot 2^{2} \cdot 2^{3} \cdot 2,2^{11} \cdot 2^{2} \cdot 2^{4} \cdot 2,2^{6+8} \cdot 2^{3} \cdot 2^{2}\right\} \subseteq \mathcal{R}_{0}\left(T_{4}, 2\right)
$$

so that $N_{M_{1}}(R)=N_{T_{7}}(R)=N_{T_{4}}(R)$ and $N_{M_{1} .2}(R)=N_{N_{M_{1} .2}\left(T_{7}\right)}(R)$.

Let $R \in \mathcal{R}_{0}\left(T_{7}, 2\right) \backslash\left\{2^{11} .2^{4} .2\right\}$, and $\sigma(R): 1<2<2^{2} .2^{10}<Q=2^{11} .2^{4} .2<R$, so that $\sigma(R)^{\prime}: 1<2<2^{2} .2^{10}<R$. A similar proof to that of Case (1) shows that we may suppose (5.4) holds with $3^{1+10}$ replaced by $2^{11} .2^{4} .2$ and $\mathcal{R}_{0}\left(M_{3}, 3\right) \backslash\left\{3^{1+10}\right\}$ by $\mathcal{R}_{0}\left(T_{7}, 2\right) \backslash\left\{2^{11} .2^{4} .2\right\}$.

Let $\sigma: 1<2<Q=2^{6+8}<2^{6+8} .2^{3}$, so that $\sigma^{\prime}: 1<2<2^{6+8} .2^{3}$, where $2^{6+8} .2^{3} \in \mathcal{R}_{0}\left(T_{5}, 2\right)$. A similar proof to that of Case (1) shows that we may suppose (5.5) holds with $3^{2} .3^{4} .3^{8}$ replaced by $2^{6+8}$.

If $T_{8}=2^{11} \cdot 2^{4} . S_{6} \leqslant T_{5}$, then we may suppose

$$
\mathcal{R}_{0}\left(T_{8}, 2\right)=\left\{2^{11} \cdot 2^{4}, 2^{11} \cdot 2^{2} \cdot 2^{4} \cdot 2,2^{6+8} \cdot 2^{3} \cdot 2,2^{6+8} \cdot 2^{3} \cdot 2^{2}\right\} \subseteq \mathcal{R}_{0}\left(T_{5}, 2\right)
$$

so that $N_{M_{1}}(R)=N_{T_{8}}(R)=N_{T_{5}}(R)$ and $N_{M_{1} .2}(R)=N_{N_{M_{1} .2}\left(T_{8}\right)}(R)$. 
Let $R \in \mathcal{R}_{0}\left(T_{8}, 2\right) \backslash\left\{2^{11} .2^{4}\right\}$ and $\sigma(R): 1<2<2^{6+8}<Q=2^{11} \cdot 2^{4}<R$, so that $\sigma(R)^{\prime}: 1<2<2^{6+8}<R$. A similar proof to that of Case (1) shows that we may suppose (5.4) holds with $3^{1+10}$ replaced by $2^{11} \cdot 2^{4}$ and $\mathcal{R}_{0}\left(M_{3}, 3\right) \backslash\left\{3^{1+10}\right\}$ by $\mathcal{R}_{0}\left(T_{8}, 2\right) \backslash\left\{2^{11} \cdot 2^{4}\right\}$.

If $T_{9}=2^{2} \cdot 2^{10} \cdot 2 \cdot 2^{4} \cdot\left(S_{3} \times S_{3}\right) \leqslant T_{5}$, then we may suppose

$$
\mathcal{R}_{0}\left(T_{9}, 2\right)=\left\{2^{2} .2^{10} \cdot 2.2^{4}, 2^{11} \cdot 2^{2} \cdot 2^{4} .2,2^{6+8} \cdot D_{8} \cdot 2,2^{6+8} \cdot 2^{3} .2^{2}\right\} \subseteq \mathcal{R}_{0}\left(T_{5}, 2\right)
$$

so that $N_{M_{1}}(R)=N_{T_{9}}(R)=N_{T_{5}}(R)$ and $N_{M_{1} .2}(R)=N_{N_{M_{1} .2}\left(T_{9}\right)}(R)$.

Let $\sigma: 1<2<2^{6+8}<Q=2^{2} \cdot 2^{10} \cdot 2.2^{4}<2^{6+8} . D_{8} .2$, so that $\sigma^{\prime}: 1<2<2^{6+8}<$ $2^{6+8} . D_{8} .2$. A similar proof to that of Case (1) shows that we may suppose (5.5) holds with $3^{2} \cdot 3^{4} \cdot 3^{8}$ replaced by $2^{2} \cdot 2^{10} \cdot 2 \cdot 2^{4}$.

Let $C^{\prime}: 1<2<2^{6+8}<2^{2} .2^{10} .2 .2^{4}<2^{11} .2^{2} .2^{4} .2<2^{6+8} .2^{3} .2^{2}$ and $g\left(C^{\prime}\right)$ : $1<2<2^{6+8}<2^{2} \cdot 2^{10} \cdot 2 \cdot 2^{4}<2^{6+8} \cdot 2^{3} \cdot 2^{2}$. Then $N\left(C^{\prime}\right)=N\left(g\left(C^{\prime}\right)\right), N_{E}\left(C^{\prime}\right)=$ $N_{E}\left(g\left(C^{\prime}\right)\right)=N\left(C^{\prime}\right) .2$ and we may suppose $C \notin_{G}\left\{C^{\prime}, g\left(C^{\prime}\right)\right\}$. Thus if $P_{1}=2$ and $P_{2}=2^{6+8}$, then $C \in_{G}\{C(j): 38 \leqslant j \leqslant 41\}$.

If $P_{1}=2$ and $P_{2}=2^{8} \in \mathcal{R}_{0}\left(T_{3}, 2\right)$, then $N_{M_{1}}\left(P_{2}\right)=T_{3}=2^{8} \cdot S_{6}(2)$. Applying the Borel-Tits Theorem to $S_{6}(2)$, it follows that $C \in_{G}\{C(j): 27 \leqslant j \leqslant 34\}$.

Let $T_{10}=2^{8} . S_{8} \leqslant T_{6}, \mathcal{T}_{4}=\left\{2^{8} .2,2^{8} \cdot 2^{4}, 2^{8} \cdot 2^{4} \cdot 2,2^{4} \cdot 2^{4} \cdot 2^{4} \cdot 2^{2}, 2^{3} .2^{8} . D_{8} .2\right\}$ and $\mathcal{T}_{4}^{*}=\left\{2^{8} \cdot 2^{3}, 2^{8} \cdot 2^{2} \cdot 2^{3}\right\}$. Then we may suppose

$$
\mathcal{R}_{0}\left(T_{10}, 2\right)=\left\{2^{8}\right\} \cup \mathcal{T}_{4} \cup \mathcal{T}_{4}^{*}
$$

and in addition, $N_{T_{10}}(R)=N_{T_{6}}(R), N_{T_{6} .2}(R)=N_{N_{T_{6} .2}\left(T_{10}\right)}(R)$ for $R \in \mathcal{T}_{4}$, and $N_{T_{10}}\left(2^{8} \cdot 2^{3}\right)=2^{8} \cdot 2^{3} \cdot L_{3}(2), N_{T_{10}}\left(2^{8} \cdot 2^{2} \cdot 2^{3}\right)=2^{8} \cdot 2^{2} \cdot 2^{3} \cdot S_{3}$.

Let $R \in \mathcal{T}_{4}$, and $\sigma(R): 1<2<\left(2^{2}\right)^{*}<Q=2^{8}<R$, so that $\sigma(R)^{\prime}: 1<2<$ $\left(2^{2}\right)^{*}<R$. A similar proof to that of Case (1) shows that we may suppose $(5.4)$ holds with $3^{1+10}$ replaced by $2^{8}$ and $\mathcal{R}_{0}\left(M_{3}, 3\right) \backslash\left\{3^{1+10}\right\}$ by $\mathcal{T}_{4}$.

If $T_{11}=2^{8} \cdot 2^{3} \cdot L_{3}(2) \leqslant T_{10} \leqslant T_{6}$, then we may suppose

$$
\mathcal{R}_{0}\left(T_{11}, 2\right)=\left\{2^{8} \cdot 2^{3}, 2^{8} \cdot 2^{2} \cdot 2^{3}, 2^{8} \cdot 2^{3} \cdot 2^{2}, 2^{8} \cdot 2^{3} \cdot D_{8}\right\} \subseteq \mathcal{R}_{0}\left(T_{10}, 2\right)
$$

so that $N_{T_{10}}(R)=N_{T_{11}}(R)$ and $N_{T_{10} .2}(R)=N_{N_{T_{10} .2}\left(T_{11}\right)}(R)$.

Let $\sigma: 1<2<\left(2^{2}\right)^{*}<2^{8}<Q=2^{8} .2^{3}<2^{8} .2^{2} .2^{3}$, so that $\sigma^{\prime}: 1<2<\left(2^{2}\right)^{*}<$ $2^{8}<2^{8} \cdot 2^{2} \cdot 2^{3}$. A similar proof to that of Case (1) shows that we may suppose (5.5) holds with $3^{2} \cdot 3^{4} \cdot 3^{8}$ replaced by $2^{8} \cdot 2^{3}$.

Let $C^{\prime}: 1<2<\left(2^{2}\right)^{*}<2^{8}<2^{8} .2^{3}<2^{8} .2^{3} .2^{2}<2^{8} .2^{3} . D_{8}$ and $g\left(C^{\prime}\right): 1<2<$ $\left(2^{2}\right)^{*}<2^{8}<2^{8} \cdot 2^{3}<2^{8} \cdot 2^{3} \cdot D_{8}$. Then $N\left(C^{\prime}\right)=N\left(g\left(C^{\prime}\right)\right), N_{E}\left(C^{\prime}\right)=N_{E}\left(g\left(C^{\prime}\right)\right)=$ $N\left(C^{\prime}\right) .2$ and we may suppose $C \notin_{G}\left\{C^{\prime}, g\left(C^{\prime}\right)\right\}$. Thus if $P_{1}=2, P_{2}=\left(2^{2}\right)^{*}$ and $P_{3}=2^{8}$, then $C \in_{G}\{C(12), C(13), C(14)\}$.

Let $T_{12}=2^{3} .2^{8} .3 .\left(S_{3} \times S_{3} \times S_{3}\right) \cdot 2 \leqslant T_{6}, \mathcal{T}_{5}=\left\{2^{3} .2^{8} .2,2^{4} .2^{3} .2^{6} .2,2^{3} .2^{8} . D_{8}\right\}$ and $\mathcal{T}_{5}^{*}=\left\{2^{8} \cdot 2^{4}, 2^{8} \cdot 2^{4} \cdot 2,2^{3} \cdot 2^{8} \cdot D_{8} \cdot 2\right\}$. Then we may suppose

$$
\mathcal{R}_{0}\left(T_{12}, 2\right)=\left\{2^{3} .2^{8}\right\} \cup \mathcal{T}_{5} \cup \mathcal{T}_{5}^{*}
$$

and in addition, $N_{T_{12}}(R)=N_{T_{6}}(R), N_{T_{6} .2}(R)=N_{N_{T_{6} .2}\left(T_{12}\right)}(R)$ for $R \in \mathcal{R}_{0}\left(T_{12}, 2\right)$.

Let $R \in \mathcal{T}_{5}$, and $\sigma(R): 1<2<\left(2^{2}\right)^{*}<Q=2^{3} .2^{8}<R$, so that $\sigma(R)^{\prime}: 1<2<$ $\left(2^{2}\right)^{*}<R$. A similar proof to that of Case (1) shows that we may suppose (5.4) holds with $3^{1+10}$ replaced by $2^{3} .2^{8}$ and $\mathcal{R}_{0}\left(M_{3}, 3\right) \backslash\left\{3^{1+10}\right\}$ by $\mathcal{T}_{5}$.

If $T_{13}=2^{8} \cdot 2^{4} .\left(S_{3} \times S_{3}\right) .2 \leqslant T_{12} \leqslant T_{6}$, then we may suppose

$$
\mathcal{R}_{0}\left(T_{13}, 2\right)=\left\{2^{8} \cdot 2^{4}, 2^{8} \cdot 2^{4} \cdot 2,2^{3} \cdot 2^{2} \cdot 2^{4} \cdot 2^{4}, 2^{3} \cdot 2^{8} \cdot D_{8} \cdot 2\right\}
$$


The Alperin weight conjecture and Dade's conjecture for the simple group $\mathrm{Fi}_{24}^{\prime}$

so that $N_{T_{13}}(R)=N_{T_{12}}(R)$ and $N_{T_{12} .2}(R)=N_{N_{T_{12} .2}\left(T_{13}\right)}(R)$ for $R \in \mathcal{R}_{0}\left(T_{13}, 2\right) \backslash$ $\left\{2^{3} \cdot 2^{2} \cdot 2^{4} \cdot 2^{4},\right\}$ and $N_{T_{12}}\left(2^{3} \cdot 2^{2} \cdot 2^{4} \cdot 2^{4}\right)=2^{3} \cdot 2^{2} \cdot 2^{4} \cdot 2^{4} \cdot S_{3}$.

Let $R \in \mathcal{R}_{0}\left(T_{13}, 2\right) \backslash\left\{2^{8} \cdot 2^{4}, 2^{3} \cdot 2^{2} \cdot 2^{4} \cdot 2^{4}\right\}$, and $\sigma(R): 1<2<\left(2^{2}\right)^{*}<2^{3} \cdot 2^{8}<$ $Q=2^{8} .2^{4}<R$, so that $\sigma(R)^{\prime}: 1<2<\left(2^{2}\right)^{*}<2^{3} .2^{8}<R$. A similar proof to that of Case (1) shows that we may suppose (5.4) holds with $3^{1+10}$ replaced by $2^{8} .2^{4}$ and $\mathcal{R}_{0}\left(M_{3}, 3\right) \backslash\left\{3^{1+10}\right\}$ by $\mathcal{R}_{0}\left(T_{13}, 2\right) \backslash\left\{2^{8} \cdot 2^{4}, 2^{3} \cdot 2^{2} \cdot 2^{4} \cdot 2^{4},\right\}$. Thus if $P_{1}=2, P_{2}=\left(2^{2}\right)^{*}$ and $P_{3}=2^{3} .2^{8}$, then $C \in_{G}\{C(15), C(16), C(17), C(18)\}$.

Let $P_{1}=2, P_{2}=\left(2^{2}\right)^{*}, P_{3}=2^{4} .2^{4} .2^{4} \in \mathcal{R}_{0}\left(T_{6}, 2\right)$. Then $N_{T_{6}}\left(P_{3}\right)=2^{4} .2^{4} .2^{4} . L_{3}(2)$ and we may take

$$
\mathcal{R}_{0}\left(2^{4} \cdot 2^{4} \cdot 2^{4} \cdot L_{3}(2), 2\right)=\left\{2^{4} \cdot 2^{4} \cdot 2^{4}, 2^{4} \cdot 2^{4} \cdot 2^{4} \cdot 2^{2}, 2^{3} \cdot 2^{8} \cdot D_{8}, 2^{3} \cdot 2^{8} \cdot D_{8} .2\right\} \subseteq \mathcal{R}_{0}\left(T_{6}, 2\right) .
$$

Applying the Borel-Tits Theorem to $L_{3}(2)$, it follows that $C \in_{G}\{C(j): 19 \leqslant j \leqslant$ $22\}$.

Let $P_{1}=2, P_{2}=\left(2^{2}\right)^{*}$ and $P_{3}=2^{4} \cdot 2^{3} \cdot 2^{6} \in \mathcal{R}_{0}\left(T_{6}, 2\right)$. Then

$$
N_{T_{6}}\left(P_{3}\right)=2^{4} \cdot 2^{3} \cdot 2^{6} \cdot\left(L_{2}(2) \times L_{2}(2)\right)
$$

and we may take $\mathcal{R}_{0}\left(2^{4} .2^{3} .2^{6} .\left(L_{2}(2) \times L_{2}(2)\right), 2\right)=$

$$
\left\{2^{4} \cdot 2^{3} \cdot 2^{6}, 2^{4} \cdot 2^{3} \cdot 2^{6} \cdot 2,2^{4} \cdot 2^{4} \cdot 2^{4} \cdot 2^{2}, 2^{3} \cdot 2^{8} \cdot D_{8} \cdot 2\right\} \subseteq \mathcal{R}_{0}\left(T_{6}, 2\right) .
$$

Applying the Borel-Tits Theorem to $L_{2}(2) \times L_{2}(2)$, it follows that $C \in \in_{G}\{C(j)$ : $23 \leqslant j \leqslant 26\}$.

It follows that if $P_{1}=2$ and $P_{2}=\left(2^{2}\right)^{*}$, then

$$
C \in_{G}\{C(j): 11 \leqslant j \leqslant 26\} .
$$

Finally, suppose $P_{1}=2$ and $P_{2}=2^{2}$, so that $N_{M_{1}}\left(P_{2}\right)=T_{1}$.

If $T_{14}=2^{11} \cdot L_{3}(4): 2 \leqslant T_{1}$, then we may take

$$
\begin{array}{r}
\mathcal{R}_{0}\left(T_{14}, 2\right)=\left\{2^{11}, 2^{11} \cdot 2,\left(2^{2} \times 2_{+}^{1+8}\right) \cdot 2^{4}, 2^{11} \cdot 2^{4},\left(2^{2} \times 2_{+}^{1+8}\right) \cdot 2^{4} \cdot 2,\right. \\
\left.2^{6+8} \cdot 2^{2},\left(2^{2} \times 2_{+}^{1+8}\right) \cdot 2^{4} \cdot 2^{2},\left(2^{2} \times 2_{+}^{1+8}\right) \cdot 2^{4} \cdot D_{8}\right\} \subseteq \mathcal{R}_{0}\left(T_{1}, 2\right),
\end{array}
$$

so that $N_{T_{1}}(R)=N_{T_{14}}(R)$ and $N_{T_{1} .2}(R)=N_{N_{T_{1} .2}\left(T_{14}\right)}(R)$ for $R \in \mathcal{R}_{0}\left(T_{14}, 2\right)$.

Let $R \in \mathcal{R}_{0}\left(T_{14}, 2\right) \backslash\left\{2^{11}\right\}$, and $\sigma(R): 1<2<2^{2}<Q=2^{11}<R$, so that $\sigma(R)^{\prime}: 1<2<2^{2}<R$. A similar proof to that of Case (1) shows that we may suppose (5.4) holds with $3^{1+10}$ replaced by $2^{11}$ and $\mathcal{R}_{0}\left(M_{3}, 3\right) \backslash\left\{3^{1+10}\right\}$ by $\mathcal{R}_{0}\left(T_{14}, 2\right) \backslash\left\{2^{11}\right\}$.

If $T_{15}=\left(2^{2} \times 2^{1+8}\right): U_{4}(2): 2 \leqslant T_{1}$, then we may take

$$
\begin{aligned}
\mathcal{R}_{0}\left(T_{15}, 2\right)= & \left\{2^{2} \times 2^{1+8},\left(2^{2} \times 2^{1+8}\right) \cdot 2,\left(2^{2} \times 2^{1+8}\right): 2^{4},\left(2^{2} \times 2^{1+8}\right) \cdot 2 \cdot 2^{4},\right. \\
& \left(2^{2} \times 2^{1+8}\right) \cdot 2^{4} \cdot 2,\left(2^{2} \times 2^{1+8}\right) \cdot 2^{4} \cdot 2^{2}, \\
& \left.\left(2^{2} \times 2^{1+8}\right) \cdot 2.2^{4} \cdot 2,\left(2^{2} \times 2_{+}^{1+8}\right) \cdot 2^{4} \cdot D_{8}\right\} \subseteq \mathcal{R}_{0}\left(T_{1}, 2\right),
\end{aligned}
$$

so that $N_{T_{1}}(R)=N_{T_{15}}(R)$ and $N_{T_{1} .2}(R)=N_{N_{T_{1} .2}\left(T_{15}\right)}(R)$ for $R \in \mathcal{R}_{0}\left(T_{15}, 2\right)$.

Let $\mathcal{T}_{6}=\left\{\left(2^{2} \times 2^{1+8}\right) .2,\left(2^{2} \times 2^{1+8}\right) .2 .2^{4},\left(2^{2} \times 2^{1+8}\right) .2 .2^{4} .2\right\} \subseteq \mathcal{R}_{0}\left(T_{15}, 2\right), R \in \mathcal{T}_{6}$, and $\sigma(R): 1<2<2^{2}<Q=2^{2} \times 2^{1+8}<R$, so that $\sigma(R)^{\prime}: 1<2<2^{2}<R$. A similar proof to that of Case (1) shows that we may suppose (5.4) holds with $3^{1+10}$ replaced by $2^{2} \times 2^{1+8}$ and $\mathcal{R}_{0}\left(M_{3}, 3\right) \backslash\left\{3^{1+10}\right\}$ by $\mathcal{T}_{6}$.

If $T_{16}=\left(2^{2} \times 2^{1+8}\right) \cdot 2^{4} \cdot S_{5} \leqslant T_{15} \leqslant T_{1}$, then we may take $\mathcal{R}_{0}\left(T_{16}, 2\right)=$ $\left\{\left(2^{2} \times 2^{1+8}\right): 2^{4},\left(2^{2} \times 2^{1+8}\right) \cdot 2^{4} \cdot 2,\left(2^{2} \times 2^{1+8}\right) \cdot 2^{4} \cdot 2^{2},\left(2^{2} \times 2_{+}^{1+8}\right) \cdot 2^{4} \cdot D_{8}\right\} \subseteq \mathcal{R}_{0}\left(T_{15}, 2\right)$ 
The Alperin weight conjecture and Dade's conjecture for the simple group $\mathrm{Fi}_{24}^{\prime}$

so that $N_{T_{1}}(R)=N_{T_{16}}(R)$ and $N_{T_{1} .2}(R)=N_{N_{T_{1} .2}\left(T_{16}\right)}(R)$.

Let $R \in \mathcal{R}_{0}\left(T_{16}, 2\right) \backslash\left\{\left(2^{2} \times 2^{1+8}\right): 2^{4}\right\}$, and $\sigma(R): 1<2<2^{2}<2^{2} \times 2^{1+8}<Q=$ $\left(2^{2} \times 2^{1+8}\right): 2^{4}<R$, so that $\sigma(R)^{\prime}: 1<2<2^{2}<2^{2} \times 2^{1+8}<R$. A similar proof to that of Case (1) shows that we may suppose (5.4) holds with $3^{1+10}$ replaced by $\left(2^{2} \times 2^{1+8}\right) .2^{4}$ and $\mathcal{R}_{0}\left(M_{3}, 3\right) \backslash\left\{3^{1+10}\right\}$ by $\mathcal{R}_{0}\left(T_{16}, 2\right) \backslash\left\{\left(2^{2} \times 2^{1+8}\right): 2^{4}\right\}$.

If $T_{17}=2^{6+8} \cdot\left(S_{3} \times S_{5}\right) \leqslant T_{1}$, then we may take

$$
\begin{gathered}
\mathcal{R}_{0}\left(T_{17}, 2\right)=\left\{2^{6+8}, 2^{11} \cdot 2^{4}, 2_{+}^{6+8} \cdot 2,\left(2^{2} \times 2^{1+8}\right) \cdot 2 \cdot 2^{4}, 2_{+}^{6+8} \cdot 2^{2},\left(2^{2} \times 2^{1+8}\right) \cdot 2.2^{4} \cdot 2,\right. \\
\left.\left(2^{2} \times 2^{1+8}\right) \cdot 2^{4} \cdot 2^{2},\left(2^{2} \times 2_{+}^{1+8}\right) \cdot 2^{4} . D_{8}\right\} \subseteq \mathcal{R}_{0}\left(T_{1}, 2\right),
\end{gathered}
$$

so that $N_{T_{1}}(R)=N_{T_{17}}(R)$ and $N_{T_{1} .2}(R)=N_{N_{T_{1} .2}\left(T_{17}\right)}(R)$.

Let $\sigma: 1<2<2^{2}<Q=2^{6+8}<2^{6+8} .2$, so that $\sigma^{\prime}: 1<2<2^{2}<2^{6+8} .2$. A similar proof to that of Case (1) shows that we may suppose (5.5) holds with $3^{2} \cdot 3^{4} \cdot 3^{8}$ replaced by $2^{6+8}$.

If $T_{18}=2^{11} \cdot 2^{4} \cdot S_{5} \leqslant T_{17} \leqslant T_{1}$, then we may take

$$
\mathcal{R}_{0}\left(T_{18}, 2\right)=\left\{2^{11} \cdot 2^{4}, 2_{+}^{6+8} \cdot 2^{2},\left(2^{2} \times 2^{1+8}\right) \cdot 2^{4} \cdot 2^{2},\left(2^{2} \times 2_{+}^{1+8}\right) \cdot 2^{4} \cdot D_{8}\right\} \subseteq \mathcal{R}_{0}\left(T_{17}, 2\right)
$$

so that $N_{T_{1}}(R)=N_{T_{18}}(R)$ and $N_{T_{1} .2}(R)=N_{N_{T_{1} .2}\left(T_{18}\right)}(R)$.

Let $R \in \mathcal{R}_{0}\left(T_{18}, 2\right) \backslash\left\{2^{11} .2^{4}\right\}$, and $\sigma(R): 1<2<2^{2}<2^{6+8}<Q=2^{11} .2^{4}<$ $R$, so that $\sigma(R)^{\prime}: 1<2<2^{2}<2^{6+8}<R$. A similar proof to that of Case (1) shows that we may suppose (5.4) holds with $3^{1+10}$ replaced by $2^{11} \cdot 2^{4}$ and $\mathcal{R}_{0}\left(M_{3}, 3\right) \backslash\left\{3^{1+10}\right\}$ by $\mathcal{R}_{0}\left(T_{18}, 2\right) \backslash\left\{2^{11} \cdot 2^{4}\right\}$.

If $T_{19}=\left(2^{2} \times 2^{1+8}\right) \cdot 2 \cdot 2^{4} \cdot\left(S_{3} \times S_{3}\right) \leqslant T_{17} \leqslant T_{1}$, then we may take $\mathcal{R}_{0}\left(T_{19}, 2\right)=$ $\left\{\left(2^{2} \times 2^{1+8}\right) \cdot 2 \cdot 2^{4},\left(2^{2} \times 2^{1+8}\right) \cdot 2 \cdot 2^{4} \cdot 2,\left(2^{2} \times 2^{1+8}\right) \cdot 2^{4} \cdot 2^{2},\left(2^{2} \times 2_{+}^{1+8}\right) \cdot 2^{4} \cdot D_{8}\right\} \subseteq \mathcal{R}_{0}\left(T_{17}, 2\right)$ so that $N_{T_{1}}(R)=N_{T_{19}}(R)$ and $N_{T_{1} .2}(R)=N_{N_{T_{1} .2}\left(T_{19}\right)}(R)$.

Let $\sigma: 1<2<2^{2}<2^{6+8}<Q=\left(2^{2} \times 2^{1+8}\right) \cdot 2.2^{4}<\left(2^{2} \times 2^{1+8}\right) \cdot 2.2^{4} .2$, so that $\sigma^{\prime}: 1<2<2^{2}<2^{6+8}<\left(2^{2} \times 2^{1+8}\right) \cdot 2.2^{4} .2$. A similar proof to that of Case (1) shows that we may suppose $(5.5)$ holds with $3^{2} \cdot 3^{4} \cdot 2^{8}$ replaced by $\left(2^{2} \times 2^{1+8}\right) \cdot 2.2^{4}$.

Let $C^{\prime}: 1<2<2^{2}<2^{6+8}<\left(2^{2} \times 2^{1+8}\right) \cdot 2 \cdot 2^{4}<\left(2^{2} \times 2^{1+8}\right) \cdot 2^{4} \cdot 2^{2}<\left(2^{2} \times\right.$ $\left.2_{+}^{1+8}\right) \cdot 2^{4} . D_{8}$ and $g\left(C^{\prime}\right): 1<2<2^{2}<2^{6+8}<\left(2^{2} \times 2^{1+8}\right) \cdot 2 \cdot 2^{4}<\left(2^{2} \times 2_{+}^{1+8}\right) \cdot 2^{4} \cdot D_{8}$. Then $N\left(C^{\prime}\right)=N\left(g\left(C^{\prime}\right)\right), N_{E}\left(C^{\prime}\right)=N_{E}\left(g\left(C^{\prime}\right)\right)=N\left(C^{\prime}\right) .2$ and we may suppose $C \notin_{G}\left\{C^{\prime}, g\left(C^{\prime}\right)\right\}$.

It follows that if $P_{1}=2$ and $P_{2}=2^{2}$, then we may suppose

$$
C \in_{G}\{C(i): 3 \leqslant i \leqslant 10\} .
$$

This completes the classification of the radical $p$-chains. The normalizers of the chains are determined by MAGMA.

REMARK 5.2. Let $\hat{G}$ be a covering group of $G=\mathrm{Fi}_{24}^{\prime}, \rho$ a faithful linear character of $Z(\hat{G})$ and $\hat{B}$ a block of $\hat{G}$ covering the block $B(\rho)$ containing $\rho$. If $D(\hat{B}) \neq O_{p}(Z(\hat{G}))$ and $p=2,3$, then

$$
\sum_{C \in \mathcal{R}(G) / G}(-1)^{|C|} \mathrm{k}\left(N_{\hat{G}}(C), \hat{B}, d, u, \rho,[r]\right)=\sum_{C \in \mathcal{R}^{0}(G) / G}(-1)^{|C|} \mathrm{k}\left(N_{\hat{G}}(C), \hat{B}, d, u, \rho,[r]\right)
$$

for all integers $d, u \geqslant 0$.

The proof of the Remark is the same as that of Lemma 5.1, since $N\left(C^{\prime}\right)=$ $N\left(g\left(C^{\prime}\right)\right)$ implies $N_{\hat{G}}\left(C^{\prime}\right)=N_{\hat{G}}\left(g\left(C^{\prime}\right)\right)$. 
The Alperin weight conjecture and Dade's conjecture for the simple group $\mathrm{Fi}_{24}^{\prime}$

\section{The proof of Uno's invariant conjecture for $\mathrm{Fi}_{24}^{\prime}$}

Let $N(C)$ be the normalizer of a radical $p$-chain. If $N(C)$ is a maximal subgroup of $\mathrm{Fi}_{24}^{\prime}$, then the character table of $N(C)$ may be found in the library of character tables distributed with GAP [13]. If this is not the case, we construct a "useful" description of $N(C)$ and attempt to compute directly its character table using Magma. Many of these normalisers posed difficulties for the standard charactertable algorithm of [18]; this motivated the development by Unger [19] of a new and more powerful algorithm to compute character tables.

If $N(C)$ is soluble, we construct a power-conjugate presentation for $N(C)$ and use this presentation to obtain the character table.

If $N(C)$ is insoluble, we construct a faithful representation for $N(C)$ and use this as input to the character table construction function. We employ two strategies to obtain faithful representations of $N(C)$.

1. Construct the action of $N(C)$ on the cosets of soluble subgroups of $N(C)$.

2. Construct the actions of $N(C)$ on the cosets of its stabilizers acting on the underlying set of $\mathrm{Fi}_{24}^{\prime}$.

The tables in Appendix A list the degrees of the irreducible characters used in the proof of Theorem 6.1.

THEOREM 6.1. Let $B$ be a p-block of $G=\mathrm{Fi}_{24}^{\prime}$ with a positive defect. Then $B$ satisfies Uno's invariant conjecture.

Proof. We may suppose $B$ has a non-cyclic defect group.

(1) Suppose $p=7$, so that by Lemma 4.2 (a), $B=B_{0}$. By Tables A-235 - A-238 (Appendix A),

$$
\mathrm{k}\left(N(C(2)), B_{0}, d, u,[r]\right)=\mathrm{k}\left(N(C(3)), B_{0}, d, u,[r]\right)= \begin{cases}21 & \text { if }(d, u, r)=(2,2,4), \\ 14 & \text { if }(d, u, r)=(2,1,1), \\ 0 & \text { otherwise. }\end{cases}
$$

If $i=4,5,6,7$, then by Tables A-239 - A-242 (Appendix A),

$$
\mathrm{k}\left(N(C(i)), B_{0}, d, u,[r]\right)= \begin{cases}16 & \text { if }(d, u, r)=(3,1,2), \\ 3 & \text { if }(d, u, r)=(3,1,1), \\ 2 & \text { if }(d, u, r)=(2,1,2), \\ 0 & \text { otherwise. }\end{cases}
$$

Thus Theorem 6.1 follows by

$$
\mathrm{k}\left(N(C(1)), B_{0}, d, u,[r]\right)=\mathrm{k}\left(N(C(8)), B_{0}, d, u,[r]\right)=\left\{\begin{array}{l}
6 \text { if }(d, u, r)=(3,2,1), \\
6 \text { if }(d, u, r)=(3,1,1), \\
4 \text { if }(d, u, r)=(3,2,2), \\
9 \text { if }(d, u, r)=(3,1,3), \\
2 \text { if }(d, u, r)=(2,2,1), \\
4 \quad \text { if }(d, u, r)=(2,1,1), \\
0 \quad \text { otherwise. }
\end{array}\right.
$$

(2) Suppose $p=5$, so that by Lemma $4.2(\mathrm{~b}), B=B_{0}, B_{1}$, or $B_{2}$ and $D(B) \simeq 5^{2}$. Apply Lemma 2.1 to both $N_{\mathrm{Fi}_{24}^{\prime}}(5)$ and $N_{\mathrm{Fi}_{24}}(5)$, where $5 \in \mathcal{R}_{0}\left(\mathrm{Fi}_{24}^{\prime}, 5\right)$. Thus 
The Alperin weight conjecture and Dade's conjecture for the simple group $\mathrm{Fi}_{24}^{\prime}$

Theorem 6.1 follows by

$$
\mathrm{k}\left(\mathrm{Fi}_{24}^{\prime}, B_{i}, d, u,[r]\right)=\mathrm{k}\left(N\left(5^{2}\right), B_{i}, d, u,[r]\right)= \begin{cases}10 & \text { if }(d, u, r)=(2,2,1), \\ 10 & \text { if }(d, u, r)=(2,2,2), \\ 0 & \text { otherwise }\end{cases}
$$

where $i=0,1$ and by

$$
\mathrm{k}\left(\mathrm{Fi}_{24}^{\prime}, B_{2}, d, u,[r]\right)=\mathrm{k}\left(N\left(5^{2}\right), B_{2}, d, u,[r]\right)= \begin{cases}4 & \text { if }(d, u, r)=(2,2,1), \\ 4 & \text { if }(d, u, r)=(2,2,2), \\ 4 & \text { if }(d, u, r)=(2,1,1), \\ 4 & \text { if }(d, u, r)=(2,1,2), \\ 0 & \text { otherwise. }\end{cases}
$$

\begin{tabular}{|r||r|r|r|r|r|r|r|}
\hline Defect d & 8 & 8 & 7 & 7 & 6 & 6 & otherwise \\
\hline Value $\mathrm{u}$ & 2 & 1 & 2 & 1 & 2 & 1 & otherwise \\
\hline \hline $\mathrm{k}(3, \mathrm{~d}, \mathrm{u})$ & 60 & 30 & 24 & 12 & 4 & 2 & 0 \\
\hline $\mathrm{k}(4, \mathrm{~d}, \mathrm{u})$ & 60 & 30 & 60 & 30 & 4 & 2 & 0 \\
\hline $\mathrm{k}(31, \mathrm{~d}, \mathrm{u})$ & 44 & 22 & 52 & 26 & 4 & 2 & 0 \\
\hline $\mathrm{k}(32, \mathrm{~d}, \mathrm{u})$ & 44 & 22 & 16 & 8 & 4 & 2 & 0 \\
\hline
\end{tabular}

Table 14: Values of $\mathrm{k}\left(N(C(i)), B_{0}, d, u\right)$ when $p=3$ and $\mathrm{d}(N(C(i)))=8$

(3) Suppose $p=3$, so that by Lemma 4.2 (c), $B \in\left\{B_{0}, B_{1}\right\}$ with $D\left(B_{1}\right) \simeq 3^{2}$.

If $B=B_{1}$, then $N\left(3^{2}\right)=N(C(32))=\left(3^{2}: 2 \times G_{2}(3)\right) .2$, so Theorem 6.1 follows by Lemma 2.1 and

$$
\mathrm{k}\left(G, B_{1}, d, u\right)=\mathrm{k}\left(N(C(32)), B_{1}, d, u\right)= \begin{cases}4 & \text { if } d=2 \text { and } u=2, \\ 2 & \text { if } d=2 \text { and } u=1 \\ 0 & \text { otherwise }\end{cases}
$$

Suppose $B=B_{0}$ and let $\mathrm{k}(j, d, u)=\mathrm{k}\left(N(C(j)), B_{0}, d, u\right)$. First, we consider the radical 3 -chains $C(j)$ with $\mathrm{d}(N(C(j)))=8$, and so $j=3,4,31,32$. The values $\mathrm{k}(j, d, u)$ are given in Table 14 .

It follows that

$$
\sum_{i=3,31}(-1)^{|C(i)|} \mathrm{k}\left(N(C(i)), B_{0}, d, u\right)=\sum_{i=4,32}(-1)^{|C(i)|} \mathrm{k}\left(N(C(i)), B_{0}, d, u\right) .
$$

Next we consider the radical 3-chains $C(j)$ such that the defect $\mathrm{d}(N(C(j)))=13$ or 14 , so that $j \in\{2,5-19\}$. The non-zero values $\mathrm{k}(i, d, u)$ are given in Table 15 .

It follows that

$$
\sum_{\mathrm{d}(N(C(i)))=13,14}(-1)^{|C(i)|} \mathrm{k}\left(N(C(i)), B_{0}, d, u\right)=0 .
$$

Finally, we consider the radical 3-chains $C(j)$ such that the defect $\mathrm{d}(N(C(j)))=$ 16 , so that $j \in\{1,20-30,33-36\}$. The non-zero values $\mathrm{k}(i, d, u)$ are given in Table 16. 
The Alperin weight conjecture and Dade's conjecture for the simple group $\mathrm{Fi}_{24}^{\prime}$

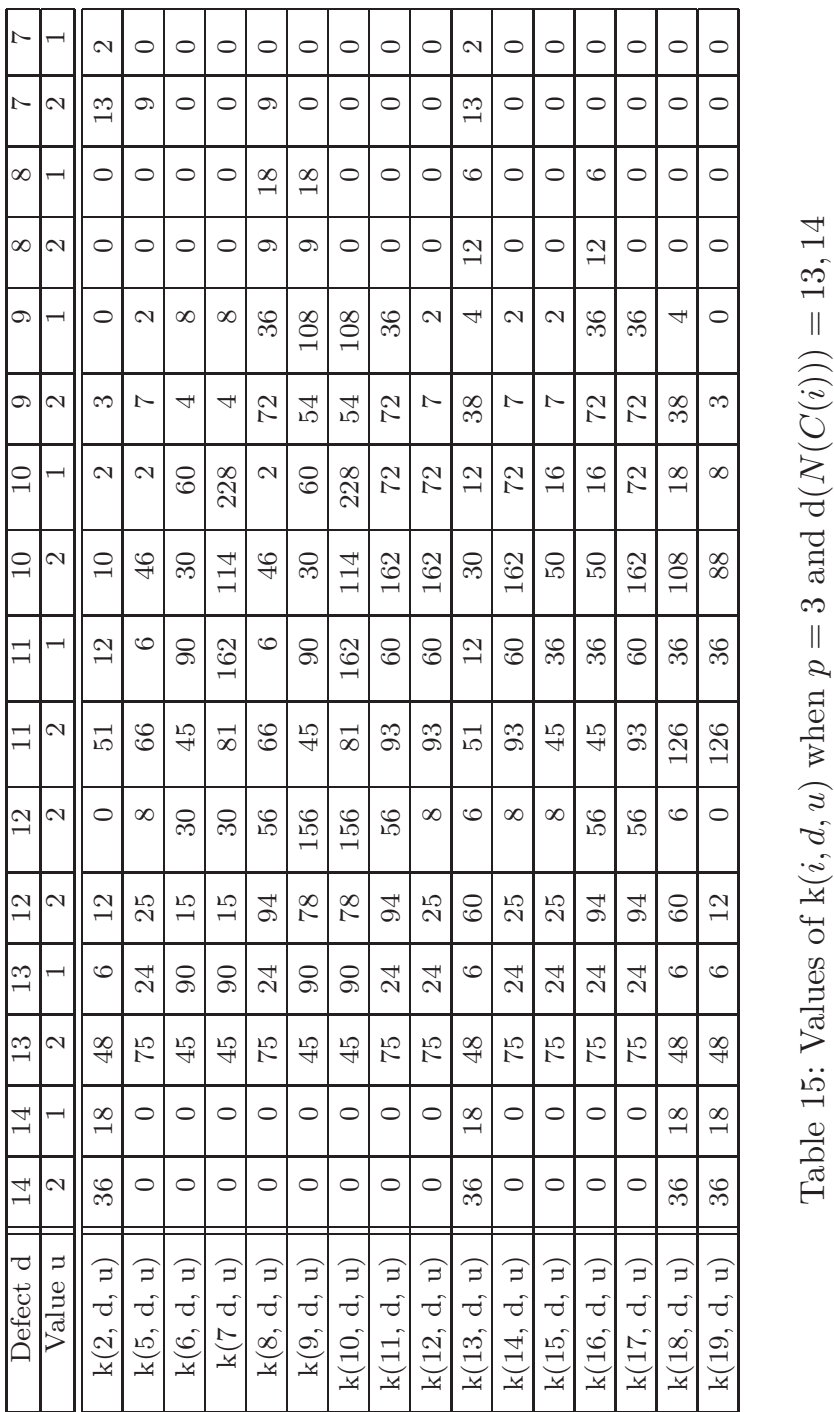


The Alperin weight conjecture and Dade's conjecture for the simple group $\mathrm{Fi}_{24}^{\prime}$

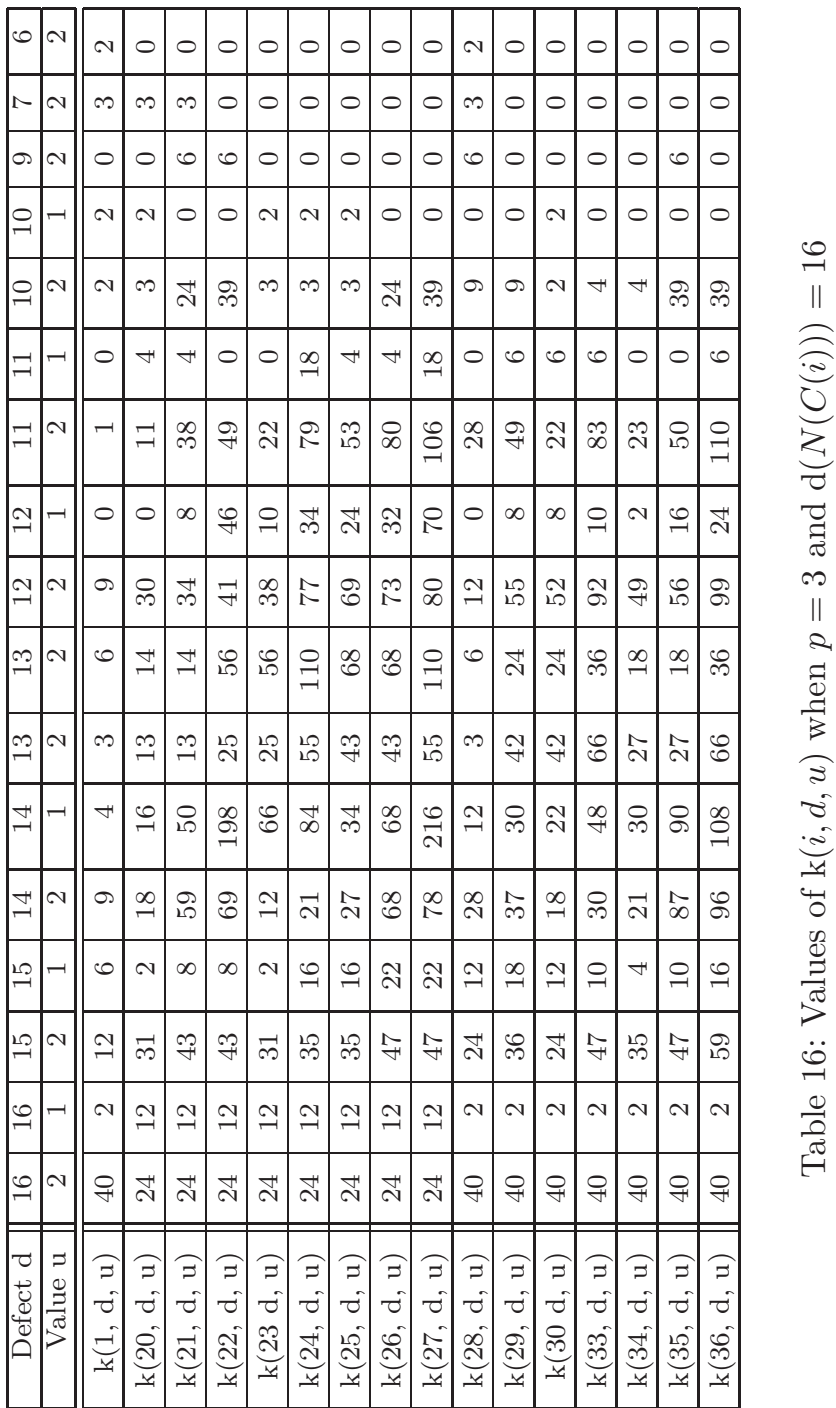


The Alperin weight conjecture and Dade's conjecture for the simple group $\mathrm{Fi}_{24}^{\prime}$

It follows that

$$
\sum_{\mathrm{d}(N(C(i)))=16}(-1)^{|C(i)|} \mathrm{k}\left(N(C(i)), B_{0}, d, u\right)=0
$$

and the theorem follows when $p=3$.

(4) Suppose $p=2$, so that by Lemma $4.2(\mathrm{c}), B \in\left\{B_{0}, B_{1}, B_{2}\right\}$ with $D\left(B_{1}\right) \simeq 2^{2}$ and $D\left(B_{2}\right) \simeq D_{8}$. If $B \neq B_{0}$, then by [20], Dade's invariant conjecture holds for $B$. Suppose $B=B_{0}$.

First we consider the radical 2-chains $C(j)$ such that the defect $\mathrm{d}(N(C(j)))=14$, so that $j \in\{13,14,16,17,62,63,67,68\}$. The non-zero values $\mathrm{k}(i, d, u)$ are given in Table 17 .

\begin{tabular}{|r||r|r|r|r|r|r|r|r|r|r|r|c|}
\hline Defect d & 14 & 14 & 13 & 13 & 12 & 12 & 11 & 11 & 10 & 10 & 9 & 9 \\
\hline Value u & 2 & 1 & 2 & 1 & 2 & 1 & 2 & 1 & 2 & 1 & 2 & 1 \\
\hline \hline $\mathrm{k}(13, \mathrm{~d}, \mathrm{u})=\mathrm{k}(62, \mathrm{~d}, \mathrm{u})$ & 32 & 32 & 16 & 16 & 32 & 32 & 10 & 10 & 0 & 0 & 0 & 0 \\
\hline $\mathrm{k}(14, \mathrm{~d}, \mathrm{u})=\mathrm{k}(63, \mathrm{~d}, \mathrm{u})$ & 32 & 32 & 16 & 16 & 56 & 56 & 46 & 46 & 0 & 0 & 0 & 0 \\
\hline $\mathrm{k}(16, \mathrm{~d}, \mathrm{u})=\mathrm{k}(67, \mathrm{~d}, \mathrm{u})$ & 32 & 32 & 56 & 56 & 32 & 32 & 10 & 10 & 16 & 16 & 8 & 8 \\
\hline $\mathrm{k}(17, \mathrm{~d}, \mathrm{u})=\mathrm{k}(68, \mathrm{~d}, \mathrm{u})$ & 32 & 32 & 56 & 56 & 56 & 56 & 46 & 46 & 16 & 16 & 0 & 0 \\
\hline
\end{tabular}

Table 17: Values of $\mathrm{k}(i, d, u)$ when $p=2$ and $\mathrm{d}(N(C(i)))=14$

It follows that

$$
\sum_{\mathrm{d}(N(C(i)))=14}(-1)^{|C(i)|} \mathrm{k}\left(N(C(i)), B_{0}, d, u\right)=0 .
$$

Next we consider the radical 2-chains $C(j)$ such that the defect $\mathrm{d}(N(C(j)))=15$, so that $j \in\{11,12,15,18-26,53-61,64-66\}$. The non-zero values $\mathrm{k}(i, d, u)$ are given in Table 18 . 
The Alperin weight conjecture and Dade's conjecture for the simple group $\mathrm{Fi}_{24}^{\prime}$

\begin{tabular}{|c|c|c|c|c|c|c|c|c|c|c|c|c|c|}
\hline 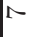 & -1 & N & 10 & 0 & $N$ & 0 & 0 & 0 & 0 & 0 & 0 & 0 & 0 \\
\hline$N$ & $N$ & $\infty$ & 0 & 0 & $m$ & 0 & 0 & 0 & $\circ$ & 0 & 0 & 0 & ○ \\
\hline$\infty$ & $N$ & 0 & $N$ & N & 0 & 0 & $\circ$ & 0 & 0 & 0 & 0 & 0 & 0 \\
\hline os & -1 & 0 & 0 & $\infty$ & $N$ & 0 & 0 & $N$ & 0 & 0 & 0 & 0 & 0 \\
\hline os & $\sim$ & $\infty$ & $\infty$ & 0 & $\stackrel{N}{\sim}$ & 0 & 0 & $\forall$ & 0 & 0 & 0 & 0 & 0 \\
\hline$\stackrel{0}{=}$ & -1 & 0 & 0 & 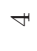 & $\forall$ & 0 & 0 & $\forall$ & $\forall$ & $\forall$ & 0 & 0 & $\forall$ \\
\hline$\stackrel{\varrho}{\circ}$ & $\sim$ & 0 & 0 & $\infty$ & 0 & 0 & 0 & 0 & $\infty$ & $\infty$ & 0 & 0 & $\infty$ \\
\hline 二 & -1 & $\forall$ & 0 & 0 & $\forall$ & $\stackrel{\sim}{\sim}$ & $\sim$ & $\sim$ & $\stackrel{N}{\sim}$ & $\stackrel{0}{-1}$ & $\stackrel{\ominus}{ }$ & $\stackrel{N}{\sim}$ & $\stackrel{\sim}{\sim}$ \\
\hline$\exists$ & $\sim$ & $N$ & $m$ & $\stackrel{\theta}{-1}$ & $\stackrel{\sim}{\sim}$ & $\stackrel{\sim}{\sim}$ & D & $\overrightarrow{\mathrm{N}}$ & 今) & $\hat{\infty}$ & $\overrightarrow{\mathrm{N}}$ & $\stackrel{2}{\sim}$ & $\stackrel{\mathrm{m}}{\mathrm{s}}$ \\
\hline$\stackrel{\sim}{\sim}$ & -1 & $\infty$ & 0 & 0 & $\infty$ & $\stackrel{0}{0}$ & $\infty$ & $\infty$ & $\stackrel{0}{\bullet}$ & $\infty$ & $\infty$ & 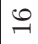 & $\stackrel{0}{0}$ \\
\hline$\stackrel{\sim}{\sim}$ & $\sim$ & $\stackrel{\infty}{\sim}$ & $\underset{\sim}{\sim}$ & $\stackrel{H}{N}$ & $\stackrel{\infty}{\sim}$ & $\stackrel{N}{N}$ & $\stackrel{\infty}{\sim}$ & $\stackrel{\infty}{\sim}$ & $\stackrel{N}{N}$ & मे & Hi & $\stackrel{N}{i}$ & $\stackrel{N}{N}$ \\
\hline 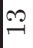 & $\neg$ & 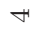 & $\forall$ & $\stackrel{\curvearrowright}{\curvearrowright}$ & $\not$ & $\forall$ & $\forall$ & $\stackrel{\overbrace{}}{\sim}$ & $\stackrel{\curvearrowright}{\circ}$ & 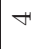 & $\forall$ & 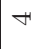 & $\stackrel{\sim}{\curvearrowright}$ \\
\hline 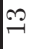 & $\sim$ & $\stackrel{\circ}{\circ}$ & 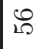 & 0 & f & 10 & $\stackrel{\circ}{\circ}$ & 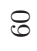 & $\stackrel{0}{R}$ & $\stackrel{0}{0}$ & 10 & 10 & $\stackrel{0}{1}$ \\
\hline 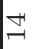 & -1 & $\infty$ & $\infty$ & $\infty$ & $\infty$ & $\infty$ & $\infty$ & $\infty$ & $\infty$ & $\infty$ & $\infty$ & $\infty$ & $\infty$ \\
\hline$\nexists$ & $\sim$ & กิ & $\approx$ & $\stackrel{\infty}{\not+}$ & $\stackrel{\infty}{\not}$ & กิ & กิ & $\stackrel{\infty}{\not}$ & $\stackrel{\infty}{\not+}$ & $\stackrel{\infty}{\underset{\gamma}{*}}$ & กิ & ஸे & $\stackrel{\infty}{\rightarrow}$ \\
\hline$\stackrel{0}{-1}$ & $\sim$ & ๙ิ & ஸे & กิ & กิ & กิ & กิ & กิ & กิ & กิ & กิ & กิ & ஸे \\
\hline$\nabla$ & $=$ & ( & 3 & & F & I & F & $\overparen{F}$ & 3 & I & F & F & 3 \\
\hline$\ddot{U}$ & $\stackrel{0}{\Xi}$ & - & 7 & రే & శ & శే & - & - & శ & f & f & fi & 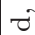 \\
\hline (2) & $\stackrel{\pi}{>}$ & fi & $\rightarrow$ & $0^{\circ}$ & $\infty$ & $\nabla^{-1}$ & $10^{\circ}$ & 0 & $N$ & 0 & 0 & $\infty$ & $10^{\circ}$ \\
\hline & & $\underset{y}{10}$ & 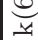 & $\underset{y}{\theta}$ & $\underbrace{10}_{y}$ & $\underbrace{\theta}_{y}$ & $\underbrace{10}_{y}$ & $\underbrace{10}_{y}$ & $\underbrace{10}_{4}$ & $\underbrace{\theta}_{y}$ & $\underbrace{10}_{y}$ & $\frac{10}{y}$ & $\underbrace{0}_{y}$ \\
\hline & & $\|$ & $\|$ & $\|$ & $\|$ & $\|$ & $\|$ & $\|$ & $\|$ & $\|$ & $\|$ & $\|$ & $\|$ \\
\hline & & 3 & F & ( & 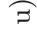 & 3 & $\exists$ & F & 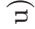 & I & $\exists$ & I & 3 \\
\hline & & రే & D & - & бే & f & б & fं & 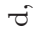 & 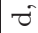 & శే & Fं & f \\
\hline & & $\approx$ & Iㄱ & 10 & $\infty_{-1}^{\infty}$ & 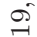 & $\stackrel{\rho}{\circ}$ & $\vec{N}$ & ㄱำ & $\stackrel{\mathscr{N}}{\mathrm{N}}$ & $\stackrel{\leftrightarrow}{\mathrm{N}}$ & $\stackrel{10}{N}$ & . \\
\hline & & 파 & $\not y$ & . & $\not y$ & 파 & $\not y$ & . & 포 & I & I & I & I \\
\hline
\end{tabular}


The Alperin weight conjecture and Dade's conjecture for the simple group $\mathrm{Fi}_{24}^{\prime}$

It follows that

$$
\sum_{\mathrm{d}(N(C(i)))=15}(-1)^{|C(i)|} \mathrm{k}\left(N(C(i)), B_{0}, d, u\right)=0 .
$$

If $\mathrm{d}(N(C(j)))=17$, then $27 \leqslant j \leqslant 34$. The non-zero values $\mathrm{k}(i, d, u)$ are given in Table 19.

\begin{tabular}{|r||r|r|r|r|r|r|r|r|r|r|r|r|}
\hline Defect d & 17 & 16 & 15 & 14 & 14 & 13 & 13 & 12 & 12 & 11 & 11 & 8 \\
\hline Value u & 2 & 2 & 2 & 2 & 1 & 2 & 1 & 2 & 1 & 2 & 1 & 2 \\
\hline \hline $\mathrm{k}(27, \mathrm{~d}, \mathrm{u})$ & 64 & 32 & 8 & 32 & 8 & 8 & 4 & 4 & 0 & 2 & 2 & 4 \\
\hline $\mathrm{k}(28, \mathrm{~d}, \mathrm{u})$ & 64 & 112 & 24 & 48 & 8 & 16 & 4 & 36 & 0 & 8 & 0 & 4 \\
\hline $\mathrm{k}(29, \mathrm{~d}, \mathrm{u})$ & 64 & 112 & 88 & 64 & 24 & 28 & 20 & 36 & 0 & 8 & 0 & 0 \\
\hline $\mathrm{k}(30, \mathrm{~d}, \mathrm{u})$ & 64 & 32 & 24 & 48 & 24 & 12 & 4 & 4 & 0 & 2 & 2 & 0 \\
\hline $\mathrm{k}(31, \mathrm{~d}, \mathrm{u})$ & 64 & 144 & 120 & 96 & 8 & 64 & 4 & 52 & 8 & 8 & 0 & 0 \\
\hline $\mathrm{k}(32, \mathrm{~d}, \mathrm{u})$ & 64 & 64 & 104 & 48 & 8 & 56 & 4 & 20 & 8 & 2 & 2 & 0 \\
\hline $\mathrm{k}(33, \mathrm{~d}, \mathrm{u})$ & 64 & 64 & 120 & 64 & 24 & 60 & 4 & 20 & 8 & 2 & 2 & 0 \\
\hline $\mathrm{k}(34, \mathrm{~d}, \mathrm{u})$ & 64 & 144 & 184 & 112 & 24 & 76 & 20 & 52 & 8 & 8 & 0 & 0 \\
\hline
\end{tabular}

Table 19: Values of $\mathrm{k}(i, d, u)$ when $p=2$ and $\mathrm{d}(N(C(i)))=17$

It follows that

$$
\sum_{\mathrm{d}(N(C(i)))=17}(-1)^{|C(i)|} \mathrm{k}\left(N(C(i)), B_{0}, d, u\right)=0 .
$$

If $\mathrm{d}(N(C(j)))=18$, then $j \in\{3-10,43-50\}$. The non-zero values $\mathrm{k}(i, d, u)$ are given in Table 20.

\begin{tabular}{|r||r|r|r|r|r|r|r|r|r|r|c|}
\hline Defect d & 18 & 17 & 16 & 15 & 14 & 13 & 12 & 11 & 10 & 8 & 7 \\
\hline Value u & 2 & 2 & 2 & 2 & 2 & 2 & 2 & 2 & 2 & 2 & 2 \\
\hline \hline $\mathrm{k}(3, \mathrm{~d}, \mathrm{u})$ & 16 & 12 & 10 & 24 & 20 & 20 & 24 & 9 & 1 & 4 & 1 \\
\hline $\mathrm{k}(4, \mathrm{~d}, \mathrm{u})$ & 16 & 12 & 10 & 20 & 19 & 7 & 8 & 5 & 0 & 0 & 0 \\
\hline $\mathrm{k}(5, \mathrm{~d}, \mathrm{u})$ & 16 & 12 & 10 & 28 & 37 & 31 & 12 & 5 & 0 & 0 & 0 \\
\hline $\mathrm{k}(6, \mathrm{~d}, \mathrm{u})$ & 16 & 12 & 10 & 24 & 40 & 36 & 32 & 9 & 5 & 4 & 1 \\
\hline $\mathrm{k}(7, \mathrm{~d}, \mathrm{u})$ & 16 & 12 & 26 & 26 & 35 & 35 & 8 & 2 & 0 & 0 & 0 \\
\hline $\mathrm{k}(8, \mathrm{~d}, \mathrm{u})$ & 16 & 12 & 26 & 30 & 36 & 40 & 24 & 6 & 1 & 0 & 0 \\
\hline $\mathrm{k}(9, \mathrm{~d}, \mathrm{u})$ & 16 & 12 & 26 & 30 & 56 & 64 & 32 & 14 & 5 & 0 & 0 \\
\hline $\mathrm{k}(10, \mathrm{~d}, \mathrm{u})$ & 16 & 12 & 26 & 34 & 53 & 59 & 12 & 10 & 0 & 0 & 0 \\
\hline $\mathrm{k}(43, \mathrm{~d}, \mathrm{u})$ & 16 & 20 & 10 & 24 & 11 & 2 & 8 & 3 & 0 & 0 & 0 \\
\hline $\mathrm{k}(44, \mathrm{~d}, \mathrm{u})$ & 16 & 20 & 18 & 28 & 16 & 17 & 14 & 9 & 1 & 4 & 1 \\
\hline $\mathrm{k}(45, \mathrm{~d}, \mathrm{u})$ & 16 & 20 & 18 & 28 & 36 & 33 & 24 & 9 & 5 & 4 & 1 \\
\hline $\mathrm{k}(46, \mathrm{~d}, \mathrm{u})$ & 16 & 20 & 10 & 32 & 29 & 26 & 10 & 3 & 0 & 0 & 0 \\
\hline $\mathrm{k}(47, \mathrm{~d}, \mathrm{u})$ & 16 & 20 & 34 & 38 & 32 & 29 & 18 & 8 & 1 & 0 & 0 \\
\hline $\mathrm{k}(48, \mathrm{~d}, \mathrm{u})$ & 16 & 20 & 34 & 38 & 52 & 45 & 28 & 16 & 5 & 0 & 0 \\
\hline $\mathrm{k}(49, \mathrm{~d}, \mathrm{u})$ & 16 & 20 & 26 & 42 & 45 & 38 & 14 & 10 & 0 & 0 & 0 \\
\hline $\mathrm{k}(50, \mathrm{~d}, \mathrm{u})$ & 16 & 20 & 26 & 34 & 27 & 14 & 12 & 2 & 0 & 0 & 0 \\
\hline
\end{tabular}

Table 20: Values of $\mathrm{k}(i, d, u)$ when $p=2$ and $\mathrm{d}(N(C(i)))=18$ 
The Alperin weight conjecture and Dade's conjecture for the simple group $\mathrm{Fi}_{24}^{\prime}$

It follows that

$$
\sum_{\mathrm{d}(N(C(i)))=18}(-1)^{|C(i)|} \mathrm{k}\left(N(C(i)), B_{0}, d, u\right)=0 .
$$

If $\mathrm{d}(N(C(j)))=19$, then $j \in\{2,35-41\}$. The non-zero values $\mathrm{k}(i, d, u)$ are given in Table 21.

\begin{tabular}{|r||r|r|r|r|r|r|r|r|r|r|r|r|r|c|}
\hline Defect d & 19 & 18 & 17 & 16 & 15 & 14 & 14 & 13 & 13 & 12 & 12 & 11 & 10 & 8 \\
\hline Value u & 2 & 2 & 2 & 2 & 2 & 2 & 1 & 2 & 1 & 2 & 1 & 2 & 2 & 2 \\
\hline \hline $\mathrm{k}(2, \mathrm{~d}, \mathrm{u})$ & 32 & 24 & 4 & 8 & 8 & 25 & 4 & 10 & 8 & 8 & 4 & 0 & 2 & 4 \\
\hline $\mathrm{k}(35, \mathrm{~d}, \mathrm{u})$ & 32 & 24 & 4 & 8 & 6 & 5 & 4 & 6 & 4 & 2 & 4 & 0 & 0 & 0 \\
\hline $\mathrm{k}(36, \mathrm{~d}, \mathrm{u})$ & 32 & 24 & 20 & 48 & 24 & 31 & 4 & 14 & 4 & 10 & 4 & 0 & 0 & 0 \\
\hline $\mathrm{k}(37, \mathrm{~d}, \mathrm{u})$ & 32 & 24 & 20 & 40 & 22 & 43 & 4 & 26 & 0 & 18 & 4 & 4 & 2 & 4 \\
\hline $\mathrm{k}(38, \mathrm{~d}, \mathrm{u})$ & 32 & 24 & 36 & 20 & 38 & 13 & 4 & 14 & 4 & 0 & 0 & 4 & 0 & 0 \\
\hline $\mathrm{k}(39, \mathrm{~d}, \mathrm{u})$ & 32 & 24 & 36 & 20 & 40 & 33 & 4 & 18 & 8 & 6 & 0 & 4 & 2 & 0 \\
\hline $\mathrm{k}(40, \mathrm{~d}, \mathrm{u})$ & 32 & 24 & 52 & 52 & 54 & 67 & 4 & 34 & 0 & 16 & 0 & 8 & 2 & 0 \\
\hline $\mathrm{k}(41, \mathrm{~d}, \mathrm{u})$ & 32 & 24 & 52 & 60 & 56 & 55 & 4 & 22 & 4 & 8 & 0 & 4 & 0 & 0 \\
\hline
\end{tabular}

Table 21: Values of $\mathrm{k}(i, d, u)$ when $p=2$ and $\mathrm{d}(N(C(i)))=19$

It follows that

$$
\sum_{\mathrm{d}(N(C(i)))=19}(-1)^{|C(i)|} \mathrm{k}\left(N(C(i)), B_{0}, d, u\right)=0 .
$$

If $\mathrm{d}(N(C(j)))=20$, then $73 \leqslant j \leqslant 80$. The non-zero values $\mathrm{k}(i, d, u)$ are given in Table 22.

It follows that

$$
\sum_{\mathrm{d}(N(C(i)))=20}(-1)^{|C(i)|} \mathrm{k}\left(N(C(i)), B_{0}, d, u\right)=0 .
$$

If $\mathrm{d}(N(C(j)))=21$, then $j \in\{1,42,51,52,69-72,81-88\}$. The non-zero values $\mathrm{k}(i, d, u)$ are given in Table 23.

It follows that

$$
\sum_{\mathrm{d}(N(C(i)))=21}(-1)^{|C(i)|} \mathrm{k}\left(N(C(i)), B_{0}, d, u\right)=0
$$

and the theorem follows when $p=2$. 
The Alperin weight conjecture and Dade's conjecture for the simple group $\mathrm{Fi}_{24}^{\prime}$

\begin{tabular}{|c|c|c|c|c|c|c|c|c|c|}
\hline$\infty$ & $\sim$ & $N$ & $N$ & 0 & 0 & 0 & 0 & 0 & 0 \\
\hline$\exists$ & -1 & $\nabla$ & 0 & 0 & 0 & 0 & 0 & 0 & $\forall$ \\
\hline$\exists$ & $N$ & $N$ & 0 & 0 & 0 & 0 & 0 & 0 & $N$ \\
\hline$\cong$ & -1 & 0 & 0 & 0 & 0 & 0 & 0 & $\infty$ & $\infty$ \\
\hline I & $\sim$ & + & 0 & 0 & 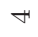 & 0 & 0 & $\nabla$ & $\nabla$ \\
\hline 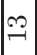 & -1 & $\infty$ & 0 & 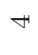 & 0 & 0 & $\stackrel{\curvearrowright}{\curvearrowright}$ & $\stackrel{\curvearrowright}{\curvearrowright}$ & $\stackrel{N}{\sim}$ \\
\hline$\dddot{\infty}$ & $\sim$ & 0 & $\sim$ & $N$ & $\stackrel{4}{-}$ & $\stackrel{0}{\circ}$ & $\stackrel{0}{-1}$ & $\exists$ & 0 \\
\hline$\nexists$ & -1 & $\infty$ & 0 & $\stackrel{0}{0}$ & $\infty$ & 0 & $\stackrel{0}{-1}$ & $\stackrel{\sim}{N}$ & $\stackrel{H}{N}$ \\
\hline$\nexists$ & $\sim$ & $\stackrel{\infty}{-1}$ & $\stackrel{0}{\circ}$ & $\stackrel{0}{\circ}$ & $\stackrel{\circ}{\sim}$ & $\stackrel{\infty}{-}$ & $\stackrel{\infty}{-1}$ & $\stackrel{\circ}{\sim}$ & $\stackrel{\infty}{-1}$ \\
\hline 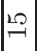 & -1 & $N$ & 0 & $\infty$ & ฟิ & $\stackrel{\curvearrowright}{\curvearrowright}$ & $\stackrel{\infty}{\sim}$ & ๙ి & $\stackrel{ }{\circ}$ \\
\hline مـ & $N$ & 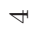 & $\sim$ & $\stackrel{0}{\circ}$ & ๙ & คి & $\stackrel{\infty}{\infty}$ & $\stackrel{0}{10}$ & $\stackrel{\infty}{\sim}$ \\
\hline 0 & -1 & 0 & 0 & $\stackrel{0}{0}$ & $\stackrel{\curvearrowright}{\sim}$ & $\stackrel{\curvearrowright}{\curvearrowright}$ & ڤ & o & $\stackrel{0}{0}$ \\
\hline 0 & $N$ & $\stackrel{N}{=}$ & $\forall$ & $\stackrel{\curvearrowright}{\circ}$ & $\stackrel{ }{\circ}$ & กิ & $\stackrel{\infty}{\not}$ & $\begin{array}{l}0 \\
12\end{array}$ & $\stackrel{\infty}{\sim}$ \\
\hline$\stackrel{\sim}{-1}$ & -1 & $\stackrel{0}{\circ}$ & $N$ & $\stackrel{+}{-}$ & $\stackrel{-}{-}$ & 0 & $\stackrel{\infty}{-1}$ & 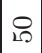 & $\stackrel{0}{\sim}$ \\
\hline 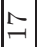 & $\sim$ & $\stackrel{\wp}{\circ}$ & $\stackrel{N}{\sim}$ & ○) & m & $\stackrel{\circ}{\sim}$ & ले & ๑ & ชె \\
\hline$\infty$ & -1 & 0 & 0 & $\stackrel{0}{-1}$ & $\infty$ & $\infty$ & $\vec{N}$ & $\vec{N}$ & 0 \\
\hline$\infty$ & $\sim$ & $\infty$ & $\stackrel{\curvearrowright}{\curvearrowright}$ & $\stackrel{\curvearrowright}{\circ}$ & $\not$ & $\stackrel{\infty}{\sim}$ & $\stackrel{\infty}{\sim}$ & F & م \\
\hline 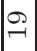 & -1 & $\stackrel{0}{-1}$ & $\infty$ & $\infty$ & $\stackrel{0}{\bullet}$ & $\infty$ & $\infty$ & 0 & 0 \\
\hline os & $\sim$ & 0 & $\infty$ & $\infty$ & $\vec{N}$ & $\stackrel{0}{-1}$ & $\stackrel{0}{-1}$ & $\vec{N}$ & $\stackrel{0}{-1}$ \\
\hline$\stackrel{\sim}{\circ}$ & -1 & $\stackrel{0}{\underline{-1}}$ & $\stackrel{0}{\bullet}$ & $\stackrel{0}{-1}$ & $\stackrel{0}{\bullet}$ & $\underset{-1}{0}$ & 0 & 0 & 0 \\
\hline$\stackrel{\odot}{\circ}$ & 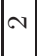 & $\stackrel{0}{-}$ & $\stackrel{0}{-1}$ & $\stackrel{0}{-1}$ & $\stackrel{0}{-1}$ & $\stackrel{0}{-1}$ & $\stackrel{0}{-1}$ & $\stackrel{0}{-1}$ & $\stackrel{0}{-1}$ \\
\hline 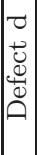 & 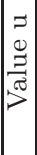 & 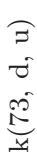 & 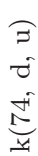 & 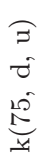 & 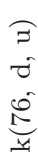 & 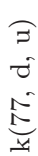 & 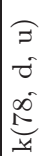 & $\begin{array}{l}3 \\
\tilde{\sigma} \\
\rho \\
\tilde{D} \\
\tilde{y}\end{array}$ & 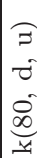 \\
\hline
\end{tabular}


The Alperin weight conjecture and Dade's conjecture for the simple group $\mathrm{Fi}_{24}^{\prime}$

\begin{tabular}{|c|c|c|c|c|c|c|c|c|c|c|c|c|c|c|c|c|c|}
\hline 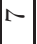 & $\sim$ & $N$ & 0 & 0 & $N$ & 0 & 0 & 0 & 0 & 0 & 0 & 0 & 0 & 0 & 0 & 0 & 0 \\
\hline$\infty$ & $N$ & $N$ & 0 & 0 & $N$ & 0 & 0 & 0 & 0 & 0 & 0 & 0 & 0 & 0 & 0 & 0 & 0 \\
\hline 으 & $N$ & -1 & 0 & 0 & -1 & 0 & 0 & 0 & 0 & 0 & $\neg$ & 0 & 0 & - & 0 & 0 & 0 \\
\hline$\exists$ & $N$ & 0 & 0 & -1 & 10 & 0 & 0 & $\infty$ & -1 & $\sim$ & $N$ & 0 & 0 & 0 & $N$ & 0 & $N$ \\
\hline$\stackrel{-}{\sim}$ & -1 & 0 & 0 & $N$ & $N$ & 0 & 0 & $N$ & $N$ & 0 & 0 & 0 & 0 & 0 & 0 & 0 & 0 \\
\hline$\stackrel{\sim}{-}$ & $\sim$ & 0 & 0 & $\forall$ & $\stackrel{\ominus}{-}$ & 0 & 0 & 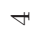 & $N$ & 0 & 0 & 0 & 0 & $\rightleftarrows$ & $\infty$ & 0 & $\infty$ \\
\hline 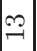 & -1 & 0 & 0 & 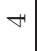 & $\infty$ & 0 & 0 & 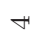 & $\infty$ & 0 & 0 & 0 & 0 & $\infty$ & $\forall$ & $\infty$ & $F$ \\
\hline 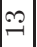 & $N$ & $m$ & -1 & $N$ & 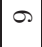 & -1 & $\infty$ & $\sigma$ & 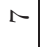 & 0 & $N$ & $N$ & 0 & $\stackrel{0}{-1}$ & $\rightleftarrows$ & $\underset{\sim}{\rightleftarrows}$ & $\stackrel{0}{-1}$ \\
\hline 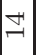 & -1 & $\forall$ & 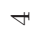 & $\infty$ & $\infty$ & 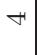 & 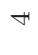 & $\infty$ & $\infty$ & 0 & 0 & 0 & 0 & 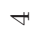 & $H$ & 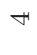 & 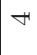 \\
\hline 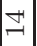 & $N$ & $\stackrel{0}{\circ}$ & 0 & 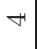 & $\stackrel{+}{-}$ & $N$ & $\infty$ & $\stackrel{\sim}{\sim}$ & 0 & 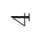 & 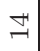 & $\stackrel{N}{\sim}$ & 0 & $\stackrel{\infty}{-1}$ & $\infty$ & $\stackrel{\circ}{\circ}$ & $\stackrel{0}{-1}$ \\
\hline 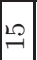 & -1 & $F$ & $N$ & 0 & $\forall$ & $\stackrel{N}{\sim}$ & 0 & 0 & $\stackrel{0}{-1}$ & $N$ & + & 0 & $\stackrel{\sim}{-1}$ & $\forall$ & 0 & $\stackrel{0}{-1}$ & 0 \\
\hline$\stackrel{20}{-1}$ & $\sim$ & $N$ & $\sim$ & ס & 10 & $\infty$ & $\infty$ & 二 & 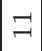 & $\stackrel{\rho}{-}$ & $\stackrel{\sigma}{\sim}$ & $\stackrel{10}{N}$ & $\stackrel{10}{N}$ & $\stackrel{\vec{N}}{\mathrm{~N}}$ & $\vec{N}$ & ฺ & ঙ \\
\hline 0 & -1 & 0 & 0 & $\infty$ & 0 & $\infty$ & $\infty$ & $\infty$ & $\stackrel{0}{0}$ & 0 & 0 & $\infty$ & $\infty$ & 0 & $\infty$ & 0 & $\infty$ \\
\hline 0 & $N$ & $N$ & 0 & $\forall$ & 0 & $\stackrel{\circ}{\circ}$ & $\infty$ & $\stackrel{\sim}{-1}$ & $\exists$ & 0 & $N$ & $\infty$ & $\stackrel{0}{-1}$ & $\stackrel{\infty}{\sim}$ & $\stackrel{0}{-1}$ & $\stackrel{0}{\sim}$ & $\stackrel{\vec{N}}{ }$ \\
\hline$\stackrel{-1}{\sim}$ & -1 & $F$ & $\forall$ & $\nabla$ & $\nabla$ & $\forall$ & 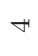 & +4 & 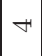 & 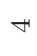 & 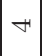 & $F$ & $\nabla$ & $\stackrel{\curvearrowright}{\curvearrowright}$ & 고 & $\stackrel{\curvearrowright}{\curvearrowright}$ & 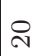 \\
\hline$\stackrel{N}{-1}$ & $\sim$ & $\infty$ & $\infty$ & 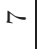 & $m$ & 20 & 10 & 10 & 드 & 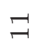 & 그 & $\stackrel{m}{-1}$ & $m$ & $\stackrel{\sim}{\sim}$ & $\vec{\infty}$ & F & $\stackrel{2}{2}$ \\
\hline$\underset{-\infty}{\infty}$ & -1 & $\infty$ & $\infty$ & $\infty$ & $\infty$ & $\infty$ & $\infty$ & $\infty$ & $\infty$ & $\infty$ & $\infty$ & $\infty$ & $\infty$ & $\infty$ & $\infty$ & $\infty$ & $\infty$ \\
\hline$\infty$ & $N$ & $\infty$ & 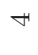 & ণ & $\infty$ & $\stackrel{0}{-1}$ & $\stackrel{\sim}{\sim}$ & $\stackrel{\sim}{\sim}$ & ஸे & ণ & $\stackrel{+}{N}$ & $\stackrel{\infty}{N}$ & m & $\stackrel{H}{N}$ & m & $\stackrel{\infty}{\not+}$ & $\stackrel{\infty}{\sim}$ \\
\hline 足 & $N$ & $H$ & $\forall$ & $\stackrel{N}{-1}$ & $\stackrel{N}{\sim}$ & $\stackrel{\overbrace{}}{\sim}$ & $\forall$ & $\stackrel{\sim}{\sim}$ & $\stackrel{\infty}{\sim}$ & $\stackrel{\sim}{\sim}$ & $\stackrel{N}{-1}$ & $\stackrel{N}{\sim}$ & $\stackrel{\infty}{\sim}$ & $\stackrel{\infty}{\underset{+}{\infty}}$ & $\stackrel{\infty}{\underset{十}{*}}$ & హే & $\stackrel{\infty}{\sim}$ \\
\hline$\stackrel{\sim}{\circ}$ & $N$ & $\infty$ & $\infty$ & $\stackrel{H}{N}$ & $\vec{N}$ & $\stackrel{H}{N}$ & $\stackrel{H}{N}$ & $\stackrel{ }{\circ}$ & $\stackrel{ }{\circ}$ & $\stackrel{+}{\mathrm{N}}$ & $\stackrel{+}{N}$ & $\stackrel{ }{ }$ & $\stackrel{ }{\circ}$ & $\stackrel{ }{ }$ & 악 & 20 & 20 \\
\hline$\vec{N}$ & $\sim$ & ஸे & ஸे & ஸे & ஸे & ஸे & กิ & ஸे & ஸै & กิ & ஸे & ஸे & ஸे & ஸे & กิ & ஸे & ஸे \\
\hline$\nabla$ & $F$ & I & 3 & $\approx$ & 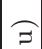 & $\approx$ & I & 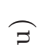 & 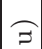 & 3 & 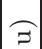 & 3 & 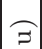 & 3 & 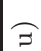 & 3 & 3 \\
\hline $\overrightarrow{0}$ & $\stackrel{9}{\Xi}$ & - & - & - & - & $\tilde{\sigma}$ & - & - & 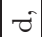 & f & tే & f & - & f & f & f & f \\
\hline 苞 & $p^{\sigma \pi}$ & $\subsetneq$ & คำ & ह1 & ง & $\dot{0}$ & $\rho^{\circ}$ & $\stackrel{-}{\pi}$ & i & $\tilde{\infty}$ & $\begin{array}{c}\text { a } \\
\infty\end{array}$ & $\infty$ & म্ & 100 & $0_{\infty}^{-}$ & $\stackrel{\infty}{\infty}$ & $\begin{array}{l}\infty \\
\infty\end{array}$ \\
\hline & & & $\not{y}$ & ચ્4 & 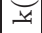 & ચ્4 & 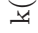 & $\not{y}$ & 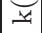 & 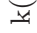 & 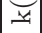 & I. & $\mathscr{y}$ & I. & I & Iy & Ix \\
\hline
\end{tabular}


The Alperin weight conjecture and Dade's conjecture for the simple group $\mathrm{Fi}_{24}^{\prime}$

7. The proof of Uno's projective conjecture for $3 . \mathrm{Fi}_{24}^{\prime}$

Let $C$ be a radical $p$-chain of $\mathrm{Fi}_{24}^{\prime}$ and $N_{3 \cdot \mathrm{Fi}_{24}^{\prime}}(C)=3 \cdot N_{\mathrm{Fi}_{24}^{\prime}}(C)$. Let $Z=$ $Z\left(3 . \mathrm{Fi}_{24}^{\prime}\right), \operatorname{Irr}(Z)=\left\{1, \zeta, \zeta^{\prime}\right\}$ and $B(\zeta)$ the block of $Z$ containing $\zeta$.

The tables in Appendix B list the degrees of the irreducible characters used in the proof of Theorem 7.1.

Theorem 7.1. Let $B$ be a p-block of $G=3 . \mathrm{Fi}_{24}^{\prime}$ with $D(B) \neq O_{p}(G)$. Then $B$ satisfies Uno's projective conjecture.

Proof. (1). Suppose $p=7$. Then $G$ has exactly one block $B=\hat{B}$ covering the block $B(\zeta)$. Let $C$ be a radical 7-chain of $\mathrm{Fi}_{24}^{\prime}$. If $|C|=0$, then $N_{G}(C)=G, N_{\mathrm{Fi}_{24}^{\prime}}(C)=$ $\mathrm{Fi}_{24}^{\prime}$ and so $\mathrm{k}\left(N_{G}(C), B, d, \zeta,[r]\right)$ is given by Lemma 4.2 , and $\mathrm{k}\left(N_{\mathrm{Fi}_{24}^{\prime}}(C), B_{0}, d, u,[r]\right)$ is given in the proof (1) of Theorem 6.1. Thus

$$
\mathrm{k}\left(N_{G}(C), B, d, \zeta,[r]\right)=\sum_{u=1}^{2} \mathrm{k}\left(N_{\mathrm{Fi}_{24}^{\prime}}(C), B_{0}, d, u,[5 r]\right) .
$$

If $|C| \neq 0$, then $N_{3 . \mathrm{Fi}_{24}^{\prime}}(C)=3 \times N_{\mathrm{Fi}_{24}^{\prime}}(C)$, so that (7.1) still holds. Thus Theorem 7.1 follows by the proof (1) of Theorem 6.1 when $p=7$.

(2). Let $p=5$ and $B=\hat{B}_{1}$ or $\hat{B}$ given by Lemma 4.2 . If $C(j)=C(2)$ or $C(3)$ given by Table 9 , then

$$
N_{3 . \mathrm{Fi}_{24}^{\prime}}(C(j))=3 \times N_{\mathrm{Fi}_{24}^{\prime}}(C(j)) .
$$

If $C=C(4)$, then $N_{G}(C)=N_{G}\left(5^{2}\right)$ and

$$
\mathrm{k}\left(3 . \mathrm{Fi}_{24}^{\prime}, B, d, \zeta,[r]\right)=\mathrm{k}\left(N_{3 . \mathrm{Fi}_{24}^{\prime}}\left(5^{2}\right), B, d, \zeta,[r]\right)= \begin{cases}10 & \text { if }(d, r)=(2,1), \\ 10 & \text { if }(d, r)=(2,2), \\ 0 & \text { otherwise }\end{cases}
$$

The theorem holds.

(3). Suppose $p=3$, so that Uno's projective conjecture is Dade's projective conjecture. By Lemma $4.2, B \in\left\{\hat{B}_{1}, \hat{B}\right\}$ with $D\left(\hat{B}_{1}\right) \simeq 3^{1+2}$.

If $B=\hat{B}_{1}$, then $N_{G}\left(3^{2}\right)=N(C(32))=3 \cdot\left(3^{2}: 2 \times G_{2}(3)\right) .2$, so Theorem 7.1 follows by Lemma 2.1 and

$$
\mathrm{k}\left(G, \hat{B}_{1}, d, \zeta\right)=\mathrm{k}\left(N(C(32)), \hat{B}_{1}, d, \zeta\right)= \begin{cases}4 & \text { if } d=2, \\ 0 & \text { otherwise. }\end{cases}
$$

Suppose $B=\hat{B}$ and let $\mathrm{k}(j, d)=\mathrm{k}(N(C(j)), \hat{B}, d, \zeta)$. First, we consider the radical 3 -chains $C(j)$ with $\mathrm{d}(N(C(j)))=9$, and so $j=3,4,31,32$. Then the values $\mathrm{k}(j, d)$ are given in Table 24 .

\begin{tabular}{|r||r|r|r|r|}
\hline Defect d & 8 & 7 & 6 & otherwise \\
\hline \hline $\mathrm{k}(3, \mathrm{~d})$ & 30 & 12 & 2 & 0 \\
\hline $\mathrm{k}(4, \mathrm{~d})$ & 30 & 30 & 2 & 0 \\
\hline $\mathrm{k}(31, \mathrm{~d})$ & 36 & 30 & 4 & 0 \\
\hline $\mathrm{k}(32, \mathrm{~d})$ & 36 & 12 & 4 & 0 \\
\hline
\end{tabular}

Table 24: Values of $\mathrm{k}(N(C(i)), \hat{B}, d, \zeta)$ when $p=3$ and $\mathrm{d}(N(C(i)))=9$ 
The Alperin weight conjecture and Dade's conjecture for the simple group $\mathrm{Fi}_{24}^{\prime}$

It follows that

$$
\sum_{i=3,31}(-1)^{|C(i)|} \mathrm{k}(N(C(i)), \hat{B}, d, \zeta)=\sum_{i=4,32}(-1)^{|C(i)|} \mathrm{k}(N(C(i)), \hat{B}, d, \zeta) .
$$

Next we consider the radical 3-chains $C(j)$ such that the defect $\mathrm{d}(N(C(j)))=14$ or 15 , so that $j \in\{2,5-19\}$. If $\mathrm{d}(N(C(j)))=14$, then $j \in\{5-12,14-17\}$ and (7.2) holds. Thus if $d \geqslant 1$, then

$$
\mathrm{k}\left(N_{3 . \mathrm{Fi}_{24}^{\prime}}(C(j)), \hat{B}, d, \zeta\right)=\sum_{u=1}^{2} \mathrm{k}\left(N_{\mathrm{Fi}_{24}^{\prime}}(C(j)), B_{0}, d-1, u\right)
$$

and so $\mathrm{k}\left(N_{3 . \mathrm{Fi}_{24}^{\prime}}(C(j)), \hat{B}, d, \zeta\right)$ is given by Table 15 . If $\mathrm{d}(N(C(j)))=15$, then $j \in\{2,13,18,19\}$ and the non-zero values $\mathrm{k}(i, d)$ are given in Table 25 .

\begin{tabular}{|r||r|r|r|r|r|r|r|r|}
\hline Defect d & 14 & 13 & 12 & 11 & 10 & 9 & 8 & 7 \\
\hline \hline $\mathrm{k}(2, \mathrm{~d})$ & 54 & 18 & 27 & 18 & 5 & 0 & 9 & 2 \\
\hline $\mathrm{k}(13, \mathrm{~d})$ & 54 & 72 & 27 & 18 & 54 & 18 & 9 & 2 \\
\hline $\mathrm{k}(18, \mathrm{~d})$ & 54 & 72 & 72 & 120 & 54 & 0 & 0 & 0 \\
\hline $\mathrm{k}(19, \mathrm{~d})$ & 54 & 18 & 72 & 120 & 5 & 0 & 0 & 0 \\
\hline
\end{tabular}

Table 25: Values of $\mathrm{k}(i, d)$ when $p=3$ and $\mathrm{d}(N(C(i)))=15$

It follows that

$$
\sum_{\mathrm{d}(N(C(i)))=14,15}(-1)^{|C(i)|} \mathrm{k}(N(C(i)), \hat{B}, d, \zeta)=0 .
$$

Finally, we consider the radical 3-chains $C(j)$ such that the defect $\mathrm{d}(N(C(j)))=$ 17 , so that $j \in\{1,20-30,33-36\}$.

The non-zero values $\mathrm{k}(i, d)$ are given in Table 26 .

It follows that

$$
\sum_{\mathrm{d}(N(C(i)))=17}(-1)^{|C(i)|} \mathrm{k}(N(C(i)), \hat{B}, d, \zeta)=0
$$

and the theorem follows when $p=3$.

(4). Suppose $p=2$, so that by Lemma $4.2, B \in\left\{\hat{B}_{1}, \hat{B}\right\}$ with $D\left(\hat{B}_{1}\right) \simeq D_{8}$. If $B=\hat{B}_{1}$, then Theorem 7.1 follows by

$$
\mathrm{k}\left(G, \hat{B}_{1}, d, \zeta\right)=\mathrm{k}\left(N(C(54)), \hat{B}_{1}, d, \zeta\right)= \begin{cases}4 & \text { if } d=3, \\ 1 & \text { if } d=2, \\ 0 & \text { otherwise. }\end{cases}
$$

Suppose $B=\hat{B}$ and let $\Omega=\{1,52,53,54,59,60,70,71\}$. If $1 \leqslant j \leqslant 88$ with $j \notin \Omega$, then $(7.2)$ holds and so $\mathrm{k}\left(N_{3 . \mathrm{Fi}_{24}^{\prime}}(C(j)), \hat{B}, d, \zeta\right)$ is given by (7.1). It follows by Tables $17-22$ that

$$
\sum_{\mathrm{d}(N(C(i)))=w}(-1)^{|C(i)|} \mathrm{k}(N(C(i)), \hat{B}, d, \zeta)=0,
$$

where $w \in\{14,17-20\}$. 
The Alperin weight conjecture and Dade's conjecture for the simple group $\mathrm{Fi}_{24}^{\prime}$

\begin{tabular}{|r||r|r|r|r|r|r|r|}
\hline Defect d & 14 & 13 & 12 & 11 & 10 & 8 & 7 \\
\hline \hline $\mathrm{k}(1, \mathrm{~d})$ & 42 & 9 & 6 & 7 & 0 & 3 & 2 \\
\hline $\mathrm{k}(20, \mathrm{~d})$ & 60 & 12 & 24 & 8 & 0 & 3 & 0 \\
\hline $\mathrm{k}(21, \mathrm{~d})$ & 60 & 36 & 51 & 24 & 6 & 3 & 0 \\
\hline $\mathrm{k}(22, \mathrm{~d})$ & 72 & 48 & 75 & 39 & 6 & 0 & 0 \\
\hline $\mathrm{k}(23, \mathrm{~d})$ & 72 & 12 & 48 & 11 & 0 & 0 & 0 \\
\hline $\mathrm{k}(24, \mathrm{~d})$ & 72 & 30 & 141 & 11 & 0 & 0 & 0 \\
\hline $\mathrm{k}(25, \mathrm{~d})$ & 60 & 30 & 84 & 8 & 0 & 0 & 0 \\
\hline $\mathrm{k}(26, \mathrm{~d})$ & 60 & 54 & 111 & 24 & 0 & 0 & 0 \\
\hline $\mathrm{k}(27, \mathrm{~d})$ & 72 & 66 & 168 & 39 & 0 & 0 & 0 \\
\hline $\mathrm{k}(28, \mathrm{~d})$ & 42 & 24 & 33 & 9 & 6 & 3 & 2 \\
\hline $\mathrm{k}(29, \mathrm{~d})$ & 42 & 51 & 78 & 9 & 0 & 0 & 0 \\
\hline $\mathrm{k}(30, \mathrm{~d})$ & 42 & 36 & 51 & 7 & 0 & 0 & 0 \\
\hline $\mathrm{k}(33, \mathrm{~d})$ & 81 & 39 & 126 & 10 & 0 & 0 & 0 \\
\hline $\mathrm{k}(34, \mathrm{~d})$ & 81 & 12 & 42 & 10 & 0 & 0 & 0 \\
\hline $\mathrm{k}(35, \mathrm{~d})$ & 81 & 45 & 69 & 39 & 6 & 0 & 0 \\
\hline $\mathrm{k}(36, \mathrm{~d})$ & 81 & 72 & 153 & 39 & 0 & 0 & 0 \\
\hline
\end{tabular}

Table 26: Values of $\mathrm{k}(i, d)$ when $p=3$ and $\mathrm{d}(N(C(i)))=17$

Suppose $\mathrm{d}(N(C(j)))=15$, so that $j \in\{11,12,15,18-26,53-61,64-66\}$. If moreover, $j \notin \Omega$, then $\mathrm{k}\left(N_{3 . \mathrm{Fi}_{24}^{\prime}}(C(j)), \hat{B}, d, \zeta\right)$ is given by (7.1) and Table 18. In addition, if $j \in\{53,54,59,60\} \subseteq \Omega$, then the non-zero values $\mathrm{k}(j, d)$ are given in Table 27.

\begin{tabular}{|c||r|r|r|r|r|r|r|r|c|}
\hline Defect d & 15 & 14 & 13 & 12 & 11 & 10 & 9 & 8 & 7 \\
\hline \hline $\mathrm{k}(53, \mathrm{~d})$ & 32 & 40 & 44 & 20 & 19 & 12 & 14 & 6 & 1 \\
\hline $\mathrm{k}(54, \mathrm{~d})$ & 32 & 24 & 36 & 20 & 3 & 0 & 8 & 6 & 1 \\
\hline $\mathrm{k}(59, \mathrm{~d})$ & 32 & 24 & 52 & 56 & 11 & 0 & 0 & 0 & 0 \\
\hline $\mathrm{k}(60, \mathrm{~d})$ & 32 & 40 & 60 & 56 & 27 & 4 & 0 & 0 & 0 \\
\hline
\end{tabular}

Table 27: Values of $\mathrm{k}(i, d)$ when $p=2$ and $\mathrm{d}(N(C(i)))=15$

It follows that

$$
\sum_{\mathrm{d}(N(C(i)))=15}(-1)^{|C(i)|} \mathrm{k}(N(C(i)), \hat{B}, d, \zeta)=0 .
$$

Suppose $\mathrm{d}(N(C(j)))=21$, so that $j \in\{1,42,51,52,69-72,81-88\}$. If moreover, $j \notin \Omega$, then $\mathrm{k}\left(N_{3 . \mathrm{Fi}_{24}^{\prime}}(C(j)), \hat{B}, d, \zeta\right)$ is given by (7.1) and Table 23. In addition, if $j \in\{1,52,70,71\} \subseteq \Omega$, then the non-zero values $\mathrm{k}(j, d)$ are given in Table 28 .

It follows that

$$
\sum_{\mathrm{d}(N(C(i)))=21}(-1)^{|C(i)|} \mathrm{k}(N(C(i)), \hat{B}, d, \zeta)=0
$$

and the theorem is now proved. 
The Alperin weight conjecture and Dade's conjecture for the simple group $\mathrm{Fi}_{24}^{\prime}$

\begin{tabular}{|r||r|r|r|r|r|r|r|r|r|r|r|r|r|}
\hline Defect d & 21 & 20 & 19 & 18 & 17 & 16 & 15 & 14 & 13 & 12 & 11 & 10 & 8 \\
\hline \hline $\mathrm{k}(1, \mathrm{~d})$ & 32 & 8 & 4 & 8 & 1 & 2 & 4 & 6 & 1 & 0 & 0 & 1 & 2 \\
\hline $\mathrm{k}(52, \mathrm{~d})$ & 32 & 24 & 12 & 8 & 5 & 6 & 5 & 14 & 15 & 8 & 3 & 1 & 2 \\
\hline $\mathrm{k}(70, \mathrm{~d})$ & 32 & 24 & 4 & 12 & 3 & 16 & 12 & 4 & 1 & 0 & 0 & 0 & 0 \\
\hline $\mathrm{k}(71, \mathrm{~d})$ & 32 & 40 & 12 & 12 & 7 & 20 & 13 & 12 & 11 & 2 & 1 & 0 & 0 \\
\hline
\end{tabular}

Table 28: Values of $\mathrm{k}(i, d)$ when $p=2$ and $\mathrm{d}(N(C(i)))=21$

\section{Appendices}

Two appendices are provided as add-ons to this paper.

- Appendix A gives the degrees of irreducible characters of chain normalizers of $\mathrm{Fi}_{24}^{\prime}$ and $\mathrm{Fi}_{24}$; it may be found at http://www.lms.ac.uk/jcm/11/lms2007-003/ appendix-a/app-a.pdf.

- Appendix B gives the degrees of irreducible characters of chain normalizers of $3 . \mathrm{Fi}_{24}^{\prime}$; it may be found at http://www.lms.ac.uk/jcm/11/lms2007-003/ appendix-b/app-b.pdf.

These characters were used in the proofs of Theorems 6.1 and 7.1, respectively.

\section{References}

1. J. L. Alperin, 'Weights for finite groups', The Arcata Conference on Representations of Finite Groups, Proc. Sympos. Pure Math. 47 (1987) 369-379. 100

2. J. An and C. W. EAton, 'The $p$-local rank of a block', J. Group Theory 3 (2000) 369-380. 101

3. J. An and C. W. EATon, 'Modular representation theory of blocks with trivial intersection defect groups', Algebra Represent. Theory 8 (2005) 427448. 104

4. J. An and E. A. O'Brien, 'A local strategy to decide the Alperin and Dade conjectures', J. Algebra 206 (1998) 183-207. 100, 103, 104

5. J. An and E. A. O'Brien, 'The Alperin and Dade conjectures for the simple Fischer group $\mathrm{Fi}_{23}$ ', Internat. J. Algebra Comput. 9 (1999) 621-670. 100, 103, 104

6. J. An and R. A. Wilson, 'The Alperin and Uno conjectures for the Baby Monster IB, p odd', LMS J. Comput. Math. 7 (2004) 120-166. 102

7. W. Bosma, J. Cannon and C. Playoust, 'The Magma algebra system I: The user language', J. Symbolic Comput. 24 (1997) 235-265. 104

8. N. Burgoyne and C. Williamson, 'On a theorem of Borel and Tits for finite Chevalley groups', Arch. Math. 27 (1976) 489-491. 118

9. J. H. Conway, R. T. Curtis, S. P. Norton, R. A. Parker and R. A. Wilson, Atlas of Finite Groups (Clarendon Press, Oxford, 1985). 103, 104, $106,108,113,114$

10. F. Celler, C. R. Leedham-Green, S. H. Murray, A. C. Niemeyer and E. A. O'Brien, 'Generating random elements of a finite group', Comm. Algebra 23 (1995) 4931-4948. 104 
The Alperin weight conjecture and Dade's conjecture for the simple group $\mathrm{Fi}_{24}^{\prime}$

11. E. C. DADE, 'Counting characters in blocks. I', Invent. Math. 109 (1992) 187-210. 100, 104, 114

12. E. C. DADE, 'Counting characters in blocks. II.9.', Representation theory of finite groups (Columbus, OH, 1995), Ohio State Univ. Math. Res. Inst. Publ. 6 (de Gruyter, Berlin, 1997) 45-59. 100, 101

13. The GAP Group, GAP - Groups, Algorithms, and Programming, Version 4.4.9, 2006, http://www.gap-system.org. 131

14. G. Hiss and K. Lux, Brauer Trees of Sporadic Groups (Oxford Science Publications, 1989). 112, 114

15. I. M. IsAacs and G. NAVARRo, 'New refinements of the McKay conjecture for arbitrary finite groups', Ann of Math. (2) 156 (2002) 333-344. 100, 102

16. H. Nagao and Y. Tsushima, Representations of Finite Groups (Academic Press, Boston, MA, 1989). 114

17. J. B. Olsson and K. Uno, 'Dade's conjecture for general linear groups in the defining characteristic', Proc. London Math. Soc. (3) 72 (1996) 359-384. 118

18. G. J. A. SchneIder, 'Dixon's character table algorithm revisited', J. Symbolic Comput. 9 (1990) 601-606. 104, 131

19. W. R. Unger, 'Computing the character table of a finite group', J. Symbolic Comput. 41 (2006) 847-862. 104, 131

20. K. Uno, 'Dade's conjecture for tame blocks', Osaka J. Math. 31 (1994) 747772. 114, 115, 135

21. K. Uno, 'Conjectures on character degrees for the simple Thompson group', Osaka J. Math. 41 (2004) no. 1, 11-36. 100, 102

22. R. A. Wilson, 'The local subgroups of the Fischer groups', J. London Math. Soc. (2) 36 (1987) 77-94. 103, 105

23. R. A. Wilson, 'Standard generators for sporadic simple groups', J. Algebra 184 (1996) 505-515. 104

24. R. A. Wilson et al., Atlas of Finite Group Representations, http://brauer.maths.qmul.ac.uk/Atlas 104

Jianbei An an@math.auckland.ac.nz

Department of Mathematics, University of Auckland, Auckland, New Zealand

John J. Cannon john@maths.usyd.edu.au

School of Mathematics and Statistics, University of Sydney, NSW 2006, Australia

E. A. O'Brien obrien@math.auckland.ac.nz

Department of Mathematics, University of Auckland, Auckland, New Zealand

W. R. Unger billu@maths.usyd.edu.au

School of Mathematics and Statistics, University of Sydney, NSW 2006, Australia 